\title{
Systematic position and composition of Merodon nigritarsis and M. avidus groups (Diptera, Syrphidae) with a description of four new hoverflies species
}

\author{
Laura Likov \\ Department of Biology and Ecology, University of Novi Sad, Serbia
}

Ante Vujić

Department of Biology and Ecology, University of Novi Sad, Serbia

Nataša Kočiš Tubić

Department of Biology and Ecology, University of Novi Sad, Serbia

natasa.kocis@dbe.uns.ac.rs

\section{Mihajla Đan}

Department of Biology and Ecology, University of Novi Sad, Serbia

Nevena Veličković

Department of Biology and Ecology, University of Novi Sad, Serbia

\section{Santos Rojo}

Department of Environmental Sciences and Natural Resources, Faculty of Sciences III, Campus of San Vicente, University of Alicante, Spain

\section{Celeste Pérez-Bañón}

Department of Environmental Sciences and Natural Resources, Faculty of Sciences III, Campus of San Vicente, University of Alicante, Spain

\section{Sanja Veselić}

Department of Biology and Ecology, University of Novi Sad, Serbia

\section{Anatolij Barkalov}

Institute of Systematics and Ecology of Animals, Russian Academy of Sciences, Siberian

Branch, Novosibirsk, Russia 


\title{
Rüstem Hayat
}

Department of Plant Protection, Faculty of Agriculture, Akdeniz University, Antalya, Turkey

\section{Snežana Radenković}

Department of Biology and Ecology, University of Novi Sad, Serbia

\begin{abstract}
The putative monophyly and systematic position of Merodon nigritarsis group was assessed based on morphological and molecular data of the mitochondrial COI and nuclear $28 \mathrm{~S}$ rRNA genes. The previously reported concept of the group has been redefined, and M. crassifemoris Paramonov, 1925 is now excluded. The related M. avidus group is redefined here, including the Merodon avidus complex and $M$. femoratus Sack, 1913. Species delimitation of morphologically defined species of $M$. nigritarsis group was well supported by COI gene analysis, with the exception of M. alagoezicus Paramonov, 1925 and M. lucasi Hurkmans, 1993. Descriptions are given for three new species of the M. nigritarsis species group: Merodon cohurnus Vujić, Likov et Radenković sp. n., Merodon longisetus Vujić, Radenković et Likov sp. n. and Merodon obstipus Vujić, Radenković et Likov sp. n., and one new species from the M. avidus group: Merodon rutitarsis Likov, Vujić et Radenković sp. n. A lectotype is designated for M. femoratus Sack, 1913, and two new synonymies of this species were proposed: M. biarcuatus Curran, 1939 and M. elegans Hurkmans, 1993. Here we review 18 species from the M. nigritarsis group and six species from the M. avidus group and provide morphological diagnoses of the species groups. Additionally, diagnosis of 12 branches (groups or individual taxa) of M. avidus-nigritarsis lineage, an illustrated diagnostic key for the males, and distribution map are provided for the new species.
\end{abstract}

\section{Keywords}

distribution - hoverfly - Merodon cohurnus sp. n. - Merodon longisetus sp. n. - Merodon obstipus sp. n. Merodon rutitarsis sp. n. - mitochondrial COI - nuclear $28 \mathrm{~S}$ rRNA

\section{Introduction}

Representing a frontier between Europe, Asia and Africa, the Mediterranean region is one of the richest biodiversity zones on the planet. With the continuous discovery of new species in this area, the Mediterranean region is becoming a globally important species hotspot (Cuttelod et al., 2009). In particular, the high number of endemic plants in the Mediterranean region play a significant role in the lifecycle and survival of many insects, including hoverflies (Diptera, Syrphidae) (Vujić et al., 2011).

The genus Merodon Meigen, 1803 (Syrphidae: Eristalinae: Merodontini) is restricted to the Palaearctic and Afrotropical regions (Ståhls et al., 2009; Šašić et al., 2016), except for M. equestris (Fabricius, 1794) which was introduced into the Nearctic and New Zealand (Speight, 2018). The highest species diversity is recorded for the Mediterranean area (Vujić et al., 2012), which is associated with a high diversity of bulb species in this region that 
serve as larval host plants (Ricarte et al., 2008; Andrić et al., 2014; Preradović et al., 2018). Asia Minor and Eastern Europe (especially the Balkan Peninsula) is considered one of the centers of diversity and endemism of the genus (Kaloveloni et al., 2015), as documented by many studies of the Merodon fauna in the Eastern Mediterranean (Vujić et al., 2007, 2011, 2013, 2015; Ståhls et al., 2009, 2016; Radenković et al., 2011; Kaloveloni et al., 2015; Ačanski et al., 2016a). These recent studies describing many new taxa of the genus Merodon has resulted in the taxon being the most speciose the $\mathrm{Eu}-$ ropean hoverfly genus (Marcos-García et al., 2007; Vujić et al., 2007, 2012, 2013, 2015, 2018; Popov, 2010; Radenković et al., 2011; Ačanski et al., 2016a) comprises more than 160 species in the world (Ståhls et al., 20o9; Vujić et al., 2013; Šašić et al., 2016; Speight, 2018).

The genus Merodon contains many complexes of cryptic and sibling species, which show minimal morphological differences. Consequently, recent studies have used an integrative taxonomic approach, combining methods such as geometric morphometry (Nedeljković et al., 2015; Ačanski et al., 2016a; Šašić et al., 2016), molecular characters of the mitochondrial (mtDNA) cytochrome c oxidase I (COI) gene (Milankov et al., 2008a, c; Francuski et al., 2011; Radenković et al., 2011; Milankov et al., 2013; Popović et al., 2015; Vujić et al., 2015; Radenković et al., 2018a) and environmental niche modelling (ENM) (Wiens \& Graham, 2005; Raxworthy et al., 2007; Schluter, 2009; Ačanski et al., 2016b) to estimate divergences among closely related taxa.

Hurkmans (1993) gave the first and most comprehensive revision of the Merodon genus, dividing 61 species with tapering abdomen into eleven groups: $M$. alagoezicus, $M$. alexeji, M. avidus, M. clavipes, $M$. crassifemoris, $M$. elegans, M. longicornis, $M$. nigritarsis, $M$. pruni, M. tarsatus and M. vandergooti. Mengual et al. (2006) recognized four well supported groups based on molecular data among species occurring in the Iberian Peninsula (M. desuturinus, $M$. albifrons, $M$. nigritarsis and $M$. aureus groups). Through introduction of the methods of integrative taxonomy, applying molecular (mtDNA COI gene, nuclear 28S rRNA gene) and phenotypic traits (geometric wing morphometry, surstylus shape and size and other morphological characters), many studies defined species groups of the genus Merodon, including species status and delimitation, e.g., within the $M$. ruficornis group (Radenković et al., 2002; Milankov et al., 2008a; Francuski et al., 2009; Vujić et al., 2012), $M$. desuturinus group (Milankov et al., 2008b; Vujić et al., 2018), M. aureus and M. cinereus groups (Milankov et al., 2008c; Francuski et al., 2011; Šašić et al., 2016; Veselić et al., 2017; Radenković et al., 2018a), avidus complex (Milankov et al., 2009; Ačanski et al., 2016a), M. albifrons group (Milankov et al., 2013), M. nigritarsis group (Vujić etal., 2013), M. nanus group (Vujić et al., 2015; Kočiš Tubić et al., 2018) and for all Merodon taxa of Lesvos (Ståhls et al., 2009).

Vujić et al. (2018) summarising previously published data (Šašić et al., 2016; Radenković et al., 2018b), cited five monophyletic lineages inside the genus Merodon: albifrons, aureus, avidus-nigritarsis, desuturinus, and natans. All taxa considered here belong to the avidusnigritarsis lineage.

The M. nigritarsis group sensu Hurkmans (1993) consisted of two species, M. nigritarsis Rondani, 1845 and M. femoratoides Paramonov, 1925. Radenković et al. (2011) redefined the $M$. nigritarsis group with a description of one new species, $M$. latifemoris Radenković and Vujić, 2011. Vujić et al. (2013) conducted a large study of Merodon species from the Middle East and produced a revision of the $M$. nigritarsis group, presenting 15 species: M. alagoezicus, M. angustus Vujić and Radenković, 2013*, M. crassifemoris, M. femoratoides, M. hakkariensis Vujić and Radenković, 2013*, M. latifemoris, M. lucasi*, 
M. nigritarsis, M. nitidifrons Hurkmans, 1993*, M. satdagensis Hurkmans*, 1993, M. schachti Hurkmans, $1993^{*}$, M. quadraticus Vujić and Radenković, 2013*, M. taniniensis Hurkmans, 1993*, M. testaceus Sack, 1913 and M. toscanus Hurkmans, 1993 (species marked with * only occur in Asia).

The $M$. nigritarsis group as defined by Radenković et al. (2011) comprises relatively large $(11-17 \mathrm{~mm})$ species with shared characteristics such as a black scutum with four white microtrichose vittae, a tapering black and orange colored abdomen with pairs of white microtrichose fasciae on terga $2-4$, and a medium-wide and slightly curved metafemur. The taxonomy of the Merodon avidus complex taxa from Europe and Asia (closely related to the $M$. nigritarsis group) were recently revised (Popović et al., 2015; Ačanski et al., 2016a; Šašić et al., 2016) revealing four sibling species: M. avidus (Rossi, 179o), M. ibericus Vujić, 2015, M. megavidus Vujić \& Radenković, 2016 and M. moenium Wiedemann in Meigen, 1822. Recently, Vujić et al. (2019) established 10 groups inside to the avidus-nigritarsis lineage (M. aberrans, M. aurifer, M. avidus, M. clavipes, $M$. fulcratus, $M$. italicus, $M$. nigritarsis, $M$. pruni, M. serrulatus and M. tarsatus), with addition of four individual species, also belonging to this lineage, $M$. clunipes Sack, 1913, $M$. eumerusi Vujić, Radenković \& Likov, 2019, $M$. murinus Sack, 1913, and M. ottomanus Hurkmans, 1993, with similar distribution in the Middle East (Vujić et al., 2019).

Recent field work and revision of additional collections has discovered four new species from the Eastern Mediterranean and Middle East, which are described in the present paper. In addition, new molecular data based on new material have enabled revision of systematic positions and relations between taxa among M. avidus and M. nigritarsis species groups.

The aims of this paper are (i) to define the $M$. avidus group and to redefine the $M$. nigritarsis species group, (ii) to present the systematic position and composition of $M$. avidus and $M$. nigritarsis species groups, (iii) to provide diagnosis for branches (groups or individual taxa) of Merodon avidus-nigritarsis lineage, (iv) to provide descriptions and diagnostic characters of four new species, and (v) to complete a key for males of $M$. nigritarsis and $M$. avidus groups.

\section{Material and methods}

\section{Study sites}

The occurrence points (geographical coordinates) were entered into the GenGIS (v2.5.1) (Parks et al., 2013) software to generate distribution map. Species richness map was created in DIVA-GIS (v 7.5) (Hijmans et al., 2012).

This paper includes new records from a few localities from SE Mediterranean: Greece (Chios island) and S-SW Turkey (Balıkesir, Burdur, Isparta, and Osmaniye provinces, Bozdağ and Rahat mountains, and around Köyceğiz lake) and Turkmenistan. Sampling localities of new species are shown on fig. 1 .

\section{Morphological analysis}

The studied material for newly described species are part of several museums which are specified in the form of the following abbreviations: AMNH (American Museum of Natural History, New York, USA); BMNH (Natural History Museum London, England); EMIT (Entomological Museum of Isparta, Turkey); FSUNS (Faculty of Sciences, University in Novi Sad, Serbia); NML (World Museum Liverpool, England); NBC (Natural Biodiversity Centre, Leiden, Netherlands); SZMN (Siberian Zoological Museum, Novosibirsk, Russia); ZMHB (Zoological Museum of Humboldt University of Berlin, Germany).

All information concerning specimens (locality, collector, etc.) are stored in the internal electronic database of the Faculty of Sciences, University of Novi Sad (FSUNS). 


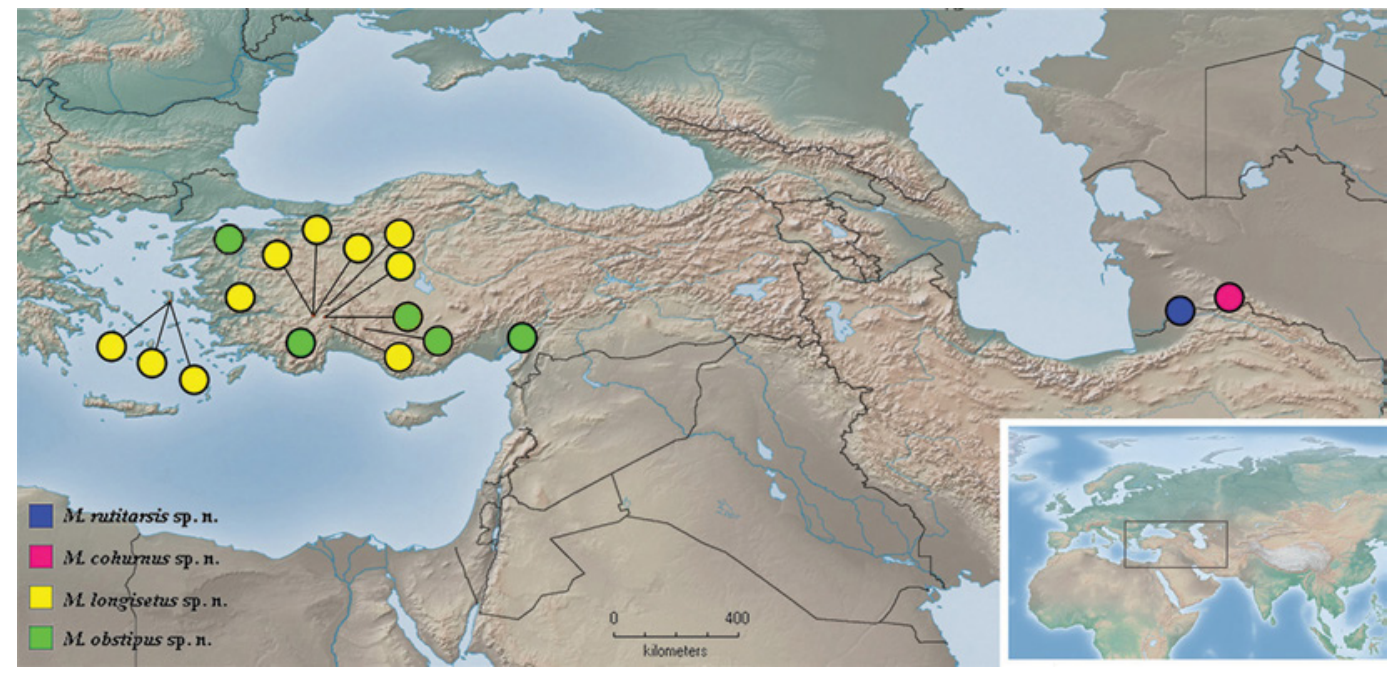

FIGURE 1 Geographic distribution of newly described species.

Terminology follows Thompson (1999) for non-genitalic morphology and Marcos-García et al. (2007) for morphology of the male genitalia. A description is provided for each new species, including figures of adult morphology. An identification key is also provided to enable the distinction of adult males. Because the new species described here are based partly on material from museum collections, ecological data and information on habitat preferences are sparse. Updated data on the biology of the genus Merodon, including species from the $M$. nigritarsis group, are presented in the database for European Syrphidae by Speight (2018).

The specimens were collected by sweep net. To study the male genitalia we follow methodology from Šimić (1987). Drawings were made with a FSA 25 PE drawing tube, while digital photographs were recorded with a Leica DFC 320 digital camera, both attached to a Leica MZ16 binocular microscope. Photo of hypandrium of Merodon avidus (fig. $33 \mathrm{C}$ ) was taken with a JEOL JSM 646oLV scanning electron microscope (SEM) operated at $20 \mathrm{kV}$. Measurements were taken with an eyepiece graticule or micrometer. Morphological characters were observed using a Nikon SMZ $745 \mathrm{~T}$ stereomicroscope. Identification of females was difficult in some cases and dependent on subtle characters and sympatric occurrence with males.

\section{Molecular analysis}

DNA extraction

Total genomic DNA was extracted using 1 to 3 legs from dry, pinned specimens following the procedure described by Chen et al. (2010). Genomic DNA vouchers were accordingly labelled and deposited at the Faculty of Sciences, Department of Biology and Ecology, University of Novi Sad (FSUNS) and Zoology unit, Finnish Museum of Natural History Luomus, Helsinki, Finland (MZH) (supplementary table $\mathrm{S} \mathbf{1})$.

\section{PCR amplification and sequencing}

The mtDNA COI 3' and 5' fragments were amplified using the following primers: forward primer C1-J-2183 (5'-CAACATTTATTTTGATTTTTTGG-3') (alias JERRY) and reverse primer TL2-N-3014 (5'-TCCAATGCACTAATCTGCCATATT-3') (alias PAT) (Simon et al., 1994); and forward primer LCO (5'-GCTCAACAAATCATAAAGATATTGG-3') and reverse primer HCO (5'-TAAACTTCAGGGTGACCAAAAAATCA-3') (Folmer et al., 1994), respectively. PCR 
amplification of the $\mathrm{D}_{2}-3$ region of the nuclear $28 \mathrm{~S}$ ribosomal RNA gene was performed using the following primer pair: forward $28 \mathrm{~S}-\mathrm{F}_{2}$ (5'-AGAGAGAGTTCAAGAGTACGTG-3') and reverse 28S-3DR (5'-TAGTTCACCATCTTT CGGGTC-3') (Belshaw et al., 2001). The reaction mix contained $1 \times$ reaction buffer (Thermo Scientific), $2.5 \mathrm{mM} \mathrm{MgCl}_{2}, 0.1 \mathrm{mM}$ of each nucleotide, 2 pmol of each primer, $1 \mathrm{U}$ Taq polymerase (Thermo Scientific), and approximately 5o ng template DNA in a total volume of $25 \mu \mathrm{l}$. Amplification was performed using the following conditions: initial denaturation at $95^{\circ} \mathrm{C}$ for $2 \mathrm{~min}$; 30 cycles of $94^{\circ} \mathrm{C}$ for $30 \mathrm{~s}, 49^{\circ} \mathrm{C}$ (for 3 ' fragment $\mathrm{COI}$ ) and $50^{\circ} \mathrm{C}$ (for 5 ' fragment COI and $28 \mathrm{~S} \mathrm{rRNA}$ ) for $30 \mathrm{~s} ; 72^{\circ} \mathrm{C}$ for $2 \mathrm{~min}$; with the final extension at $72^{\circ} \mathrm{C}$ for $8 \mathrm{~min}$. The PCR products were purified using ExoSAP (Thermo Scientific) following the manufacturer's recommendations. Sequencing was conducted using forward primer of each amplified region on an ABI373oxl Genetic Analyzer (Applied Biosystems, Foster City, CA, USA).

\section{Data analyses}

In order to establish the systematic position and composition of the $M$. nigritarsis group, we included samples representing the avidus-nigritarsis lineage in addition to species belonging to the albifrons+desuturinus, natans and aureus lineages and two outgroups, Platynochaetus maquarti Loew, 1862 and Eumerus grandis Meigen, 1822. For the analyses of molecular data we created two datasets: 1 ) first dataset consisted of 35 ingroup species (and two outgroups) for which the combined two-genes data matrix (COI and 28S rRNA) was obtained and 2) second dataset of 105 specimens (and two outgroups) for COI gene sequences. For the names and GenBank accession numbers of examined species and outgroups, see supplementary table S1.

Alignment of obtained sequences was done using the ClustalWalgorithm(Thompson etal., 1994) as implemented in BioEdit software
(Hall, 1999) with final adjustments conducted by eye. All sequences in both datasets were trimmed to equal lengths.

The final aligned and pruned first dataset including two-genes data matrix (COI+28S rRNA) comprised a total of 1862 nucleotide characters for in total 37 species (35 ingroup species of the studied genus Merodon lineages + two outgroups). Within the number of aligned sites for COI gene (concatenated 3 ' and 5 fragments of the gene) was 1273 nucleotides, while 589 nucleotides were included in analyses for the D2-3 region of the $28 \mathrm{~S}$ rRNA gene.

The second dataset of the COI gene sequences, which included 84 specimens from the Merodon avidus-nigritarsis lineage, and specimens from albifrons+desuturinus, aureus and natans lineages and 2 outgroups, consisted of 107 sequences. A combined dataset of the 3' and 5' COI fragments contained 1371 nucleotides, among which the 5' fragment COI had a final length of $639 \mathrm{bp}$ and the final length of the 3 ' fragment COI was $73^{2}$ nucleotides. For construction of COI gene trees a combined dataset of the 3 ' and 5' fragment COI gene sequences was used and identical sequences were removed using DAMBE v.5 (Xia, 2013), so the final dataset for trees construction consisted of 94 haplotypes.

For both datasets trees were constructed using Maximum Parsimony (MP), Maximum Likelihood (ML) and Bayesian analyses (BI). All obtained trees were rooted using Platynochaetus macquarti Loew, 1862.

Maximum Parsimony (MP) analysis was conducted using NONA (Goloboff, 1999), spawned with the aid of Winclada (Nixon, 2002). We used the heuristic search algorithm with 1000 random addition replicates (mult*1000), holding 100 trees per round (hold/100), maxtrees set to 100,000 and applying tree-bisection-reconnection (TBR) branch swapping. Nodal support was estimated using nonparametric bootstrapping with 1,000 replicates. 
Maximum Likelihood (ML) trees were constructed using MEGA 7 (Kumar et al., 2015) under a general time-reversible (GTR) evolutionary model using a discrete Gamma distribution with five rate categories and by assuming that a certain fraction of sites are evolutionarily invariable, since this was shown to be the best evolutionary model for both generated datasets (as estimated in MEGA 7). Nodal support was estimated with 1000 non-parametric bootstrap replicates.

Bayesian analysis (BI) for second dataset (COI sequences) was carried out using the same evolutionary model as for ML tree, as priors in MrBayes ver.3.2 (Ronquist et al., 2012). In $\mathrm{BI}$ analysis the first dataset was divided into two partitions: COI gene and $28 \mathrm{~S}$ rRNA gene sequences. We determined the best choice of the model for each partition using MEGA 7 (Kumar et al., 2015). The selected model, which is not implemented in MrBayes, was substituted by the closest over-parameterized model (Huelsenbeck \& Rannala, 2004). The T92+G substitution model determined for the $28 \mathrm{~S}$ partition was replaced by an $\mathrm{HKY}+\mathrm{G}$ model. For the COI gene partition, a GTR+G+I model was selected. Two independent runs of four Markov chain Monte Carlo (MCMC) permutations were performed for 10,000,000 generations (the first dataset) and 20,000,000 generations (the second dataset) with sampling every 100 generations. For both datasets analyses were performed online using the CIPRES Science Gateway V 3.3. (Miller et al., 2010, http://www.phylo.org/index.php/portal/ v33). The program Tracer 1.5 (Drummond \& Rambaut, 2007; Rambaut et al., 2014) was used to check convergence and acceptable mixing. The first $25 \%$ of the sampled iterations/generations were discarded as burn-in, and 50\% consensus trees were computed using FigTree v1.4.o (Rambaut, 2014).

Additionally, with the aim to delineate species based on COI gene sequences, we used the Generalized Mixed Yule Coalescent
(GMYC) method (Pons et al., 2006; Monaghan et al., 2009; Fujisawa \& Barraclough, 2013; Michonneau, 2015). The ultrametric trees required for this method were obtained using BEAST v1.8.o (Drummond et al., 2012). GMYC analyses were performed as described in a tutorial by Michonneau (2016).

\section{Results}

\section{Phylogenetic analyses and systematic position of M. nigritarsis and M. avidus groups}

Aiming to resolve the systematic position of the $M$. nigritarsis group, the phylogenetic trees based on two-gene (COI and $28 \mathrm{~S}$ rRNA) matrix were constructed (fig. 2, supplementary figs. $S_{1}$ and $S_{2}$ ). In obtained MP tree (fig. 2), the position of Merodon avidus-nigritarsis lineage is in agreement with the placement reported in Šašić et al. (2016) and Radenković et al. (2018b). Merodon avidus-nigritarsis lineage is here confirmed as one of four main lineages (bootstrap 89) in the genus Merodon, in addition to the albifrons+desuturinus, aureus and natans lineages. The ML tree with the highest log likelihood (-12147.4855) (supplementary fig. S1), as well as 50\% majority-rule consensus tree resulting from MrBayes analysis (supplementary fig. S2) were consistent and in agreement with the MP tree supporting the four main lineages. The monophyly of the avidus-nigritarsis lineage was clearly supported by bootstrap values of 89 (MP, fig. 2) and 99 (ML, supplementary fig. S1), as well as by a posterior probability (PP) value of $100 \%$ (BI, supplementary fig. S2). Based on the morphological characters and supported by molecular data of available taxa, $M$. avidus-nigritarsis lineage is divided into 12 branches (groups or individual taxa): M. aberrans, M. aurifer, $M$. avidus, $M$. clavipes, $M$. clunipes, $M$. crassifemoris, $M$. fulcratus, $M$. italicus, $M$. nigritarsis, M. ottomanus, $M$. pruni and M. serrulatus. 


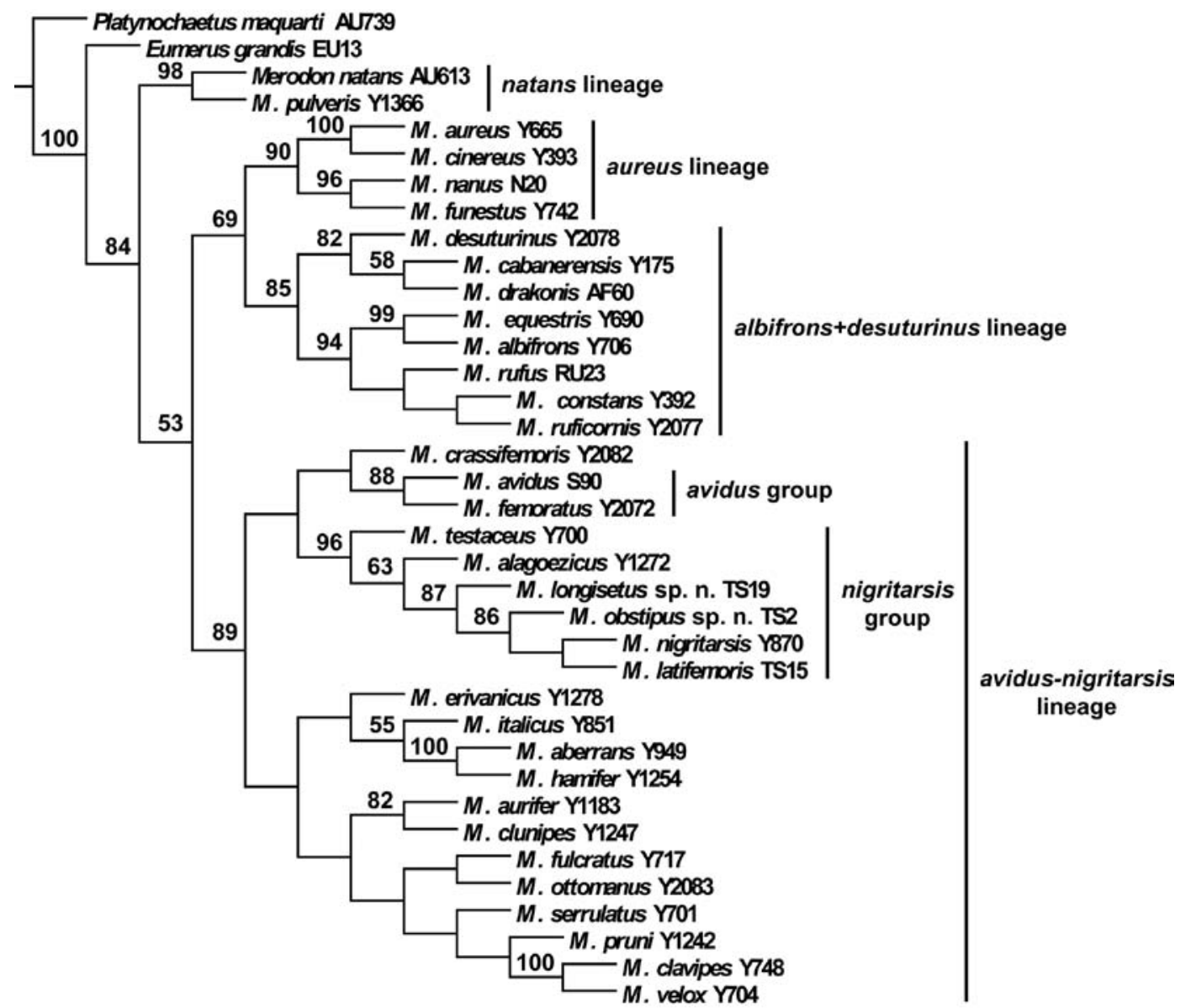

FIGURE 2 Strict consensus tree of two most parsimonious trees from the analysis of combined COI mitochondrial and 28S nuclear genes sequences. Length 2116 steps, Consistency Index (CI) 37, Retention Index (RI) 44. Bootstrap support values are depicted near nodes $\left(\geq 5^{\circ}\right)$. Numbers and letters after the species name referred to the DNA labcode IDs. Four lineages observed in genus Merodon, as well as two groups of avidus-nigritarsis lineage are marked on the tree.

Merodon aberrans group (M. aberrans Egger, 1860 and M. hamifer Sack, 1913) (fig. 3A-B) is characterized by: an elongated and narrow abdomen with dark terga; terga 2-4 with a pair of microtrichose fasciae; metafemur long and narrow; hypandrium with very long lingula (fig. $3 \mathrm{~B}: 1$ ).

Merodon aurifer group contains taxa with very short body pilosity (fig. ${ }_{3} \mathrm{C}$ ), yellow basoflagellomere, pale tibiae and tarsi. Beside $M$. aurifer Loew, 1862, group consists of at least one additional taxon, an undescribed species from Turkey and Azerbaijan (Vujić et al., in prep.).

Merodon avidus group (M. avidus complex, M. femoratus and Merodon rutitarsis sp. n.) is characterized by elongated and tapering abdomen, at least tergum 2 with reddish-yellow lateral maculae (fig. 11A-C), and reddish-yellow tarsi (fig. 14A-D). Separation of the group is supported by bootstraps 88 and 98 (MP and ML, respectively) and PP $=100 \%$ (fig. 2, supplementary figs. S1 and $S_{2}$ ). 


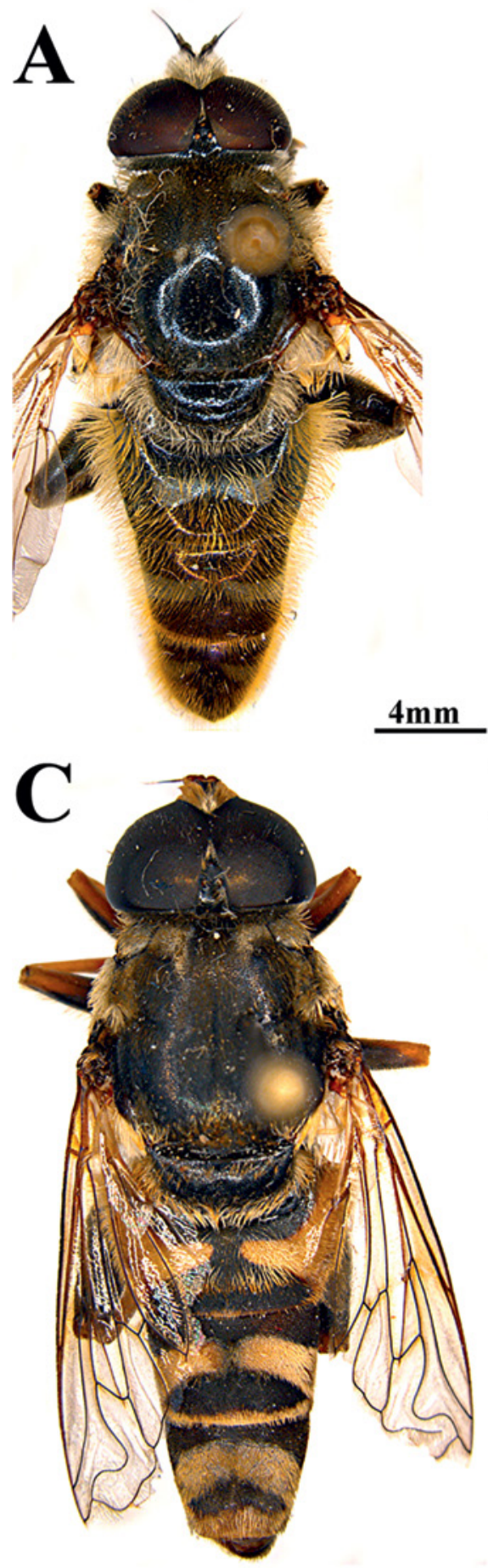

\section{B}
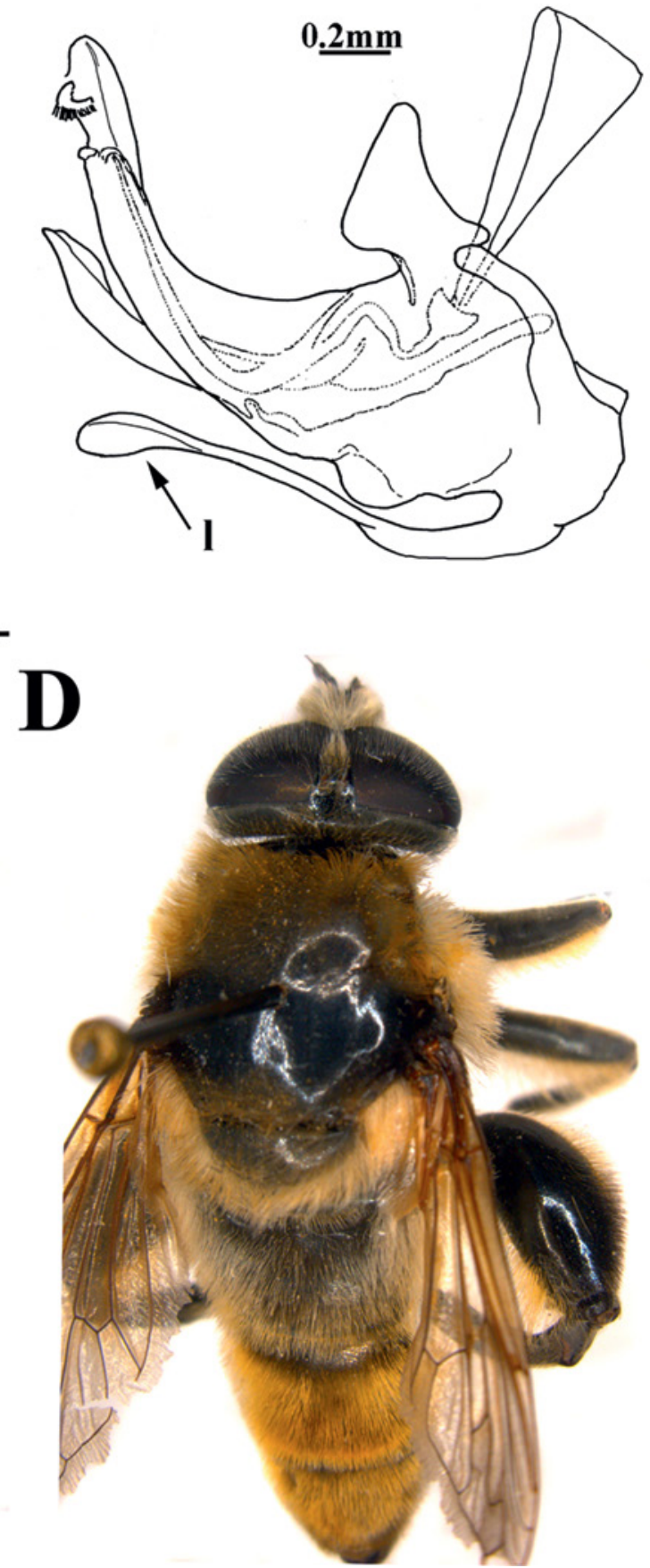

FIGURE 3 A) Merodon aberrans, male; body, B) Merodon aberrans, male; hypandrium, C) Merodon aurifer, male; body, D) Merodon clavipes, male; body. Scale: A), C-D) 4 mm, B) $0.2 \mathrm{~mm}$. l-lingula. 


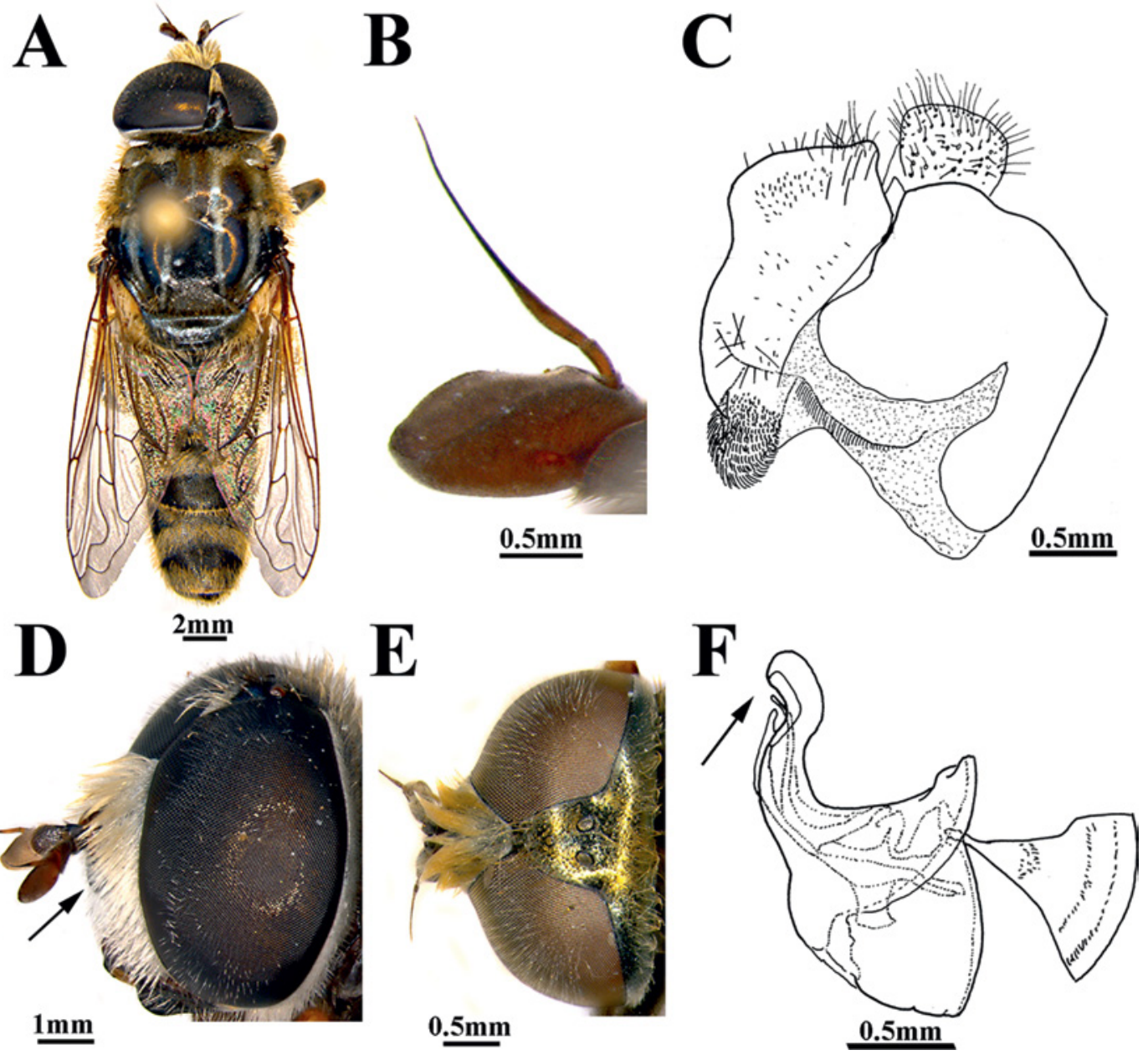

FIG URE 4 A) Merodon clunipes, male; body, B) Merodon clunipes, male; antennae, C) Merodon clunipes, male; epandrium, D) Merodon crassifemoris, male; head, E) Merodon fulcratus, male; head, F) Merodon fulcratus, male; hypandrium (lack of ctenidium marked with arrow). Scale: A) $2 \mathrm{~mm}, \mathrm{~B}-\mathrm{C}$ ), E-F) $0.5 \mathrm{~mm}$, D $1 \mathrm{~mm}$.

Merodon clavipes group (M. clavipes (Fabricius, 1781) and $M$. velox Loew, 1869) includes large species $\left(15^{-20} \mathrm{~mm}\right)$ with long body pilosity and broad metafemur covered with long pile (fig. 3D).

Merodon clunipes is a species with broad metatibiae and dark terga (fig. $4 \mathrm{~A}$ ), and has clear apomorphic diagnostic characters, including antennae shape (fig. 4B) and the characteristic shape of the surstyle lobe (fig. $4 \mathrm{C}$ ).

Merodon crassifemoris is a taxon with tubercle on the face below the antenna (fig. 4D: marked with arrow), and a hook-like posterior surstyle lobe (fig. 13A: pl) unique among all other taxa of the avidus-nigritarsis lineage.

Merodon fulcratus group is clearly separated from other groups from the lineage with distinctly dichoptic eyes (fig. 4E) and lack of ctenidium at hypandrium (fig. $4 \mathrm{~F}$ : marked with arrow). Two species are known, $M$. dichopticus Stackelberg, 1968 and M. fulcratus (Becker, 1913).

Merodon italicus group includes species with elongate basoflagellomere (fig. $5 \mathrm{D}$ ) and quadratic posterior surstyle lobe (fig. 6A-C: pl). Two species share these morphological 


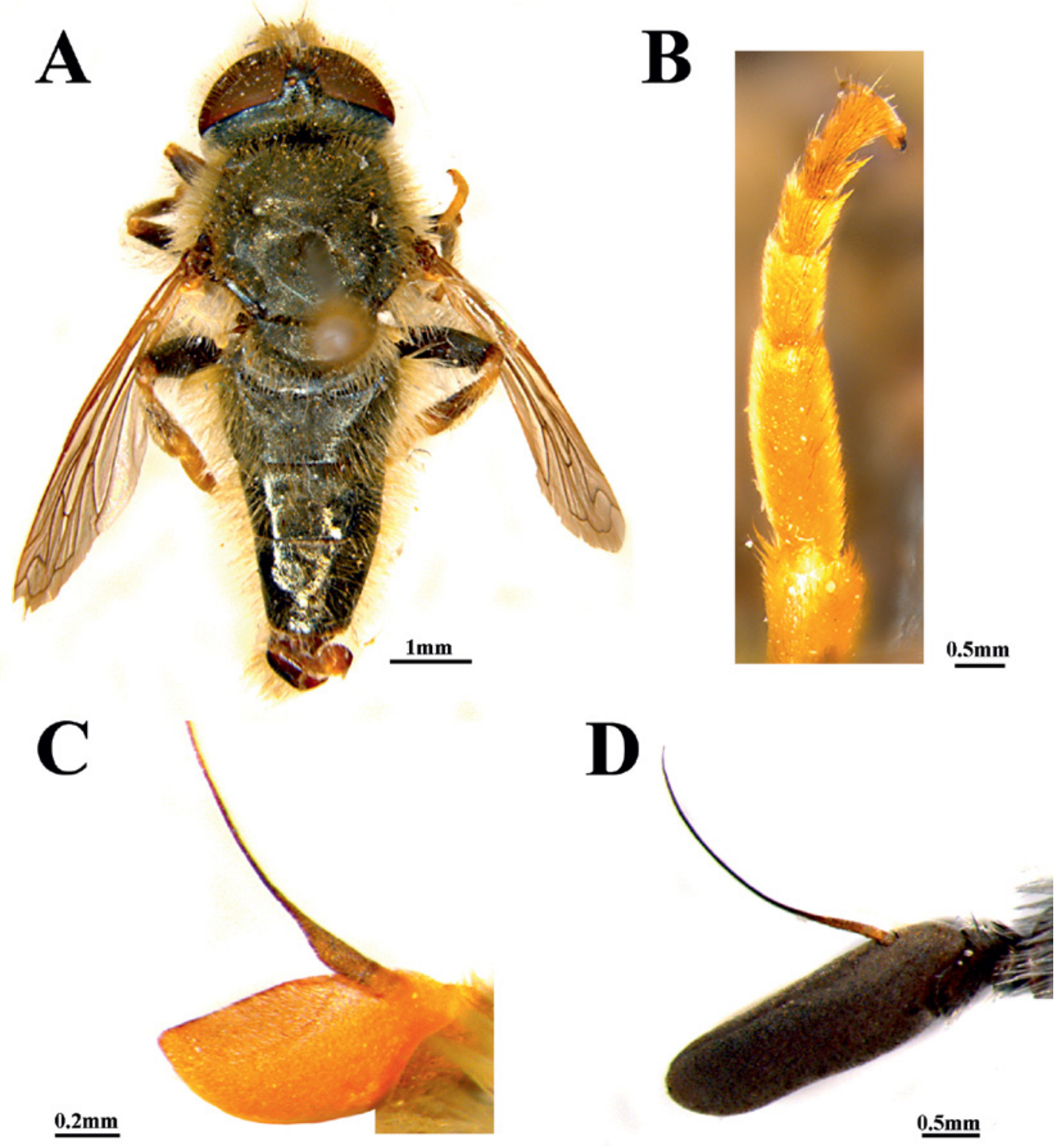

FIGURE 5 A) Merodon ottomanus, male; body, B) Merodon ottomanus, male; metabasotarsomere, C) Merodon ottomanus, male; basoflagellomere, (D) Merodon italicus, male; basoflagellomere. Scale: A) 1 mm,

B) $0.5 \mathrm{~mm}, \mathrm{D}) 0.5 \mathrm{~mm}, \mathrm{C}) 0.2 \mathrm{~mm}$.

features: M. italicus Rondani, 1845 and M. erivanicus Paramonov, 1925, but they are not resolved together in the tree (fig. 2).

Merodon nigritarsis group contains taxa with abdomen elongate, narrow and tapering (fig. 10A-B), tarsi dark brown/black dorsally and partly orange ventrally (fig. $14 \mathrm{E}-\mathrm{H}$ ). Male genitalia: anterior surstyle lobe more or less rhomboid shape (as on fig. 13: al), except in alagoezicus subgroup where the anterior surstyle lobe is transformed into a narrow, elongate, strongly curved projection (as on fig. 12: al). Hypandrium with pair of apical thorns on ventral margin directed backwards (as on 
fig. 24: th), but often with a pair of lateral projections near the base (as on fig. 3oA, C:lp) and well-developed lingula (as on fig. $24 \mathrm{~A}-\mathrm{D}: \mathrm{l}$ ). Separation of the group is supported by bootstraps 96 and 99 (MP and ML, respectively) and $\mathrm{PP}=100 \%$ (fig. 2, supplementary figs. S1 and $\mathrm{S}_{2}$ ). Merodon nigritarsis group includes 18 species (listed in Introduction with additional 3 here described species), from which 6 species belong to alagoezicus subgroup: Merodon nitidifrons, $M$. alagoezicus, $M$. satdagensis, $M$. schachti, M. hakkariensis and M. lucasi.

Merodon ottomanus is a species with dark abdomen (fig. $5 \mathrm{~A}$ ), reddish-yellow basoflagellomere (fig. $5 \mathrm{C}$ ) and yellow tarsi of metaleg (at least basotarsomere) (fig. $5^{\mathrm{B}}$ ).

Merodon pruni group is characterized by short body pilosity (scutum and abdomen) (fig. ${ }_{7} \mathrm{C}$ ) and short basoflagellomere, as long as broad (fig. $7 \mathrm{~A}$ ); metatrochanter with distinct thorn (fig. $7 \mathrm{~B}$ : marked with arrow). Two species belong here: M. pallidus Macquart, 1842 and M. pruni Rossi, 1790.

Merodon serrulatus group includes taxa with characteristic basolateral protrusion on the posterior surstyle lobe at outer surface (fig. 8B: marked with arrow). This group includes five already known species: $M$. bequaerti Hurkmans, 1993, M. hirsutus Sack, 1913, $M$. kawamurae Matsumura, 1916. M. sacki Paramonov, 1936, and M. serrulatus Wiedemann in Meigen, 1822.

According to the results presented on the two-genes trees (fig. 2, supplementary figs. S1 and S2) $M$. nigritarsis group with previously identified species (in Vujić et al., 2013) is related to $M$. avidus group (M. avidus complex and $M$. femoratus). The supposed monophyletic position of $M$. nigritarsis group (Vujić et al., 2013) is confirmed and supported by high bootstrap values (MP 96, ML 99) and a posterior probability with a value of $100 \%$; with the exception of $M$. crassifemoris species. This species was clearly separated from members of the $M$. nigritasis group. Merodon avidus group considered to be an independent line (MP bootstrap 88, ML bootstrap $98, \mathrm{PP}=100 \%$, and includes taxa previously recognized as $M$. avidus complex, the taxon $M$. femoratus redefined here and the newly described species $M$. rutitarsis sp. n., which was not available for molecular analyses.

\section{Species delimitation based on molecular data (COIgene)}

In order to reveal the composition of the $M$. nigritarsis group, we included 105 specimens representing avidus-nigritarsis (84 specimens), albifrons+desuturinus, natans and aureus lineages and applied analyses on COI gene sequences, which are proved to be highly informative for species delimitation. All obtained COI gene trees (ML, BI and MP) corroborate the four main lineages (putative subgenera) within the Merodon genus (MP bootstraps over 89 , ML bootstraps over 98 and PP over 75\% except for aureus lineage; fig. 15, supplementary figs. $\mathrm{S}_{3}$ and $\left.\mathrm{S}_{4}\right)$, as resolved in analyses of two-gene (COI and $28 \mathrm{~S}$ rRNA) data matrix. Within the M. avidus-nigritarsis lineage, we observed clear differentiation of the $M$. nigritarsis group (MP bootstrap 98, ML bootstrap 100 and PP 97\%; fig. 15, supplementary figs. $\mathrm{S}_{3}$ and $\mathrm{S}_{4}$ ) consisting of 9 species: $M$. nigritarsis, M. obstipus sp. n., M. femoratoides, $M$. latifemoris, $M$. toscanus, $M$. longisetus sp. n., M. alagoezicus, M. lucasi and M. testaceus. Merodon crassifemoris, previously known to belong to this group (Vujić et al., 2013) was not resolved into the $M$. nigritarsis group, but belongs to avidus-nigritarsis lineage. Additionally, two morphologically different species, M. alagoezicus and M. lucasi, were not separated in different clusters on COI gene trees. They are distributed into two clusters on all obtained trees, the first one consisted of 3 individuals of $M$. alagoezicus collected on Samos island in Greece (specimens with 


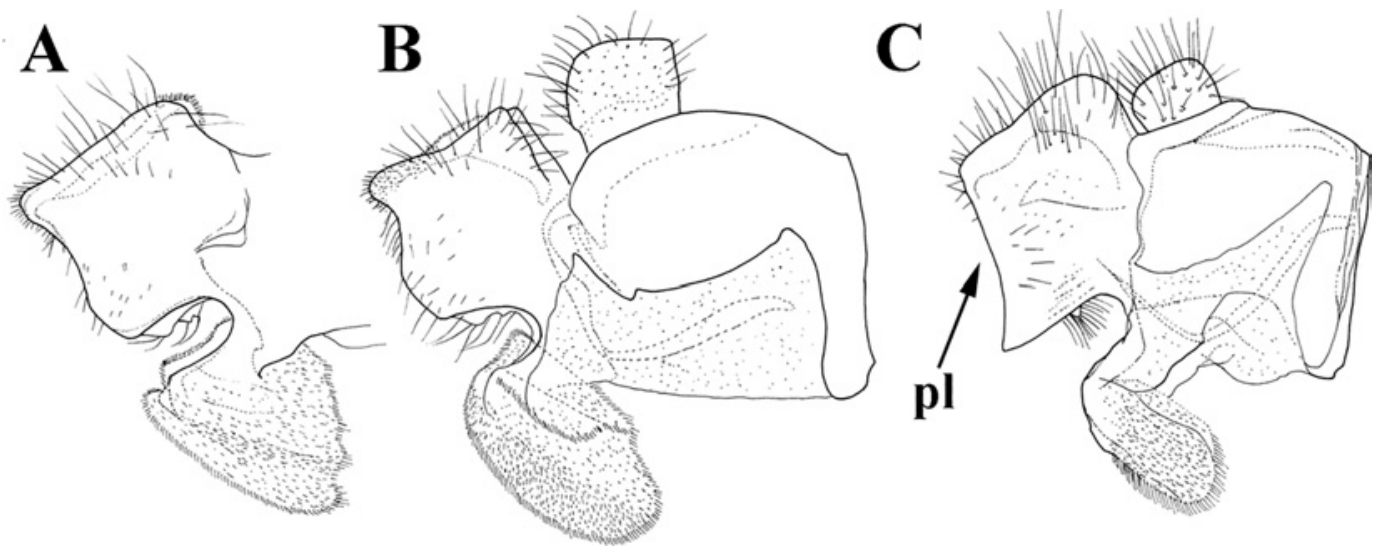

FIGURE 6 Male genitalia. Lateral view, A) Merodon erivanicus, surstyle lobe B) Merodon erivanicus, epandrium, C) Merodon italicus, epandrium. pl-posterior surstyle lobe.

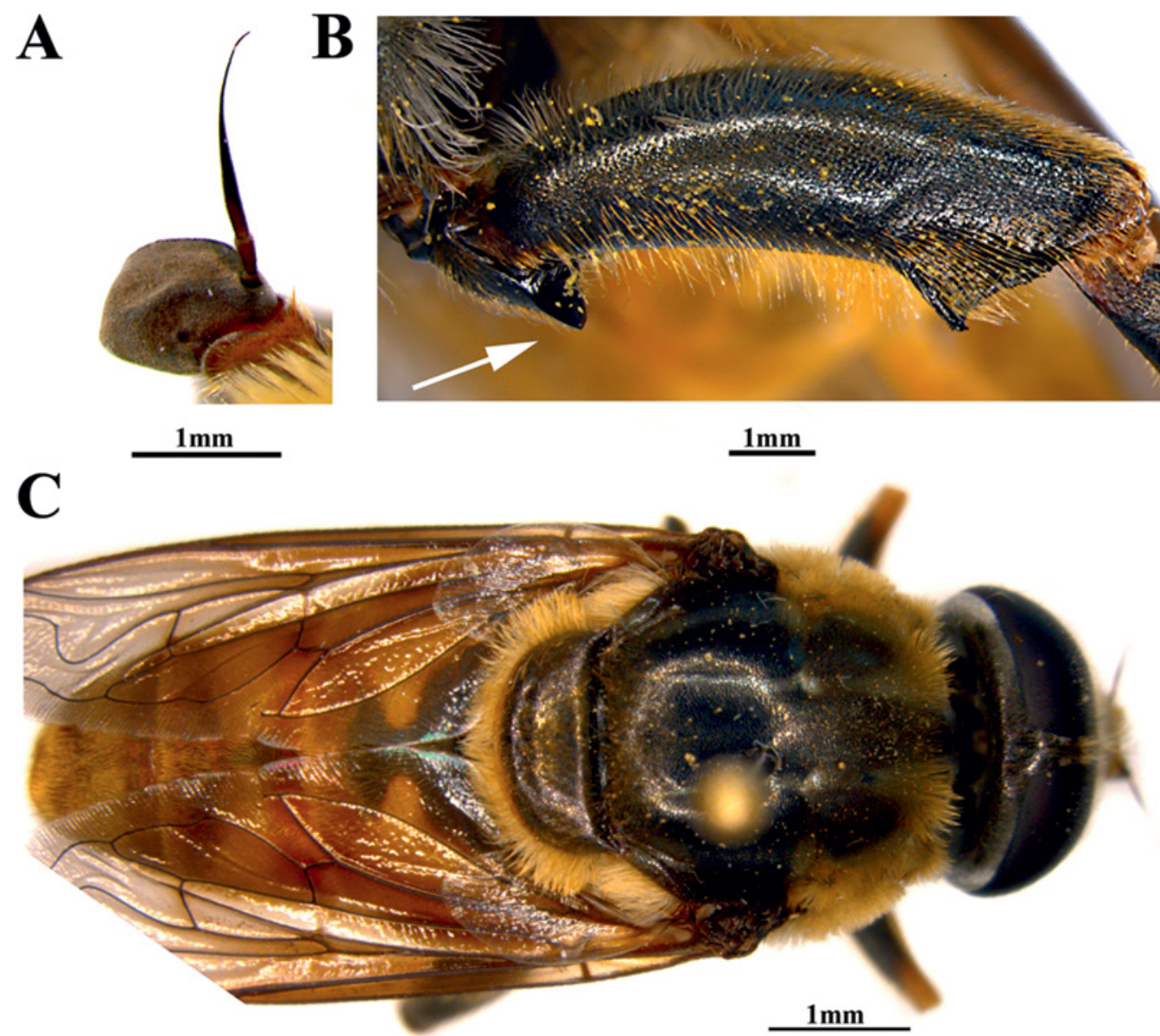

FIGURE 7 Male of Merodon pruni. A) basoflagellomere, B) metatrochanter and metafemur (distinct thorn on metatrochanter marked with arrow), C) body. Scale: $1 \mathrm{~mm}$. 


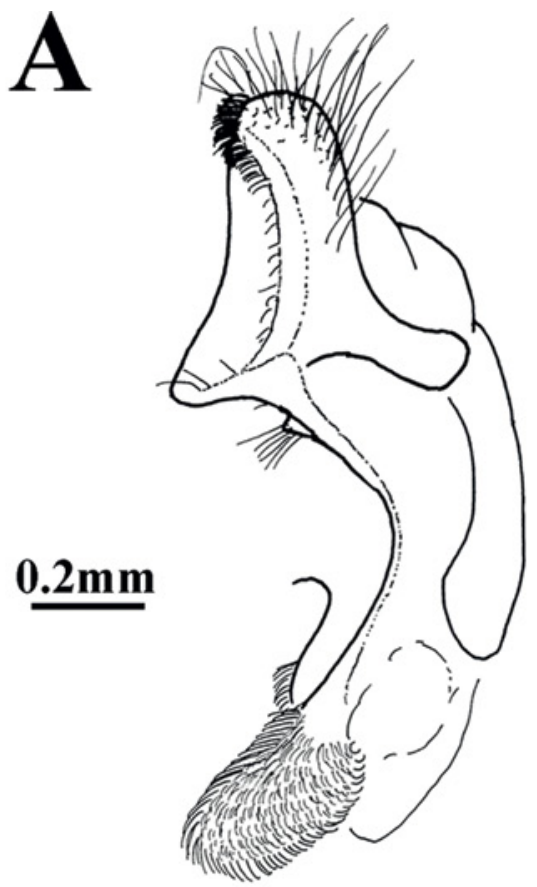

B
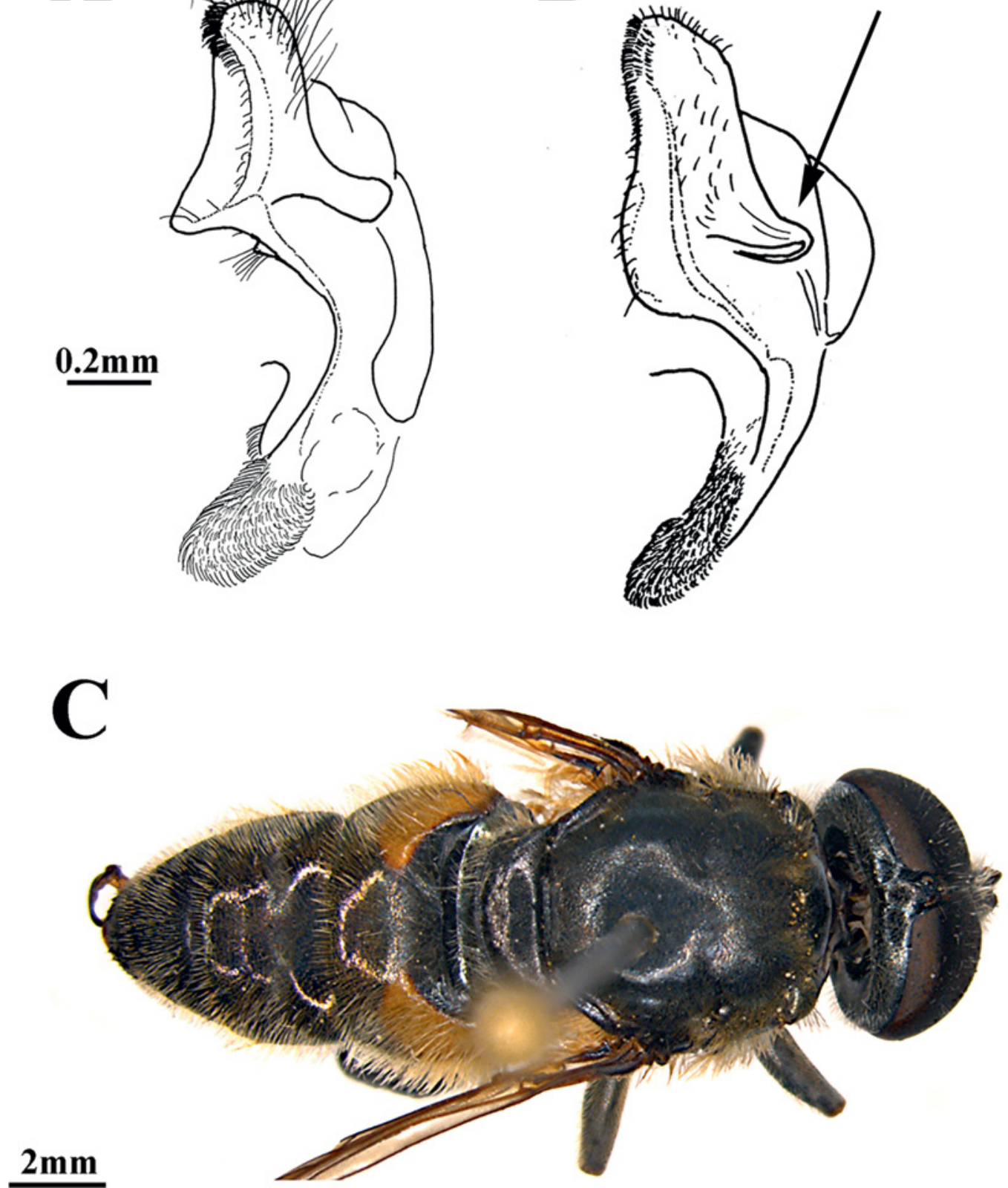

FIGURE 8 Male of Merodon serrulatus. A) and B) surstyle lobe (basolateral protrusion on the posterior surstyle lobe marked with arrow), C) body. Scale: A-B) $0.2 \mathrm{~mm}, \mathrm{C}) 2 \mathrm{~mm}$. 
A

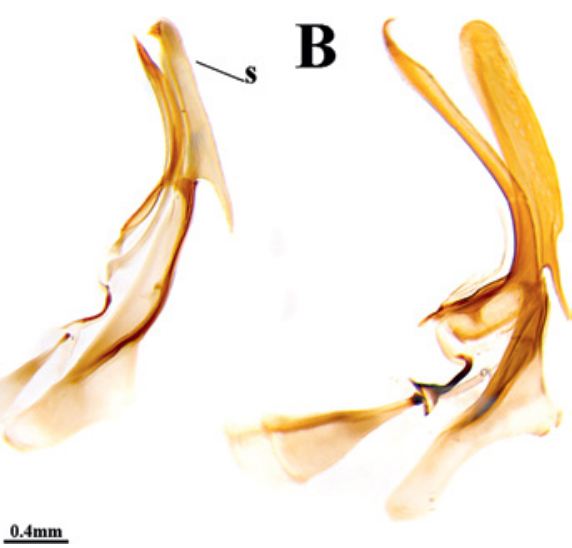

FIGURE 9 Male genitalia, aedeagus. Lateral view, A) Merodon nigritarsis, B) M. avidus. Scale $0.4 \mathrm{~mm}$. s-lateral sclerite of aedeagus.
A
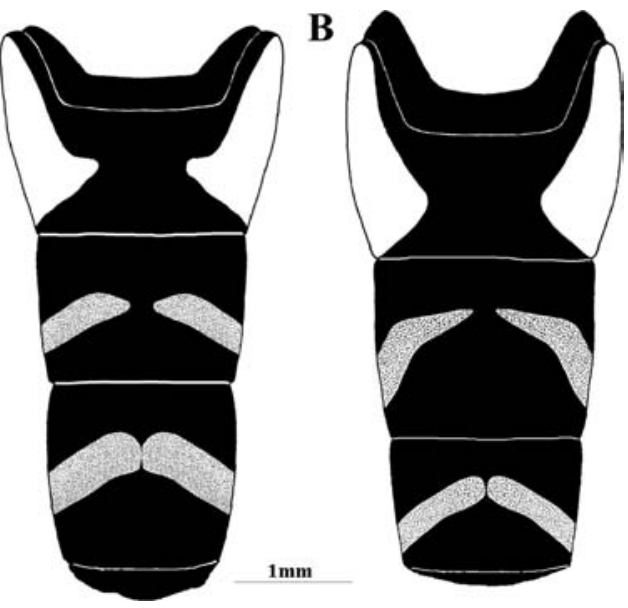

FIgURE 10 Abdomen of male. Dorsal view, A) Merodon cohurnus sp. n., B) Merodon nigritarsis. Scale: $1 \mathrm{~mm}$.

A

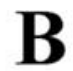

C
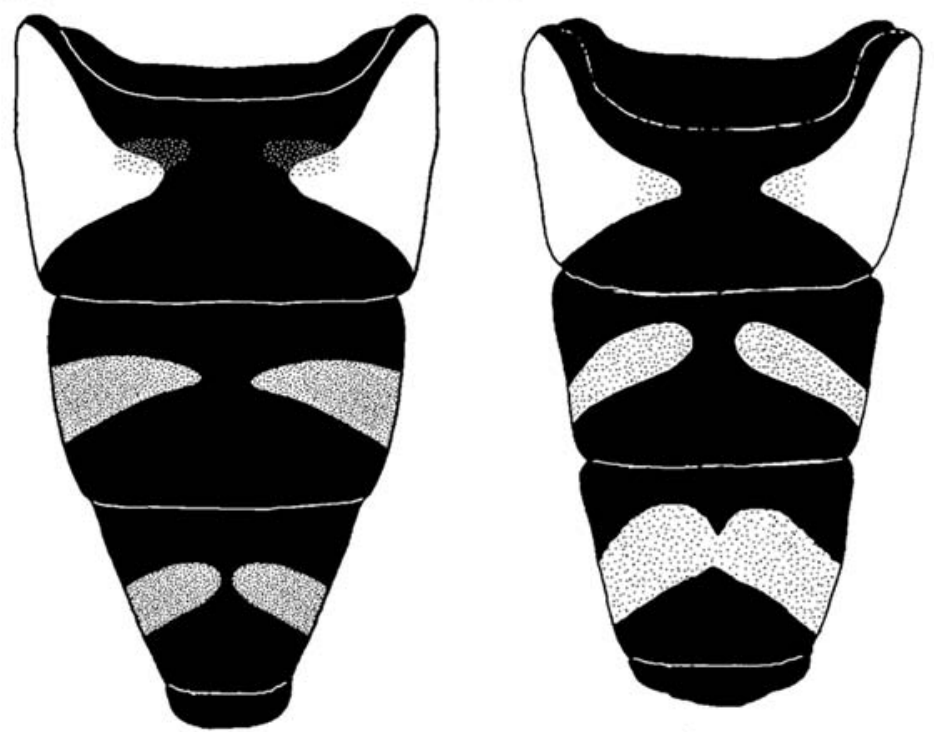

$1 \mathrm{~mm}$

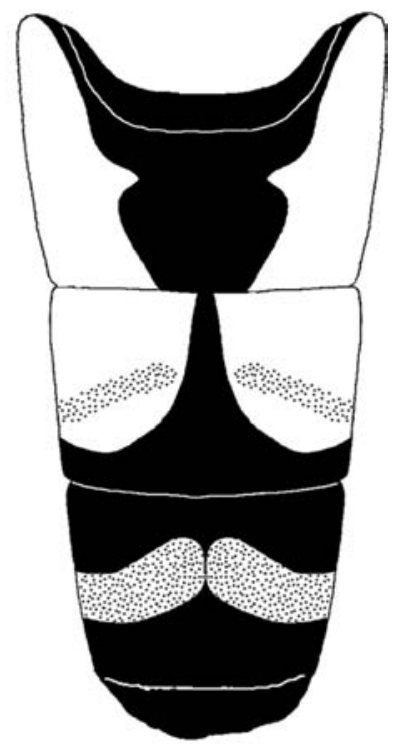

FIGURE 11 Abdomen of male. Dorsal view, A) Merodon rutitarsis sp. n., B) Merodon quadraticus, C) Merodon toscanus. Scale: $1 \mathrm{~mm}$. 


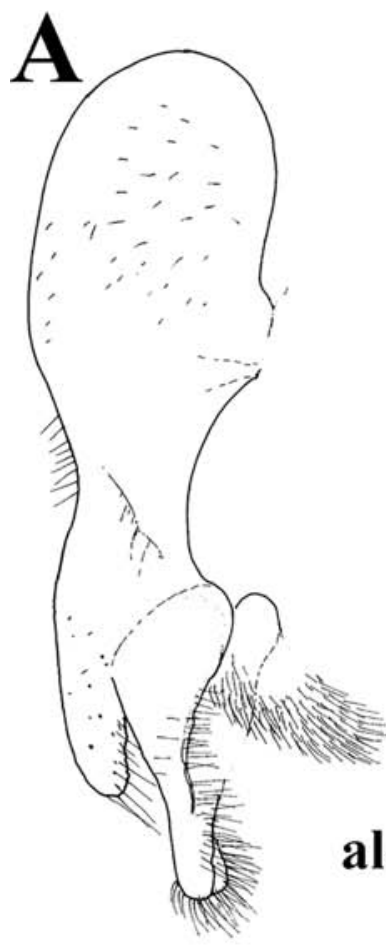

D
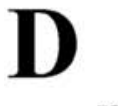
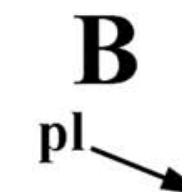

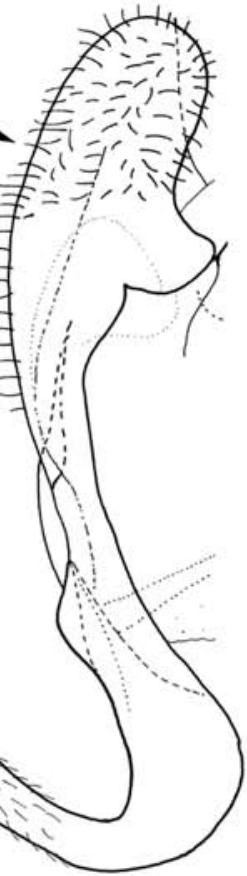

$\underline{0.2 \mathrm{~mm}}$

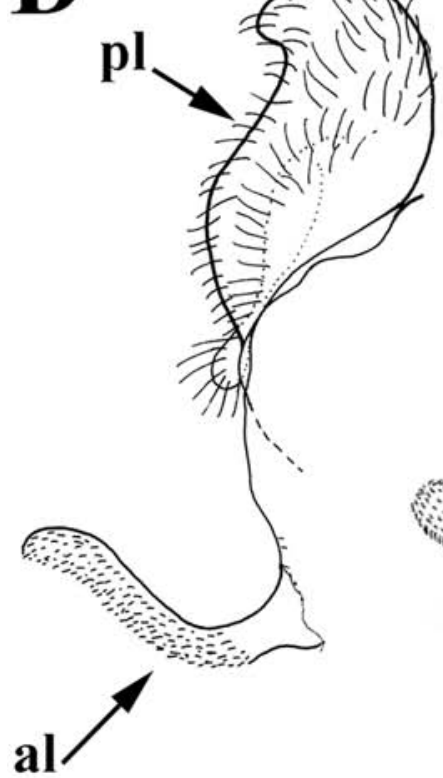

\section{$\mathbf{E}$

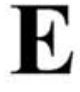

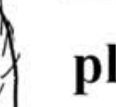
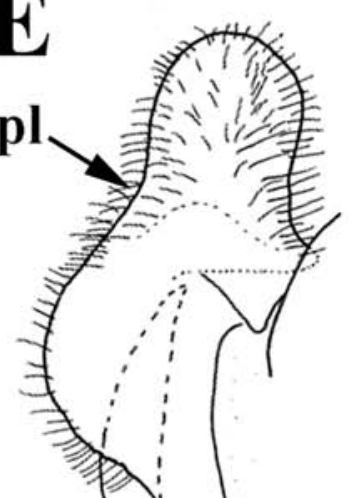
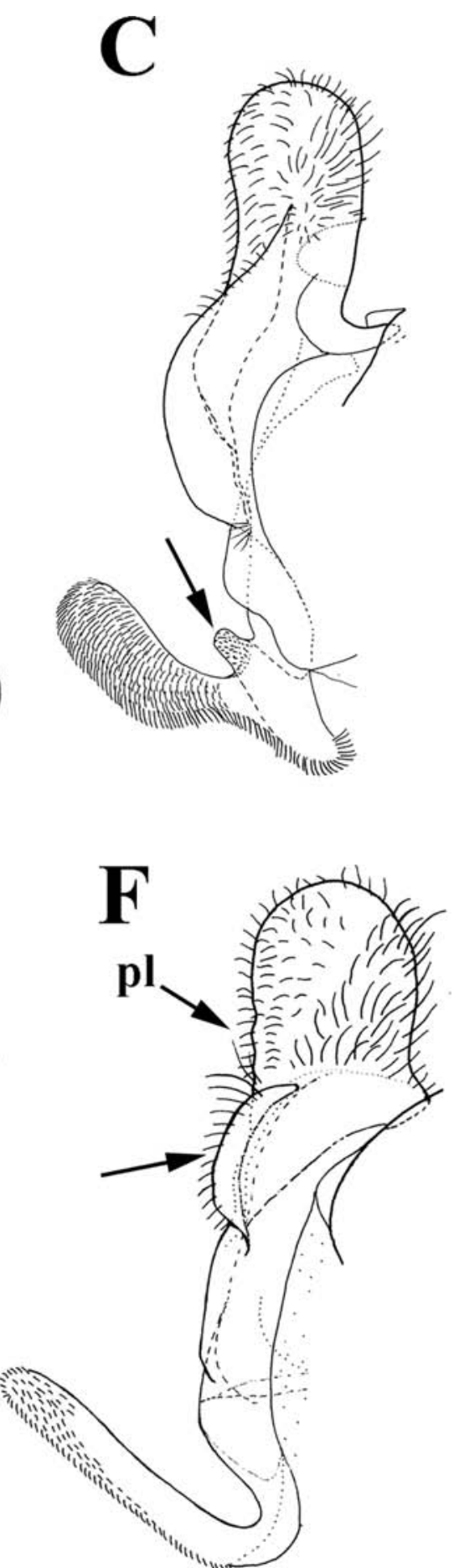

FIgURE 12 Male genitalia. Surstyle lobe. Ventral view, A) Merodon nitidifrons, B) Merodon alagoezicus, C) Merodon satdagensis (basal extension marked with arrow), D) Merodon schachti, E) Merodon hakkariensis,

F) Merodon lucasi (lamellar structure marked with arrow). Scale: $0.2 \mathrm{~mm}$. al-anterior lobe of surstylus, pl-posterior lobe of surstylus. 

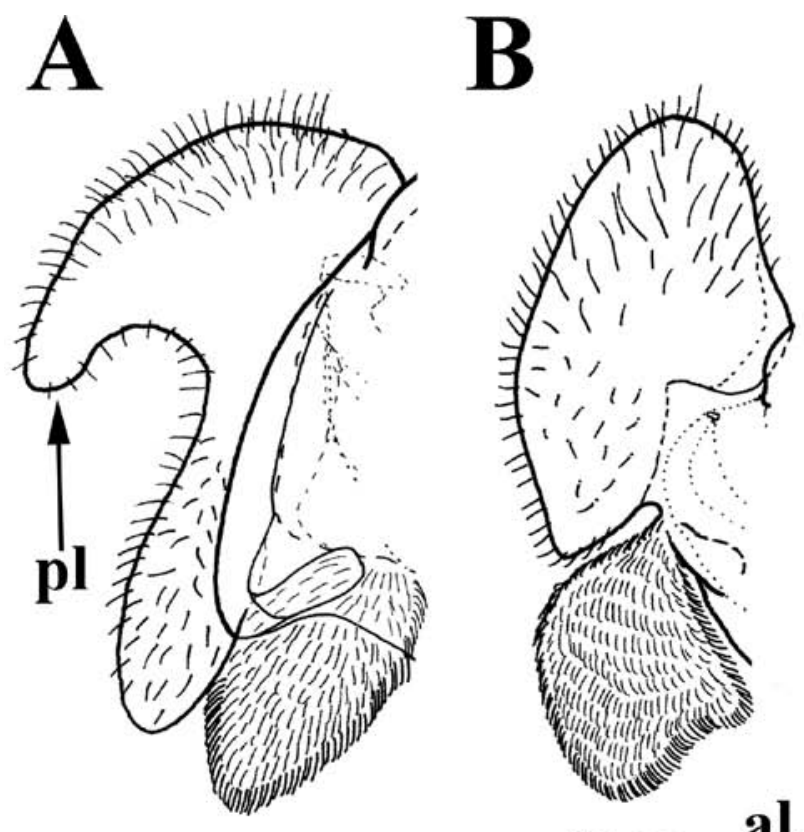

C
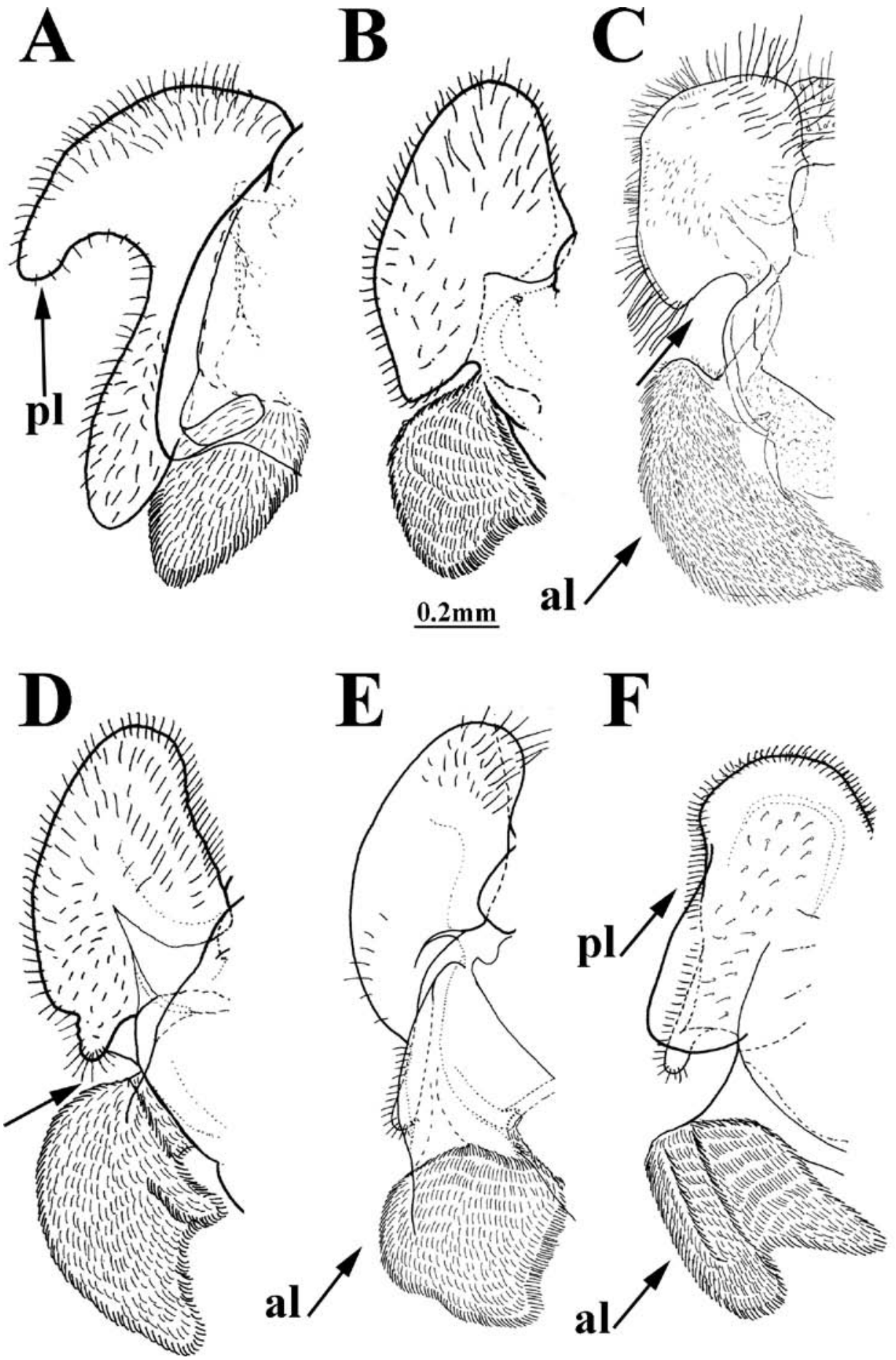

$\mathbf{F}$

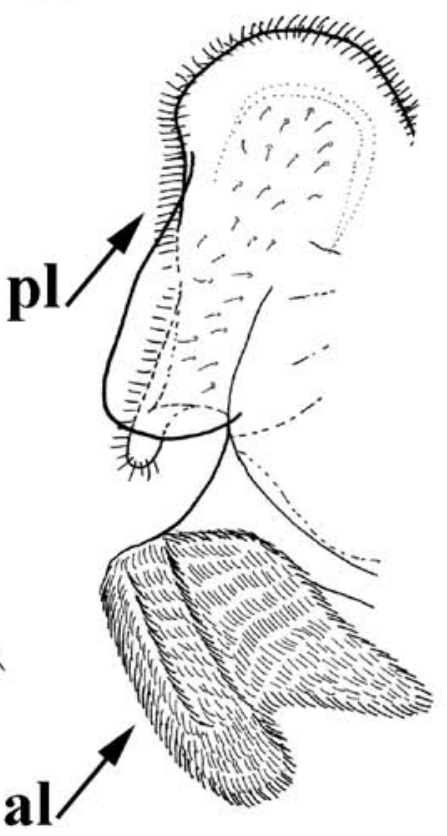

FIGURE 13 Male genitalia. Surstyle lobe. Ventral view, A) Merodon crassifemoris, B) Merodon angustus, C) Merodon femoratus (incision between anterior and posterior lobes of surstylus marked with arrow), D) Merodon testaceus (incision between anterior and posterior lobes of surstylus marked with arrow), E) Merodon quadraticus, F) Merodon taniniensis. Scale: $0.2 \mathrm{~mm}$. al-anterior lobe of surstylus, pl-posterior lobe of surstylus. 

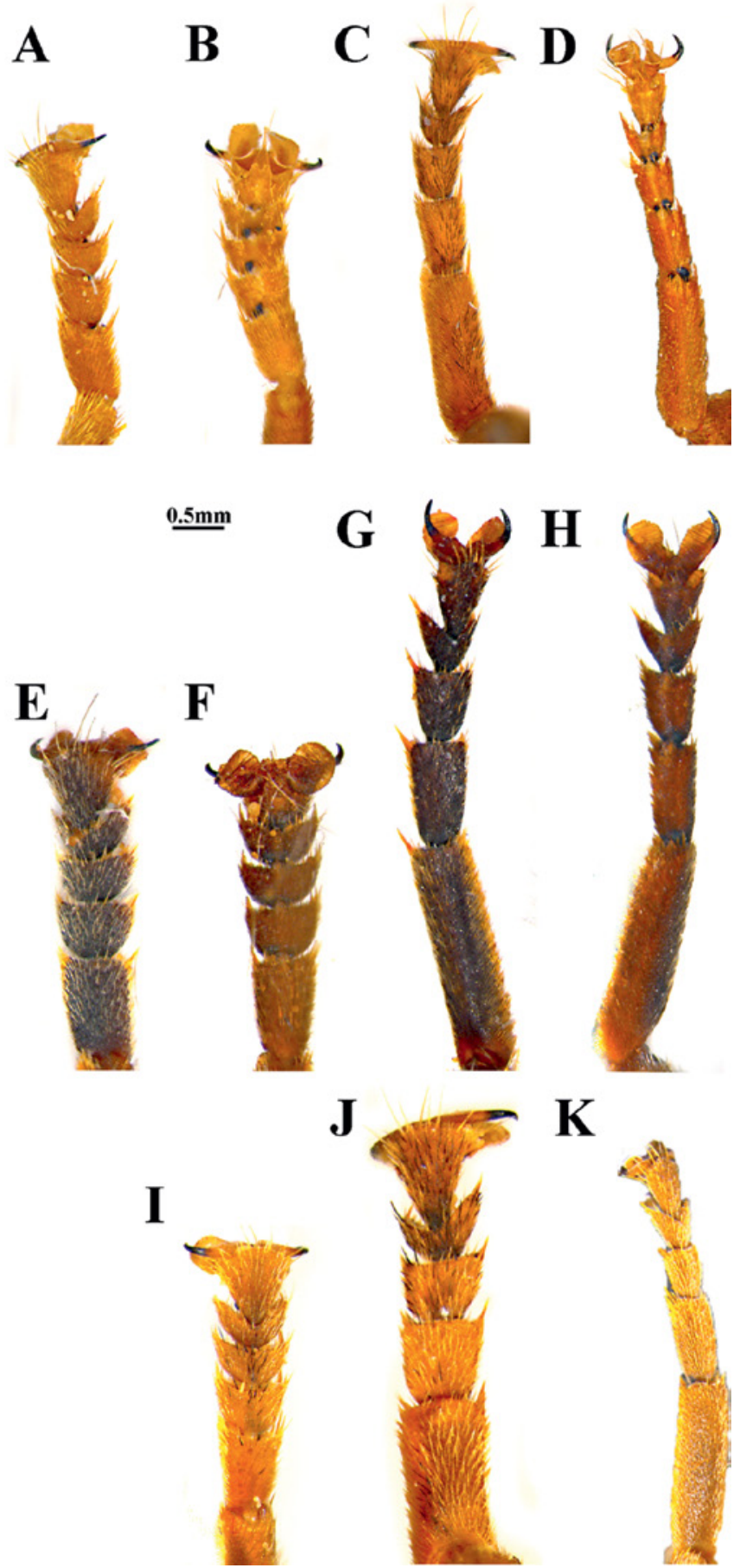

FIGURE 14 Tarsomeres of male. A) Merodon avidus, protarsus, dorsal view, B) Merodon avidus, protarsus, ventral view, C) Merodon avidus, metatarsus, dorsal view, D) Merodon avidus, metatarsus, ventral view, E) Merodon nigritarsis, protarsus, dorsal view, F) Merodon nigritarsis, protarsus, ventral view, G) Merodon nigritarsis, metatarsus, dorsal view, H) Merodon nigritarsis, metatarsus, ventral view, I) Merodon femoratus, protarsus, dorsal view, J) Merodon femoratus, metatarsus, dorsal view, K) Merodon rutitarsis sp. n., metatarsus, dorsal view. Scale: $0.5 \mathrm{~mm}$. 


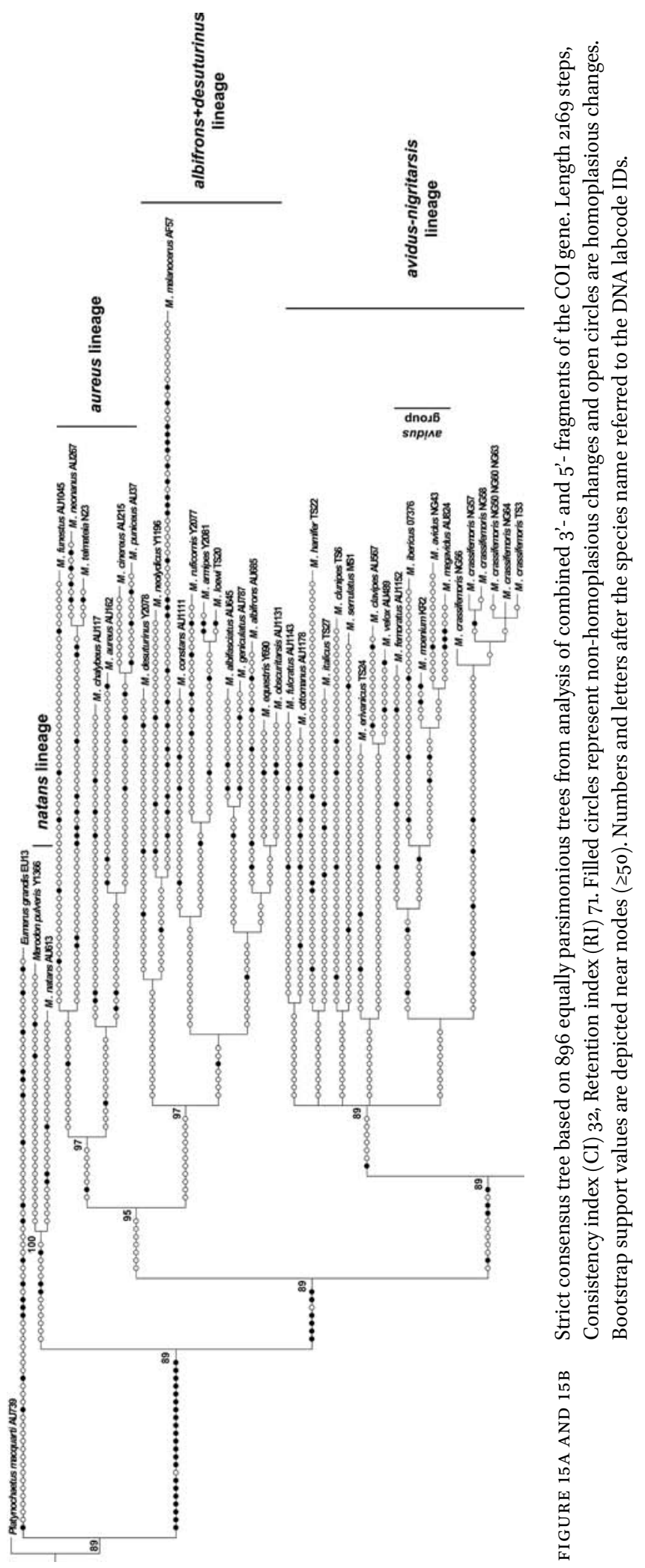




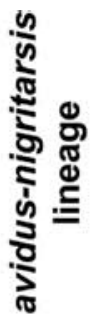

dnoג6 s!sıe!!n6!u

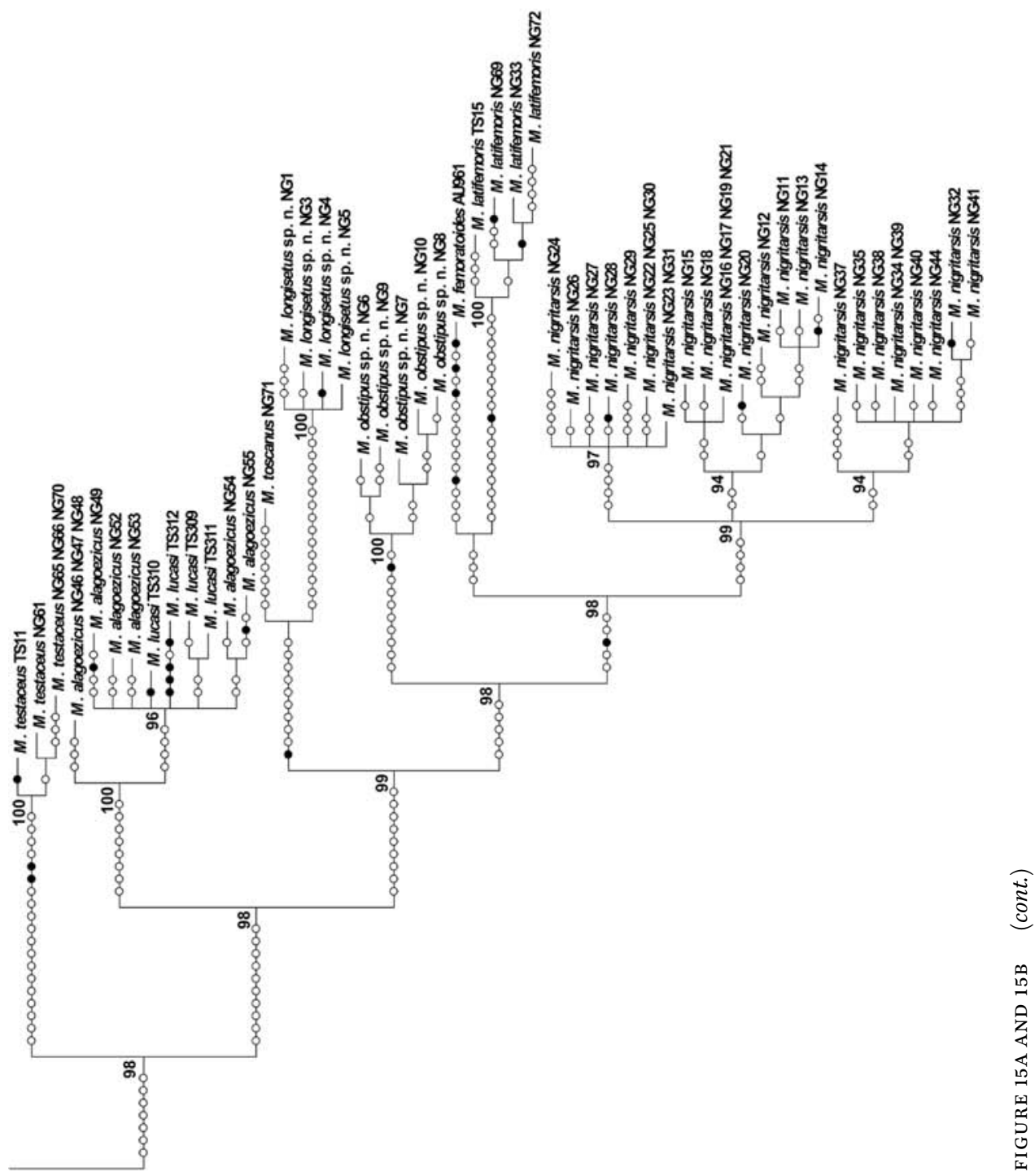


codes NG46-48) and the second consisted of 5 individuals $M$. alagoezicus (specimens with codes NG49, NG52-55) and 4 individuals $M$. lucasi (specimens with codes $\mathrm{TS}_{309}$-312), all collected in Turkey. Furthermore, individuals that belong to $M$. nigritarsis species showed three genetic clusters on COI gene trees: one with samples collected in Spain (specimens with codes NG22-31), the second with samples collected in Turkey (specimens with codes $\mathrm{NG}_{32}, \mathrm{NG}_{34}-35, \mathrm{NG}_{37-41}$ and $\mathrm{NG}_{44}$ ) and the third with samples collected in Serbia and Montenegro (specimens with codes NG11-21).

Species delineation using GMYC was consistent across the different priors used: Yule, Constant Coalescent and Relaxed Clock, but using Relaxed Clock did not reach convergence even with an extension of the number of MCMCs, so this prior was excluded from further analyses. For both, Yule and Constant Coalescent priors, the number of maximumlikelihood clusters was 11 (supplementary fig. $\mathrm{S}_{5} \mathrm{~A}$ ), while the number of ML entities was 48 due to the fact that some species were represented only by one sequence. GMYC confidently delineates the following species: $M$. latifemoris, M. obstipus sp. n., M.femoratoides, $M$. longisetus sp. n., M. toscanus, $M$. testaceus and $M$. crassifemoris (outside of $M$. nigritarsis group), but not $M$. alagoezicus, $M$. lucasi and $M$. nigritarsis (supplementary fig. $\mathrm{S}_{5} \mathrm{~B}$ ). For these species, multiple candidate nodes with possible threshold positions were observed, indicating that we might be dealing with more than one species within these clusters. For species M. alagoezicus and M. lucasi, similar cluster differentiation was observed as on ML, BI and MP trees, where for cluster of $M$. alagoezicus individuals collected on Samos Island in Greece the observed threshold was 0.68 , while for cluster of individuals of M. alagoezicus and M. lucasi collected in Turkey, multiple candidate nodes were detected indicating two species within this cluster. For
$M$. nigritarsis multiple candidate nodes were also detected indicating we might be dealing with 3 species/subspecies within this cluster, congruent with clustering observed in MP, ML and BI trees.

\section{Discussion}

The position of M. nigritarsis and M. avidus groups into Merodon avidus-nigritarsis lineage

Although many recent taxonomic papers which dealt with the genus Merodon have studied different groups of species (Vujić et al., 2012, 2013, 2015; Ačanski et al., 2016a; Šašić et al., 2016; Veselić et al., 2017; Kočiš Tubić et al., 2018; Radenković et al., 2018a), there is still an apparent need for a subgeneric classification and resolving the taxonomic status of some species and groups.

Recently Šašić et al. (2016) provided a system of four ranks of classification of the genus Merodon based on morphological differentiation and previous results of Mengual et al. (2006) that also included molecular data. The first level constitutes four monophyletic clades, including the $M$. avidus (nigritarsis) clade, while the second presents morphologically defined species groups within clades. Previously, Vujić et al. (2012) recognized two sister groups albifrons and desuturinus as one clade, resolved here as well. Later on, Radenković et al. (2018b) based on COI data, besides the three previously established lineages, albifrons+desuturinus, aureus (sensu lato) and avidus-nigritarsis, recognized one more lineage, named natans, that is in congruence with here produced trees using both mitochondrial COI and nuclear 28S rRNA genes. Here we examined the systematic position and composition of the groups within the M. avidus-nigritarsis lineage. Phylogenetic analyses based on the combined sequences of two genes (COI and $28 \mathrm{~S}$ rRNA) resolved the 
M. nigritarsis and M. avidus groups as branches within one common lineage.

Furthermore, both groups comprise the same lineage in COI gene trees, including larger number of individuals and longer COI gene sequence. Regarding the $M$. nigritarsis group, data from the present study agree broadly with those of Vujić et al. (2013). The concept of this group is here redefined, now consisting of the previously identified species (Vujić et al., 2013) and here described new species, with exclusion of $M$. crassifemoris species. The excluded taxon was clearly separated from the other members of the studied group based on MP, ML and BI trees generated from both molecular datasets, as well by lack of subapical thorns on ventral margin of hypandrium (apomorphic morphological character of the M. nigritaris group) and unique hook-like shape of posterior surstyle lobe that additionally strengthened this exception. Merodon avidus group of species is defined here by molecular and morphological data (clearly different by yellow tarsi contrary to $M$. nigritarsis group characterized by dorsally dark tarsi). It includes besides, previously defined $M$. avidus complex (Popović et al., 2015; Ačanski et al., 2016a), the new species Merodon rutitarsis sp. $\mathrm{n}$. and also M. femoratus. The present study establishes a clear distinction of 12 separate branches within the Merodon avidusnigritarsis lineage based on phylogenetic analyses and supported by apomorphic morphological characters, namely 9 groups: $M$. $a b$ errans, M. aurifer, $M$. avidus, $M$. clavipes, $M$. fulcratus, $M$. italicus, M. nigritarsis, $M$. pruni and $M$. serrulatus, and three species with separate position (M. clunipes, M. crassifemoris, and $M$. ottomanus). Besides the above mentioned groups, the avidus-nigritarsis lineage includes one additional group named $M$. tarsatus and two species M. eumerusi Vujić, Radenković \& Likov, 2019 and M. murinus Sack, 1913, without obtained molecular data, distributed in the Middle East (Asia) (Vujić et al., 2019).

\section{Species delimitation based on COI data}

The in depth analysis, focusing on species delimitation in the M. nigritarsis group, employed COI gene sequences, which is proved to be genetic marker with an adequate resolution for species delimitation in genus Merodon and other genera in Syrphidae family (Massetti et al., 2006; Mengual et al., 2006; Marcos-García et al., 2011; Vujić et al., 2012, 2013; Nedeljković et al., 2015; Popović et al., 2015; Šašić et al., 2016; Chroni et al., 2017). Moreover, analyses of the COI gene has proven to be a reliable tool for revealing cryptic taxa in the genus Merodon (Vujić et al., 2012; Šašić et al., 2016; Radenković et al., 2018a). Analyses based on COI gene sequences included multiple specimens per species within the M. nigritarsis group (except for $M$. femoratoides and M. toscanus where only one individual per species was available) and those of the longest and of the best quality 3' and 5 ' fragment COI gene sequences (in order to yield the maximum information for species delimitation; after processing total length of 1371 nucleotides).

MP, ML and BI analyses based on the COI gene sequences allowed us to clearly separate 7 species: M. nigritarsis, M. obstipus sp. n., M. femoratoides, M. latifemoris, M. toscanus, $M$. longisetus sp.n., and M. testaceus, while species $M$. alagoezicus and $M$. lucasi were not clearly separated, and shown to be clustered together (fig. 15, supplementary figs. $S_{3}$ and $S_{4}$ ). Applied cluster analyses allowed us to confirm the exclusion of M. crassifemoris from the M. nigritarsis group, and to conclude that this species belongs to the avidus-nigritarsis lineage as a separate genetic entity. Morphologically defined species M. alagoezicus and M. lucasi clustered together in all gene trees, and to try to resolve their position we further used Generalized Mixed Yule Coalescent method for additional identification of putative species within the M. nigritarsis group. The GMYC, as one of the most popular coalescent-based species delimitation methods, is designed for 
single-locus data (Fujisawa \& Barraclough, 2013) and has proven to be a powerful tool for evaluating species limits (Birky et al., 2011; Michonneau, 2015) and therefore should be added to integrative taxonomy studies. For our dataset, GMYC additionally confirmed the following species: M. latifemoris, M. obstipus sp. n., M. femoratoides, $M$. longisetus sp. n., M. toscanus, M. testaceus and M. crassifemoris (the latter outside of the $M$. nigritarsis group). For species M. alagoezicus and M. lucasi GMYC analyses showed that we may be dealing with more than one species, even though individuals belonging to these species were mixed in one cluster on constructed gene trees. Inspection of such constructed trees, together with GMYC results, revealed that three specimens morphologically defined as $M$. alagoezicus and all collected on Samos Island in Greece represent a one genetic cluster, while five $M$. alagoezicus specimens and four M. lucasi (all collected in Turkey) were clustered together in separate cluster, for which GMYC showed multiple candidate nodes indicating that more than one species belong to this cluster. The low COI divergence between these species in separate geographic region may be explained by retained polymorphism or mitochondrial introgression between the taxa, as was earlier shown to be case for the Merodon genus (Ståhls et al., 2009). On the other hand, genetic clustering of COI sequences of M. alagoezicus from Samos Island may be consequence of founder effect typical for isolated island populations which were formed by specimens migrating from the continental population. Subsequent genetic drift might led to fixation of one single observed haplotype (all three individuals share the same COI haplotype). In order to clearly understand $M$. alagoezicus and $M$. lucasi species boundaries in Turkey, additional research should be performed, namely distribution of the taxa, their interaction with plants, and inclusion of new genetic/genomic methods. In addition, GMYC analyses revealed multiple candidate nodes within $M$. nigritarsis species, and three genetic clusters that contained specimens from the following countries and Peninsulas: 1) Spain (Iberian Peninsula); 2) Turkey (Anatolian Peninsula); and 3) Serbia and Montenegro (Balkan Peninsula). Observed genetic differentiation of the COI gene within $M$. nigritarsis may be a consequence of geographical distribution of analyzed individuals and it is possible that we might be dealing with three independent taxa, where speciation is result of geographical isolation and adaptation to different environmental conditions. Nevertheless, it is noteworthy to mention that there are studies where GMYC delivered a higher species number than it is observed by morphology (Esselstyn et al., 2012; Paz \& Crawford, 2012; Sauer \& Hausdorf, 2012; Talavera et al., 2013). It is shown that GMYC produces more splits when intra- and interspecific pairwise distances are low (Zhang et al., 2013) and this is usually a case in the recently differentiated species lacking a 'barcode gap' (Wiemers \& Fiedler, 2007; Dupuis et al., 2012).

\section{Diversity and new taxa}

The present study is an additional contribution that illustrates the great diversity of the Merodon avidus-nigritarsis lineage, and especially the $M$. nigritarsis and $M$. avidus groups. The species richness of the $M$. nigritarsis group (18 species) is one of the highest in comparison with other recognized species groups of the genus Merodon: the M. ruficornis group with 18 (Vujić et al., 2012), the $M$. nanus group with six (Kočiš Tubić et al., 2018), and the $M$. constans group with 14 members (Vujić et al., in prep.), with exception of the $M$. aureus group which contains an extremely high number of 39 detected species (Veselić et al., 2017). From an initial number of only two species (Hurkmans, 1993), through the 15 species later presented in Vujić et al. (2013), our present results increased the number of taxa 
to 18 , including three new species from the $M$. nigritarsis group. Additionally, in the present study we described one new species from the M. avidus group, Merodon rutitarsis sp. n., thus the recent number of this species group is six.

Among newly collected and revised material, based on morphological characteristics, especially male genitalia, four new species from the $M$. nigritarsis and M. avidus groups have been discovered and described. Merodon obstipus sp. n. is related to $M$. femoratoides, based on both morphological and molecular data. Merodon longisetus sp. $\mathrm{n}$. is a sister species to $M$. toscanus, with morphological similarities, but quite distinct with respect to the shape of male genitalia. Merodon cohurnus sp. n. has male genitalia structures that are most similar to $M$. longisetus sp. n., while $M$. rutitarsis sp. n. shows some morphological similarities (yellow tarsi) with members of $M$. avidus complex. In contrast, it is hard to distinguish females, and their identification will be subject to future studies using a combined integrative approach.

\section{Distribution}

According to Myers et al. (2000), the Mediterranean Basin was identified as a biodiversity hotspot, with a high concentration of endemic species. According to Speight (2018) Merodon is the largest genus of European hoverflies and has predominantly a Mediterranean distribution (Ståhls et al., 2016), with the Eastern Mediterranean as the main centre of diversification of this genus (Vujić et al., 2011). These areas connect different biogeographic regions between Asia, Africa and Europe, providing passages for species spread (Vujić et al., 2015). Iberian (Marcos- Garcia et al., 2007), Balkan (Kaloveloni et al., 2015) and Anatolian Peninsulas (Vujić et al., 2011), including the Greek islands (Vujić et al., 2007), have the largest number of Merodon species. The higher diversity in these areas could be a result of typical Mediterranean climatic conditions (Çelik et al., 2004), and an evolutionary result of the high diversity of geophytes in the Mediterranean flora, as Merodon species larval development is closely related to bulbous plants (Kaloveloni et al., 2015) mainly of the families Liliaceae, Amaryllidaceae, and Hyacinthaceae (Ståhls et al., 2016; Preradović et al., 2018). The present study represents an additional contribution to the already reported high diversity of the $M$. avidus and $M$. nigritarsis groups in Mediterranean region.

Merodon nigritarsis species group comprises taxa with a mainly mountainous distribution, mostly on the Balkan, Anatolian, Apennine and Iberian Peninsulas, in central Europe as well as the Middle and Near East. The richest localities with the presence of more than 8 different species are mountains in the western and eastern parts of Anatolian Peninsula (fig. 16). Anatolia is a bridge between Asia and Europe, and was an important refugium during the Quaternary ice ages (Çiplak, 2003). The widest distribution within $M$. nigritarsis group is shown by the species $M$. nigritarsis, occurring throughout Central Europe, the European part of Mediterranean basin and areas surrounding the Black and Caspian Sea.

Members of $M$. avidus group are distributed all across Europe, mainly in the central and southern parts, and less in the Near and Middle East and in North Africa (Algeria and Libya). They are most abundant in the S-SW Mediterranean and in Morocco (fig. 17). Merodon avidus is the most widely distributed species in this group, mostly in Europe, and in areas surrounding the Black and Caspian Seas, with occurrence in Morocco and Libya as well.

Out of the 18 species that are members of the $M$. nigritarsis group, 12 are endemics, which illustrates the exceptionally high level of endemism within this species group (66\%). Most of these species occur in mountainous regions of the Balkan and Anatolian Peninsulas, on larger islands in the Eastern Mediterranean and in Asia Minor and the Middle East. 


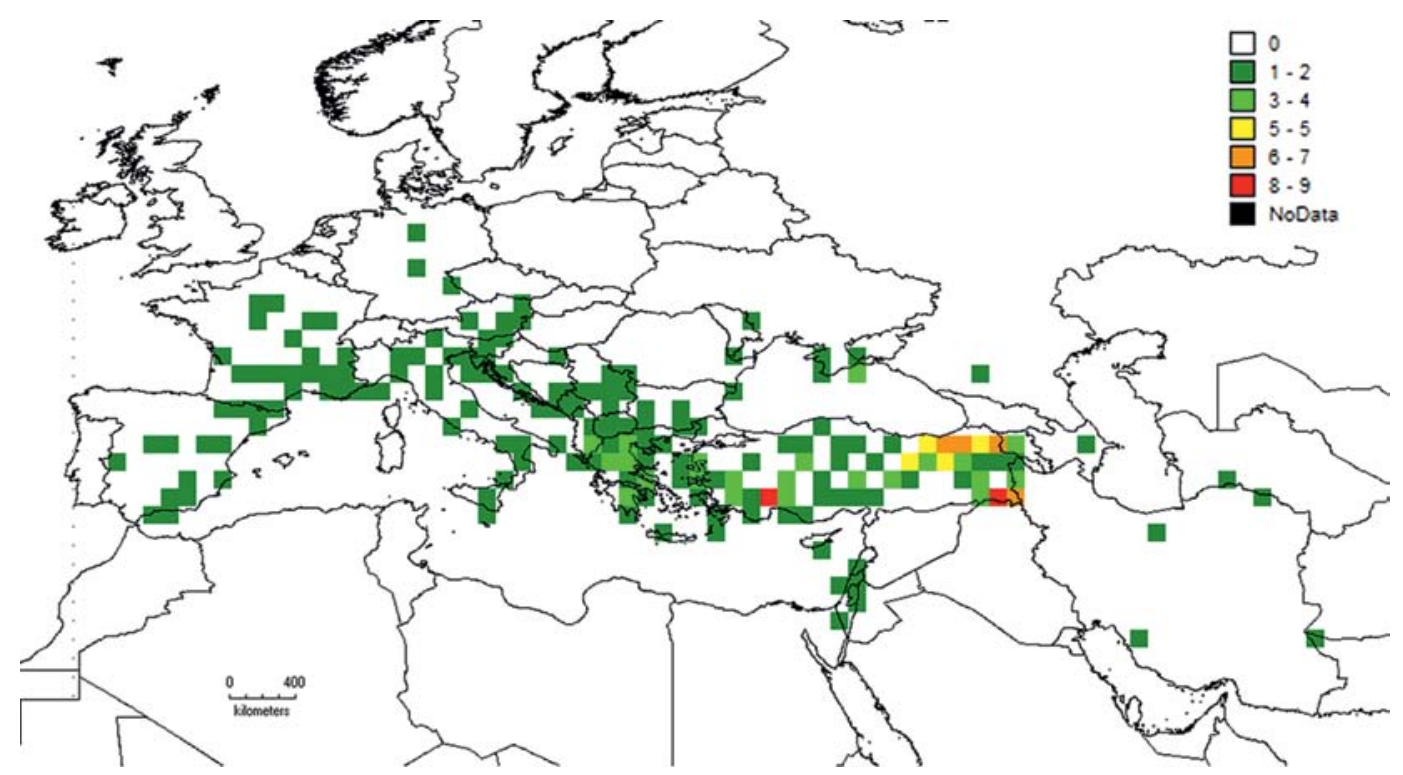

FIGURE 16 Species richness map of Merodon nigritarsis species group.

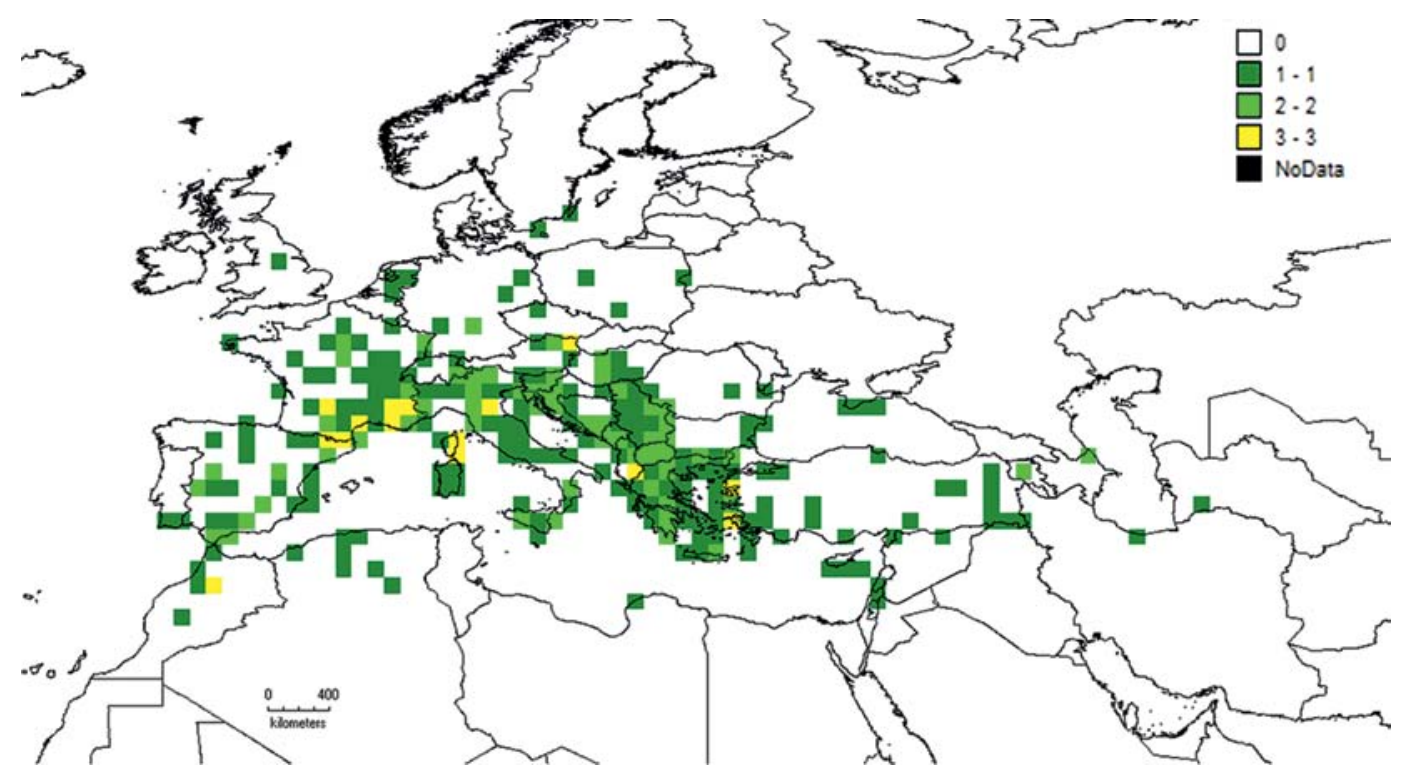

FIGURE 17 Species richness map of Merodon avidus species group.

Based on the limited distribution of the four new described species, these are considered to be endemic to the Anatolian Peninsula (M. longisetus sp. n. and M. obstipus sp. n.) and the Middle East (M. rutitarsis sp. n. and M. cohurnus sp. n.), respectively. Merodon rutitarsis sp. $n$. is a species found at the lowest elevation
(58 m), while other species from the Merodon avidus-nigritarsis lineage reach up to $3000 \mathrm{~m}$. Many recent taxonomic publications have shown a large number of newly described taxa belonging to this genus and primarily in the Middle East and SE Mediterranean (Radenković et al., 2011; Vujić et al., 2011, 2013, 
2015, 2018, 2019; Ricarte et al., 2012; Ačanski et al., 2016a; Šašić et al., 2016). These findings serve as proof that areas of the Balkan and Anatolian Peninsulas, as well as the surrounding Caucasus, represent one of the most important glacial refugia of the Palaearctic region during the last glaciations (Ačanski et al., 2016b). The significance of the eastern Mediterranean region as a hotspot for hoverflies is reaffirmed by the results presented in this paper.

\section{Acknowledgements}

We thank the curators of several museums listed in the Material and Methods that facilitated visits and loans for the study of specimens in their care. We thank Gunilla Ståhls for valuable comments. We thank Professor Edward Petri for English-editing. Financial support was provided by the Serbian Ministry of Education, Science and Technological Development (project III43002, OI173002) the Provincial Secretariat for Science and Technological Development ("Evaluation of Ecological Networks in AP Vojvodina as support for nature conservation") and the Scientific and Technological Research Council of Turkey (TÜBİTAK, project number: $213 \mathrm{O}_{243}$ ). The authors declare no conflict of interest.

\section{Supplementary material}

Supplementary material is available online at: https://doi.org/10.6084/mg.figshare.9741323

\section{References}

Ačanski, J., Miličić, M., Likov, L., Milić, D., Radenković, S. \& Vujić, A. (2016a) Environmental niche divergence of species from Merodon ruficornis group (Diptera: Syrphidae).Arch. Bio.l Sci., 69, 247-259.
Ačanski, J., Vujić, A., Djan, M., Obreht-Vidaković, D., Ståhls, G. \& Radenković, S. (2016b) Defining species boundaries in the Merodon avidus complex (Diptera, Syrphidae) using integrative taxonomy, with the description of a new species. Eur. J. Taxon., 237, 1-25.

Andrić, A., Šikoparija, B., Obreht, D., Đan, M., Preradović, J., Radenković, S., Pérez-Bañón, C. \& Vujić, A. (2014) DNA barcoding applied: Identification of the larva of Merodon avidus (Diptera: Syrphidae). Acta Entomol. Mus. Natl. Pragae, 54, 741-757.

Belshaw, R., Lopez-Vaamonde, C., Degerli, N. \& Quicke, D.L.J. (2001) Paraphyletic taxa and taxonomic chaining: evaluating the classification of braconine wasps (Hymenoptera: Braconidae) using 28S D2-3 rDNA sequences and morphological characters. Biol. J. Linn. Soc. Lond., 73, 411-424.

Birky, C.V., Ricci, C., Melone, C. \& Fontaneto, D. (2011) Integrating DNA and morphological taxonomy to describe diversity in poorly studied microscopic animals: new species of the genus Abrochtha Bryce, 1910 (Rotifera: Bdelloidea: Philodinavidae). Zool. J. Linn. Soc., 161, 723-734. Chen, H., Rangasamy, M., Tan, S.Y., Wang, H. \& Siegfried, B.D. (2010) Evaluation of five methods for total DNA extraction from western corn rootworm beetles. PLOS ONE, 5 , el1963.

Chroni, A., Djan, M., Vidaković, D.O., Petanidou, T. \& Vujić, A. (2017) Molecular species delimitation in the genus Eumerus (Diptera: Syrphidae). Bull. Entomol. Res., 107, 126-138.

Cuttelod, A., García, N., Malak, D.A., Temple, H.J. \& Katariya, V. (2009) The Mediterranean: a biodiversity hotspot under threat. In: J.C. Vié, C. Hilton-Taylor \& S.N. Stuart (Eds) Wildlife in a Changing World - An Analysis of the 2008 IUCN Red List of Threatened Species, pp. 89-101. IUCN, Gland, Switzerland.

Çelik, A., Çiçek, M., G. Semizm \& Karıncalı, M. (2004) Taxonomical and ecological investigations on some geophytes growing around Denizli province (Turkey). Turk. J. Botany, 28, 205-211. 
Çiplak, B. (2003) Distribution of Tettigoniinae (Orthoptera, Tettigoniidae) bush-crickets in Turkey: the importance of the Anatolian Taurus Mountains in biodiversity and implications for conservation. Biodivers. Conserv., 12, 47-64.

Drummond, A.J. \& Rambaut, A. (2007) BEAST: Bayesian Evolutionary Analysis by Sampling Trees. BMC Evol. Biol., 7, 214.

Drummond, A.J., Suchard, M.A., Xie, D. \& Rambaut, A. (2012) Bayesian phylogenetics with BEAUti and the BEAST 1.7. Mol. Biol. Evol., 29, 1969-1973.

Dupuis, J.R., Roe, A.D. \& Sperling, F.A.H. (2012) Multi-locus species delimitation in closely related animals and fungi: one marker is not enough. Mol. Ecol., 21, 4422-4436.

Esselstyn, J.A., Evans, B.J., Sedlock, J.L., Khan, F.A.A. \& Heaney, L.R. (2012) Single-locus species delimitation: a test of the mixed Yule-coalescent model with an empirical application to Philippine round-leaf bats. Proc. R. Soc. Lond., B, Biol. Sci., 279, 3678-3686.

Folmer, O., Black, M., Hoeh, W., Lutz, R. \& Vrijenhoek, R. (1994) DNA primers for amplification of mitochondrial cytochrome c oxidase subunit I from diverse metazoan invertebrates. $\mathrm{Mol} . \mathrm{Ma}$ rine Biol. Biotechnol., 3, 294-299.

Francuski, L.J., Ludoški, J., Vujić, A. \& Milankov, V. (2009) Wing geometric morphometric inferences on species delimitation and intraspecific divergent units in the Merodon ruficornis group (Diptera: Syrphidae) from the Balkan Peninsula. Zool. Sci., 26, 301-308.

Francuski, L.J., Ludoški, J., Vujić, A. \& Milankov, V. (2011) Phenotypic evidence for hidden biodiversity in the Merodon aureus group (Diptera: Syrphidae) on the Balkan Peninsula: conservation implication. J. Insect Conserv., 15, 379-388.

Fujisawa, T. \& Barraclough, T.G. (2013) Delimiting species using single-locus data and the generalized mixed yule coalescent approach: a revised method and evaluation on simulated data sets. Syst. Biol., 62, 707-724.

Goloboff, P.A. (1999) NONA (NO NAME), version 2 [computer program]. The Author, Tucumán, Argentina.
Hall, T.A. (1999) BioEdit: a user-friendly biological sequence alignment editor and analysis program for Windows 95/98/ NT. Nucleic Acids Symp. Ser., 41, 95-98.

Hijmans, R.J., Guarino, L. \& Mathur, P. (2012) DIVAGIS, version 7.5. A geographic information system for the analysis of species distribution data.

Huelsenbeck, J.P. \& Rannala, B. (2004) Frequentist properties of bayesian posterior probabilities of phylogenetic trees under simple and complex substitution models. Syst. Biol., 53, 904-913.

Hurkmans, W. (1993) A monograph of Merodon (Diptera: Syrphidae). Pt.1. Tijdschr. Entomol., 136, 147-234.

Kaloveloni, A., Tscheulin, T., Vujić, A., Radenković, S. \& Petanidou, T. (2015) Winners and losers of climate change for the genus Merodon (Diptera: Syrphidae) across the Balkan Peninsula. Ecol. Modell., 313, 201-211.

Kočiš Tubić, N., Ståhls, G., Ačanski, J., Djan, M., Obreht Vidaković, D., Hayat, R., Khaghaninia, S., Vujić, A. \& Radenković, S. (2018) An integrative approach in the assessment of species delimitation and structure of the Merodon nanus species group (Diptera: Syrphidae). Org. Divers. Evol., 18, 479-497.

Kumar, S., Stecher, G. \& Tamura, K. (2015) MEGA7. Molecular Evolutionary Genetics Analysis. Version 7.o for bigger datasets. Mol. Biol. Evol., 33, 1870-1874.

Marcos-García, M.A., Vujić, A. \& Mengual, X. (2007) Revision of Iberian species of the genus Merodon (Diptera: Syrphidae). Eur. J. Entomol., 104, 531-572.

Marcos-García, M.A., Vujić, A., Ricarte, A. \& Ståhls, G. (2011) Towards an integrated taxonomy of the Merodon equestris species complex (Diptera: Syrphidae) including description of a new species, with additional data on Iberian Merodon. Can. Entomol., 143, 332-348.

Masetti, A., Luchetti, A., Sommaggio, D., Burgio, G. \& Mantovani, B. (2006) Phylogeny of Chrysotoxum species (Diptera: Syrphidae) inferred from morphological and molecular characters. Eur. J. Entomol., 103, 459-467. 
Mengual, X., Ståhls, G., Vujić, A. \& Marcos-García, M.A. (2006) Integrative taxonomy of Iberian Merodon species (Diptera: Syrphidae). Zootaxa, 1377, 1-26.

Michonneau, F. (2015) Cryptic and not-so-cryptic species in the complex "Holothuria (Thymiosycia) imaptiens" (Forsskål, 1775) (Echinodermata: Holothuroidea: Holothuriidae). Biorxiv, 014225 .

Michonneau, F. (2016) Using GMYC for Species Delineation. Zenodo.

Milankov, V., Ludoški, J., Francuski, L.J., Ståhls, G. \& Vujić, A. (2013) Genetic and phenotypic diversity patterns in Merodon albifrons Meigen, 1822 (Diptera: Syrphidae): evidence of intraspecific spatial and temporal structuring. Biol. J. Linn. Soc. Lond., 110, 257-280.

Milankov, V., Ludoški, J., Ståhls, G., Stamenković, J. \& Vujić, A. (2009) High molecular and phenotypic diversity in the Merodon avidus complex (Diptera, Syrphidae): cryptic speciation in a diverse insect taxon. Zool. J. Linn. Soc., 155, 819-833.

Milankov, V., Ståhls, G. \& Vujić, A. (2008) Molecular diversity of populations of the Merodon ruficornis group on the Balkan Peninsula.J. Zool. Syst. Evol. Res., 46, 143-152.

Milankov, V., Ståhls, G. \& Vujić, A. (2008) Genetic characterization of the Balkan endemic species, Merodon desuturinus (Diptera: Syrphidae). Eur.J. Entomol., 105, 197-204.

Milankov, V., Ståhls, G. \& Vujić, A. (2008) Genetic diversity of populations of Merodon aureus and M. cinereus species complexes (Diptera, Syrphidae): integrative taxonomy and implications for conservation priorities on the Balkan Peninsula. Conserv. Genet., 9, 1125-1137.

Miller, M.A., Pfeiffer, W. \& Schwartz, T. (2010) Creating the CIPRES Science Gateway for inference of large phylogenetic trees. Proceedings of the Gateway Computing Environments Workshop (GCE), New Orleans, $1-8$.

Monaghan, M.T., Wild, R., Elliot, M., Fujisawa, T., Balke, M., Inward, D.J.G., Lees, D.C., Ranaivosolo, R., Eggleton, P., Barraclough, T.G. \& Vogler,
A.P. (2009) Accelerated species inventory on madagascar using coalescent-based models of species delineation. Syst. Biol., 58, 298-311.

Myers, N., Mittermeier, R.A., Mittermeier, C.G., da Fonseca, G.A.B. \& Kent, J. (200o) Biodiversity hotspots for conservation priorities. Nature, 103, $853-858$.

Nedeljković, Z., Ačanski, J., Đan, M., ObrehtVidaković, D., Ricarte, A. \& Vujić, A. (2015) An integrated approach to delimiting species borders in the genus Chrysotoxum Meigen, 1803 (Diptera: Syrphidae), with description of two new species. Contrib. Zool., 84, 285-304.

Nixon, K.C. (2002) WinClada ver. 1.00.08. Published by author, Ithaca, NY.

Parks, D.H., Mankowski, T., Zangooei, S., Porter, M.S., Armanini, D.G., Baird, D.J., Langille, M.G.I. \& Beiko, R.G. (2013) GenGIS 2: Geospatial analysis of traditional and genetic biodiversity, with new gradient algorithms and an extensible plugin framework. PLOS ONE, 8, e69885.

Paz, A. \& Crawford, A.J. (2012) Molecular-based rapid inventories of sympatric diversity: A comparison of DNA barcode clustering methods applied to geography-based vs clade-based sampling of amphibians. J. Biosci., 37, 887-896.

Pons, J., Barraclough, T.G., Gomez-Zurita, J., Cardoso, A., Duran, D.P., Hazell, S., Kamoun, S., Sumlin, W.D. \& Vogler, A.P. (2006) Sequence-based species delimitation for the DNA taxonomy of undescribed insects. Syst. Biol., 55, 595-6og.

Popov, G.V. (2010) Merodon alexandri spec. nov. a new species of hoverfly (Diptera: Syrphidae) from the northern Black Sea Region. Stud. Dipterol., 16, 133-151.

Popović, D., Ačanski, J., Đan, M., Obreht, D., Vujić, A. \& Radenković, S. (2015) Sibling species delimitation and nomenclature of the Merodon avidus complex (Diptera: Syrphidae). Eur.J. Entomol., 112, 790-809.

Preradović, J., Andrić, A., Radenković, S., Šašić Zorić, L.J., Pérez-Bañón, C., Campoy, A. \& Vujić, A. (2018) Pupal stages of three species of the phytophagous genus Merodon Meigen (Diptera: Syrphidae). Zootaxa, 4420, 229-242. Downloaded from Brill.com04/26/2023 01:30:09PM 
Radenković, S., Šašić Zorić, L.J., Đan, M., Obreht Vidaković, D., Ačanski, J., Ståhls, G., Veličković, N., Markov, Z., Petanidou, T., Kočiš Tubić, N. \& Vujić, A. (2018a) Cryptic speciation in the Merodon luteomaculatus complex (Diptera: Syrphidae) from the eastern Mediterranean. J. Zool. Syst. Evol. Res., 56, 170-191.

Radenković, S., Veličković, N., Ssymank, A., Obreht Vidaković, D., Djan, M., Ståhls, G., Veselić, S. \& Vujić, A. (2018b) Close relatives of Mediterranean endemo-relict hoverflies (Diptera, Syrphidae) in South Africa: Morphological and molecular evidence in the Merodon melanocerus subgroup. PLOS ONE, 13, e0200805.

Radenković, S., Vujić, A. \& Šimić, S. (2002) On the identity and synonymy of two species from Merodon ruficornis Meigen group (Diptera: Syrphidae). Acta Entomol. Serbica, 7, 51-57.

Radenković, S., Vujić, A., Ståhls, G., Pérez-Bañón, C., Rojo, S., Petanidou, T. \& Šimić, S. (2011) Three new cryptic species of the genus Merodon Meigen (Diptera: Syrphidae) from the island of Lesvos (Greece). Zootaxa, 2735, 35-56.

Rambaut, A. (2014) FigTree-The Figure Drawing Tool, version 1.4.2. http://tree.bio.ed.ac.uk/figtree/ [accessed 15 November 2018].

Rambaut, A., Suchard, M.A., Xie, D. \& Drummond, A.J. (2014) Tracer, version 1.6. http:// beast.bio.ed.ac.uk/Tracer [accessed 15 November 2018].

Raxworthy, C., Ingram, C., Rabibisoa, N. \& Pearson, R. (2007) Applications of ecological niche modeling for species delimitation: a review and empirical evaluation using day geckos (Phelsuma) from Madagascar. Syst. Biol., 56, 907-923.

Ricarte, A., Marcos-García, M.A. \& Rotheray, G.E. (2008) The early stages and life histories of three Eumerus and two Merodon species (Diptera: Syrphidae) from the Mediterranean region. Entomol. Fenn., 19, 129-141.

Ricarte, A., Nedeljković, Z., Rotheray, G.E., Lyszkowski, R.M., Hancock, E.G., Watt, K., Hewitt, S.M., Horsfield, D. \& Wilkinson, G. (2012) Syrphidae (Diptera) from the Greek island of Lesvos, with description of two new species. Zootaxa, 3175, 1-23.

Ronquist, F., Teslenko, M., van der Mark, P., Ayres, D.L., Darling, A., Höhna, S., Larget, B., et al. (2012) MrBayes 3.2: efficient Bayesian phylogenetic inference and model choice across a large model space. Syst. Biol., 61, 539-542.

Sauer, J. \& Hausdorf, B. (2012) A comparison of DNA-based methods for delimiting species in a Cretan land snail radiation reveals shortcomings of exclusively molecular taxonomy. Cladistics, $28,300-316$.

Schluter, D. (2009) Evidence for ecological speciation and its alternative. Science, 323, 737-741.

Simon, C., Frati, F., Beckenbach, A., Crespi, B., Liu, H. \& Flook, P. (1994) Evolution, weighting, and phylogenetic utility of mitochondrial gene sequences and a compilation of conserved polymerase chain reaction primers. Ann. Entomol. Soc. Am., $87,651^{-701 .}$

Speight, M.C.D. (2018) Species Accounts of European Syrphidae, 2018. Syrph the Net, the Database of European Syrphidae (Diptera). Dublin. 103: Syrph the Net publications, pp. 302.

Ståhls, G., Vujić, A., Petanidou, T., Cardoso, P., Radenković, S., Ačanski, J., Pérez-Bañón, C., Rojo, S. (2016) Phylogeographic patterns of Merodon hoverflies in the Eastern Mediterranean region: revealing connections and barriers. Ecol. Evol., 6, 2226-2245.

Ståhls, G., Vujić, A., Pérez-Bañón, C., Radenković, S., Rojo, S. \& Petanidou, T. (2009) COI barcodes for identification of Merodon hoverflies (Diptera, Syrphidae) of Lesvos Island, Greece. Mol. Ecol. Resour., 9, 1431-1438.

Šašić, Lj., Ačanski, J., A. Vujićm, G. Ståhlsm, S. Radenkovićm, Milić, D., Obreht-Vidaković, D. \& Đan, M. (2016) Molecular and morphological inference of three cryptic species within the Merodon aureus species group (Diptera: Syrphidae). PLOS ONE, 11, eo160oo1.

Šimić, S. (1987) Syrphidae (Insecta, Diptera). Biogeografska i ekološka analiza faune osolikih muva Durmitora sa osvrtom na faunu osolikih 
muva Crne Gore. In: Fauna Durmitora, sveska 2. Crnogorska akademija nauka i umjetnosti, pp. 11-154. Posebno izdanja, knjiga 21, Odeljenje prirodnih nauka, knjiga 13. Titograd.

Talavera, G., Dinca, V. \& Vila, R. (2013) Factors affecting species delimitations with the GMYC model: insights from a butterfly survey. Methods Ecol. Evol., 4, 1101-1110.

Thompson, F.C. (1999) Key to the genera of the flower flies (Diptera: Syrphidae) of the Neotropical Region including descriptions of new genera and species and a glossary of taxonomic terms. Contrib. Entomol., 3, 321-378.

Thompson, J.D., Higgins, D.G. \& Gibson, T.J. (1994) Clustal W: improving the sensitivity of progressive multiple sequence alignment through sequence weighting, position-specific gap penalties and weight matrix choice. Nucleic Acids Res., 22, 4673-4680.

Veselić, S., Vujić, A. \& Radenković, S. (2017) Three new Eastern-Mediterranean endemic species of the Merodon aureus group (Diptera: Syrphidae). Zootaxa, 4254, 401-434.

Vujić, A., Marcos-García, M.A., Sarıbıyık, S. \& Ricarte, A. (2011) New data on the Merodon Meigen, 1803 fauna (Diptera: Syrphidae) of Turkey, including description of a new species and changes in the nomenclatural status of several taxa. Annales de la Societe Entomologique de France, 47, 78-88.

Vujić, A., Petanidou, T., Tscheulin, T., Cardoso, P., Radenković, S., Ståhls, G., Baturan, Ž., Mijatović, G., Rojo, S., Pérez-Bañón, C., Devalez, J., Andrić, A., Jovičić, S., Krašić, D., Markov, Z., Radišić, D. \& Tataris, G. (2016) Biogeographical patterns of the genus Merodon Meigen, 1803 (Diptera: Syrphidae) in islands of the Eastern Mediterranean and adjacent mainlands. Insect Conserv. Divers., 9, 181-191.

Vujić, A., Pérez-Bañón, C., Radenković, S., Ståhls, G., Rojo, S., Petanidou, T. \& Šimić, S. (2007) Two new species of genus Merodon Meigen, 1803 (Syrphidae, Diptera) from the island of Lesvos (Greece), in the eastern Mediterranean.
Annales de la Societe Entomologique de France, 43, 319-326.

Vujić, A., Radenković, S., Ačanski, J., Grković, A., Taylor, M., Şenol, S.G. \& Hayat, R. (2015) Revision of the species of the Merodon nanus group (Diptera: Syrphidae) including three new species. Zootaxa, 4006, 439-462.

Vujić, A., Radenković, S. \& Likov, L. (2018) Revision of the Palaearctic species of the Merodon desuturinus group (Diptera, Syrphidae). ZooKeys, 771, 105-138.

Vujić, A., Radenković, S., Likov, L., Andrić, A., Gilasian, E. \& Barkalov, A. (2019) Two new enigmatic species of the genus Merodon Meigen (Diptera: Syrphidae) from the north-eastern Middle East. Zootaxa, 4555, 187-208.

Vujić, A., Radenković, S., Likov, L., Trifunov, S. \& Nikolić, T. (2013) Three new species of the Merodon nigritarsis group (Diptera: Syrphidae) from the Middle East. Zootaxa, 3640, 442-464.

Vujić, A., Radenković, S., Ståhls, G., Ačanski, J., Stefanović, A., Veselić, S., Andrić, A. \& Hayat, R. (2012) Systematics and taxonomy of the ruficornis group of genus Merodon (Diptera: Syrphidae). Syst. Entomol., 37, 578-602.

Wiemers, M. \& Fiedler, K. (2007) Does the DNA barcoding gap exist? A case study in blue butterflies (Lepidoptera: Lycaenidae). Front. Zool., $4,8$.

Xia, X. (2013) DAMBE5: A comprehensive software package for data analysis in molecular biology and evolution. Mol. Biol. Evol., 30, 1720-1728.

Wiens, J.J. \& Graham, C.H. (2005) Niche conservatism: integrating evolution, ecology, and conservation biology. Annu. Rev. Eco.l Evol. Syst., 36, 519-39.

Zhang, J., Kapli, P., Pavlidis, P. \& Stamatakis, A. (2013) A general species delimitation method with applications to phylogenetic placements. Bioinformatics, 29, 2869-2876.

RECEIVED: 17 MAY 2019 | REVISED AND ACCEPTED: 26 AUGUST 2019

EDITOR: A. IVANOVIĆ 


\section{APPENDIX}

\section{Taxonomy}

\section{Merodon nigritarsis group}

Diagnosis. Relatively large (11-17 mm) species with white microtrichose vittae on black scutum and white microtrichose fasciae on orange-brown (in females orange-black) terga (as on figs. 21, 26, 10, 11); at least tergum 2 with a pair of reddish-orange maculae. Scutum covered with erect, yellow pile. Pile on metasternum erect, as long as those on metacoxa. Abdomen elongate, narrow and tapering, always longer than scutum and scutellum together (as on figs. $3 \mathrm{~A}, \mathrm{C}-\mathrm{D}, 4 \mathrm{~A},{ }_{7} \mathrm{C}$ ). Posterior part of mesocoxa without long pile. Tarsi dark brown/ black dorsally and orange ventrally. Basoflagellomere about 1.5-2 times as long as wide (fig. 18). Legs without spinae or other protuberances (fig. 20AD). Male genitalia: anterior surstyle lobe (as on figs. 13, 35: al) more or less of rhomboid shape, covered with dense short pile, except in the alagoezicus subgroup where the anterior surstyle lobe is transformed into a narrow, elongate, strongly curved projection (as on fig. 12: al); posterior surstyle lobe with oval apical part (as on figs. 12-13, 35: pl) usually longer than the anterior surstyle lobe; cercus rectangular, without prominences (as on figs. $23 \mathrm{~A}$, 27A: c). Hypandrium narrow, elongate and sickleshaped (as on figs. $24 \mathrm{~A}, \mathrm{C}, 30 \mathrm{~A}, \mathrm{C}$ ), with a pair of subapical thorns on ventral margin directed backwards (as on fig. 24: th), and often with a pair of lateral projections near the base (as on fig. 30A, C: lp) and well-developed lingula (as on fig. 24A-D: l); apical part of lateral sclerite of aedeagus tapering (fig. 9A:s).

Merodon longisetus Vujić, Radenković et Likov sp. n.

Merodon aff. nigritarsis in Vujić et al., 2016 Type material. Holotype. Male. Greece: Chios, Armolia valley, 38.2833N, 26.0333E, 23.ix.2009, leg. Vujić (FSUNS). Paratypes. Greece, one male, Chios, Armolia valley, $38.2833 \mathrm{~N}, 26.05 \mathrm{E}, 2$ 20.v.2003, leg.
Taylor (NML) (det. C.J. Palmer as Merodon toscanus); one male, Chios, Armolia valley, 38.2833N, 26.0333E, 16.v.2003, leg. Taylor (NML) (det. C.J. Palmer as Merodon toscanus); one male, Chios, Armolia valley, $38.2863 \mathrm{~N}, 26.0494 \mathrm{E}$, 16.v.2003, leg. M.J. Taylor (NML). Turkey, three male, Isparta, eastern campus of Süleyman Demirel University, 37.8405N, 30.538oE, 13.ix.2014, leg. Vujić (FSUNS); two male, two female, Isparta, Keçiborlu, Gülköy, 1502 m a.s.l., 37.9066N, 30.1758E, 22.vi.2015, leg. Vujić, Hayat, Uzal, Gök (EMIT); two male, Isparta, Keçiborlu, between Kavak and Kaplanll, 1500m a.s.l., 37.9269N, 30.1908E, 22.vi.2015, leg. Vujić, Hayat, Uzal, Gök (EMIT); two male, Isparta, between Keçiborlu and Yeniköy, 1740 m, 37.8764N, 30.2075E, 8.vii.2015, leg. Vujić, Hayat, Demirözer, Uzal, Gök (EMIT); three male, one female, Isparta, Gönen, Güneykent road, $1033 \mathrm{~m}, 37.95927 \mathrm{~N}$, 30.483611E, 01.ix.2015, leg. Hayat, Demirözer, Gök, Uzal (EMIT); two male, Isparta, Senirkent, Kabaca-Yalvaç road, $950 \mathrm{~m}, 38.19825 \mathrm{~N}, 30.722444 \mathrm{E}$, 01.ix.2015, leg. Hayat, Demirözer, Gök, Uzal (EMIT); three male, Bozdağ mountain, Sart to Bozdağ 1, 994 $\mathrm{m}$ a.s.l., 38.4030N, 28.0805E, 16.ix.2013, leg. Vujić (FSUNS).

Diagnosis. Large species $\left(13^{-15} \mathrm{~mm}\right)$, with bronze lustre; black scutum with four whitish microtrichose vittae, and covered with erect, yellowish pile, except some black ones at the wing basis; tapering black abdomen with pairs of microtrichose fasciae on terga 3 and 4 ; at least tergum 2 with a pair of lateral orange maculae (fig. 21); metafemur moderately swollen and curved, with long yellow pile postero- and anteroventrally, pile about as half of width of metafemur (fig. 20A); tarsi dark brown dorsally and orange ventrally; male genitalia: anterior surstyle lobe rhomboid shape, and 2.5 times shorter than posterior surstyle lobe (fig. 23A: al). Merodon longisetus sp. $\mathrm{n}$. belongs to the $M$. nigritarsis group and closely related to $M$. toscanus. They can be separate based on the structure of male genitalia: anterior surstyle lobe in $M$. toscanus is about long as wide (fig. ${ }_{23} \mathrm{C}$ : al), while in $M$. longisetus sp. $\mathrm{n}$. is about two times wider than long 

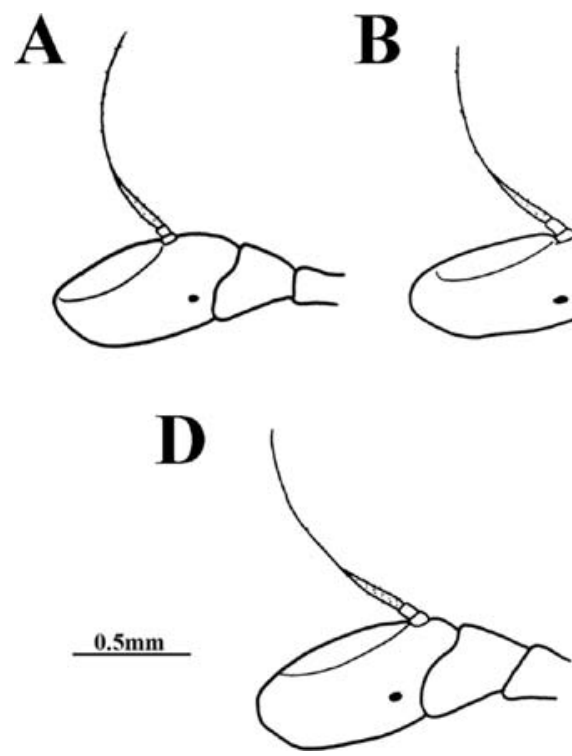
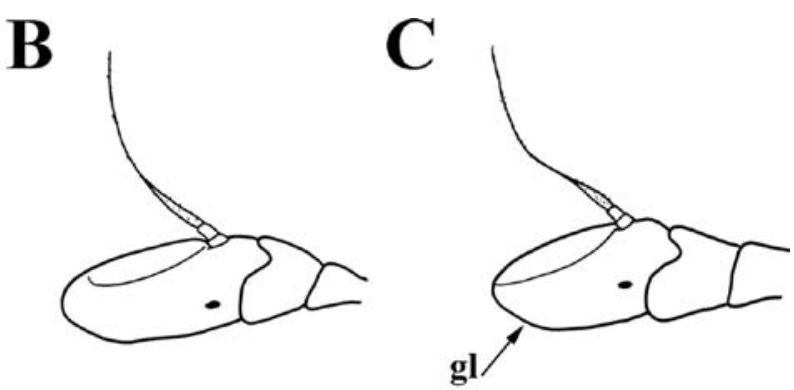

$\mathbf{E}$

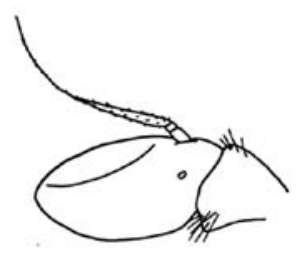

FIG URE 18 Antenna. Lateral view, A) Merodon longisetus sp. n., male, B) Merodon longisetus sp. n., female, C) Merodon obstipus sp. n., male, D) Merodon obstipus sp. n., female, E) Merodon cohurnus sp. n., male. Scale: $0.5 \mathrm{~mm}$. gl-basoflagellomere.
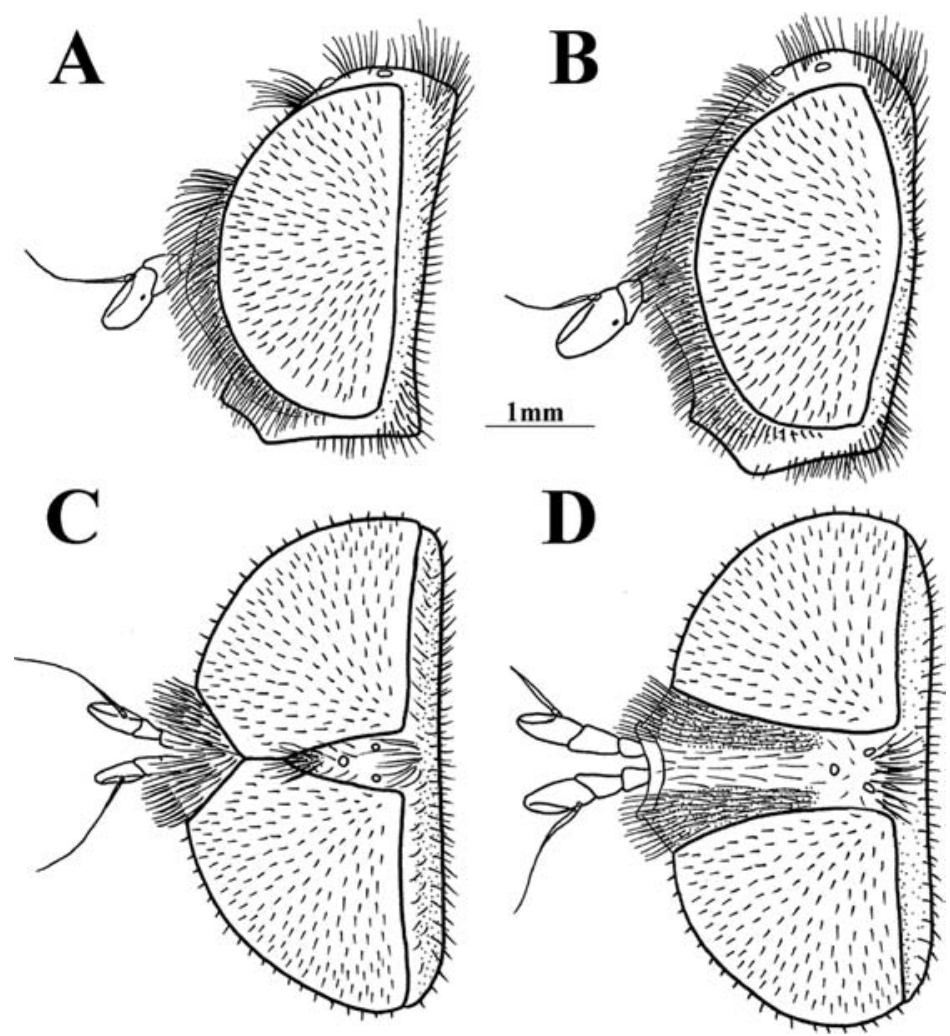

FIGURE 19 Head of Merodon longisetus sp. n. A) male, lateral view, B) female, lateral view, C) male, dorsal view; D) female, dorsal view. Scale: $1 \mathrm{~mm}$. 


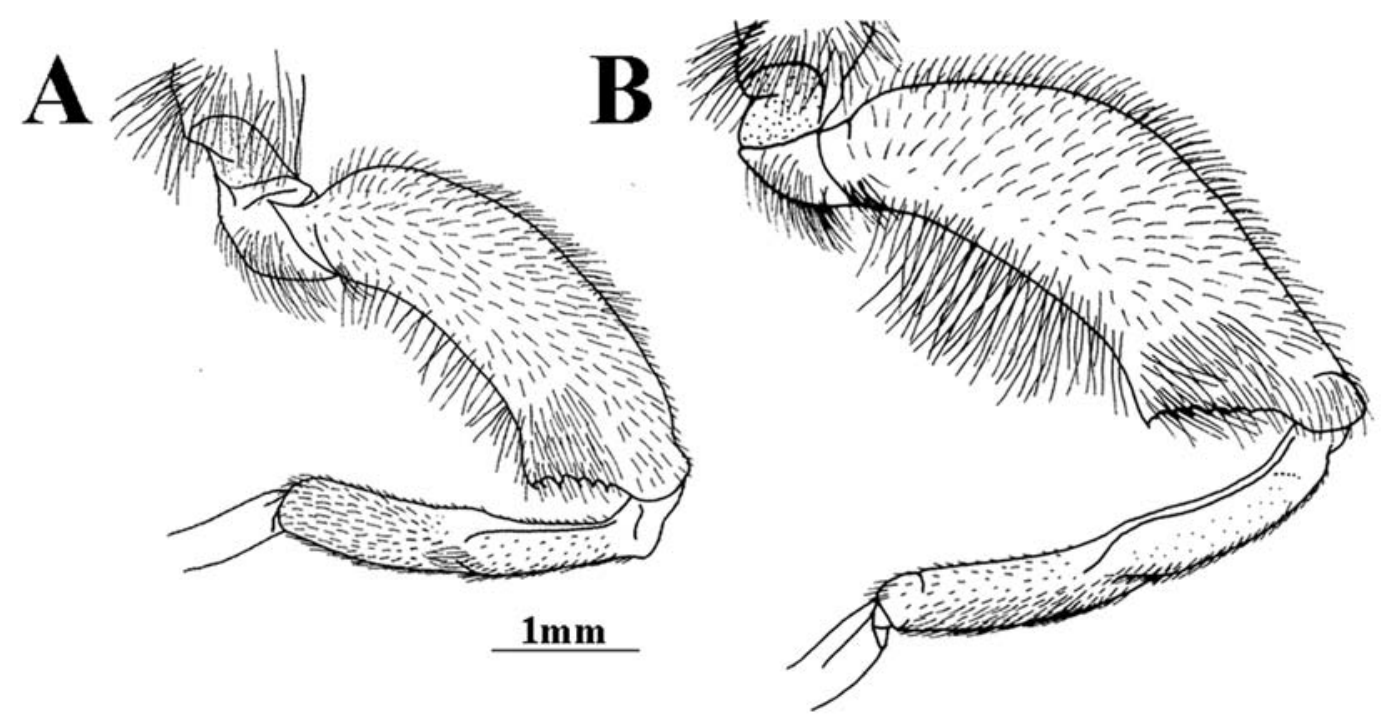

C
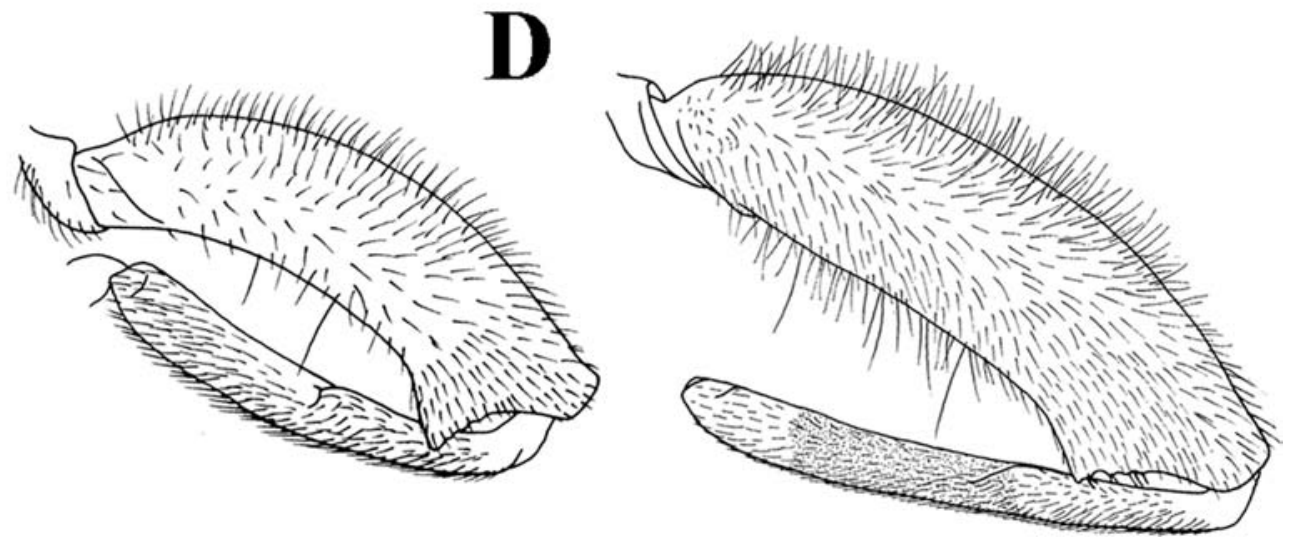

FIGURE 20 Metaleg of male (without metatarsi). Lateral view, A) Merodon longisetus sp. n., B) Merodon obstipus sp. n., C) Merodon cohurnus sp. n., D) Merodon rutitarsis sp. n. Scale: 1 mm.

(fig. 23A: al); posterior and anterior surstyle lobe separated by deeper incision in $M$. longisetus sp. $n$. (fig. 23A: i); hypandrium with longer lingula in $M$. longisetus sp. n., pointed upward (fig. 24A-B:l).

Distribution. Merodon longisetus sp. $\mathrm{n}$. belongs to Eastern Mediterranean endemic species, with type locality on Aegean island Chios, and distributed in south-eastern part of Anatolian Peninsula, recorded on Bozdağ Mountain, on Isparta plateau and on high mountains around (fig. 1).

Description. Male. Head (figs 18A, 19A, C). Antennae reddish/dark brown; basoflagellomere about 1.5 times as long as wide, and about 1.8 times as long as the pedicel, with acute apex; arista dark brown and thickened, covered with dense microtrichia; arista about 1.5 times as long as basoflagellomere (fig. 18A); face and frons black, covered with dense whitish pile, and silver microtrichia except for shiny ventral part of face shiny; vertical triangle isosceles, shining black, except in front of anterior ocellus with whitish microtrichia, pilosity long, pale yellow-whitish (in some cases mixed with few black pile on the ocellar triangle); ocellar triangle equilateral; eyes covered with dense pile; 


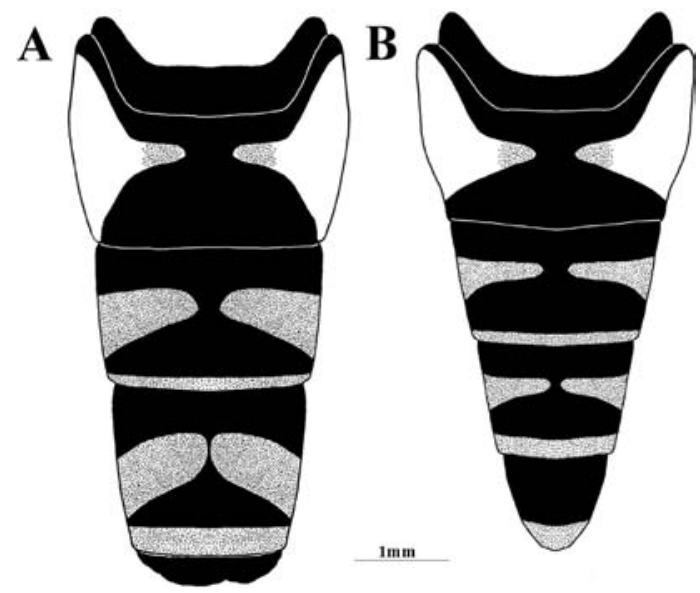

FIGURE 21 Abdomen of Merodon longisetus sp. n. Dorsal View, A) male, B) female. Scale: $1 \mathrm{Mm}$.

eye contiguity about 12 facets long; occiput with whitish-yellow pile, covered with a dense, white microtrichia; vertical triangle: eye contiguity: ocellar triangle $=2: 1: 0.8$ (fig. $19 \mathrm{C}$ ).

Thorax (fig. 20A). Scutum and scutellum black with bronze lustre, covered with dense, erect, yellow pile; sides of scutum at wing basis with patch of black pile; scutum with four microtrichose vittae, anteriorly connected and posteriorly reaching the scutellum and postalar callus; posterodorsal part of anterior anepisternum, posterior anepisternum (except anteroventral angle), anterior anepimeron, dorsomedial anepimeron, and posterodorsal and anteroventral parts of katepisternum with long, dense pale yellow pile and greyish microtrichia; wings covered with microtrichia (except basal parts of cells R, BM and CuP sparsely microtrichose); wing veins brown; calypteres pale yellow; halteres yellow, in some cases with dark brown knob; legs without spinae or other protuberances; legs mostly black, except pale yellow apex of pro- and mesofemora (but sometimes apex of metafemora also), basal half of pro- and mesotibiae, basal $1 / 3$ of metatibiae, and all tarsi ventrally; pile on legs pale yellow; metafemur moderately broad and curved, about as 3 times longer than wide; long pile on postero- and anteroventral surface yellow and sparse, and about as half of width of metafemur, but much longer than the pile on the dorsal surface (fig. 20A).

Abdomen (figs. 21A, 22A). Tapering, about 1.2 times longer than mesonotum; terga dark, except for a pair of yellow-orange, triangular, lateral maculae on tergum 2; terga 3 and 4 each with pairs of white microtrichose, wide, oblique fasciae (on tergum 2 a pair of smaller microtrichose spot, weaker or stronger developed); additionally terga 3 and 4 with microtrichose fasciae at posterior margins of terga (fig. $21 \mathrm{~A}$ ); pile on terga yellow; sterna light brown, translucent, covered with long whitish/ yellow pile; sternum 4 with large posteromedial notch, reaching to the $2 / 3$ of the length of sternum (fig. 22A: cf) and rectangular posterolateral corner (fig. 22A: p).

Male genitalia (figs $23 \mathrm{~A}-\mathrm{B}, 24 \mathrm{~A}-\mathrm{B}$ ). Anterior surstyle lobe rhomboid shape, about 2 times wider than long, covered with dense, short pile (fig. 23A: al); posterior surstyle lobe oval (fig. 23A: pl); cercus rectangular (fig. 23A: c); hypandrium sickleshaped, without lateral projections; lingula narrow and long (fig. $24 \mathrm{~A}-\mathrm{B}: \mathrm{l}$ ).

Female (figs. 18B, 19B, D, 21B). Similar to the male except for normal sexual dimorphism and for the following characteristics: basoflagellomere with rounded tip, about 2 times longer than wide (fig. 18B); frons with wide, microtrichose vittae along eye margins (fig. $19 \mathrm{D}$ ); ocellar triangle covered with dense black pile; tergum 2 with yellow pile, terga 3 and 4 with mixed whitish/yellow and black pile; microtrichose fasciae on terga 3 and 4 narrower (fig. 21B); sterna 2 and 3 light brown, sternum 4 dark brown; sternum 4 with central longitudinal dent/suture.

Etymology. The name longisetus is derived from Latin words longus (adjective) and setus (meaning hair/pile), referring to long pile on the ventral surface of the metafemur.

Remarks. Two specimens previously determined by C.J. Palmer as Merodon toscanus from Chios island are included in paratypes. This species was reported under name $M$. aff. nigritarsis in biogeographic analysis of the genus in Eastern Mediterranean (Vujić et al., 2016).

Downloaded from Brill.com04/26/2023 01:30:09PM 

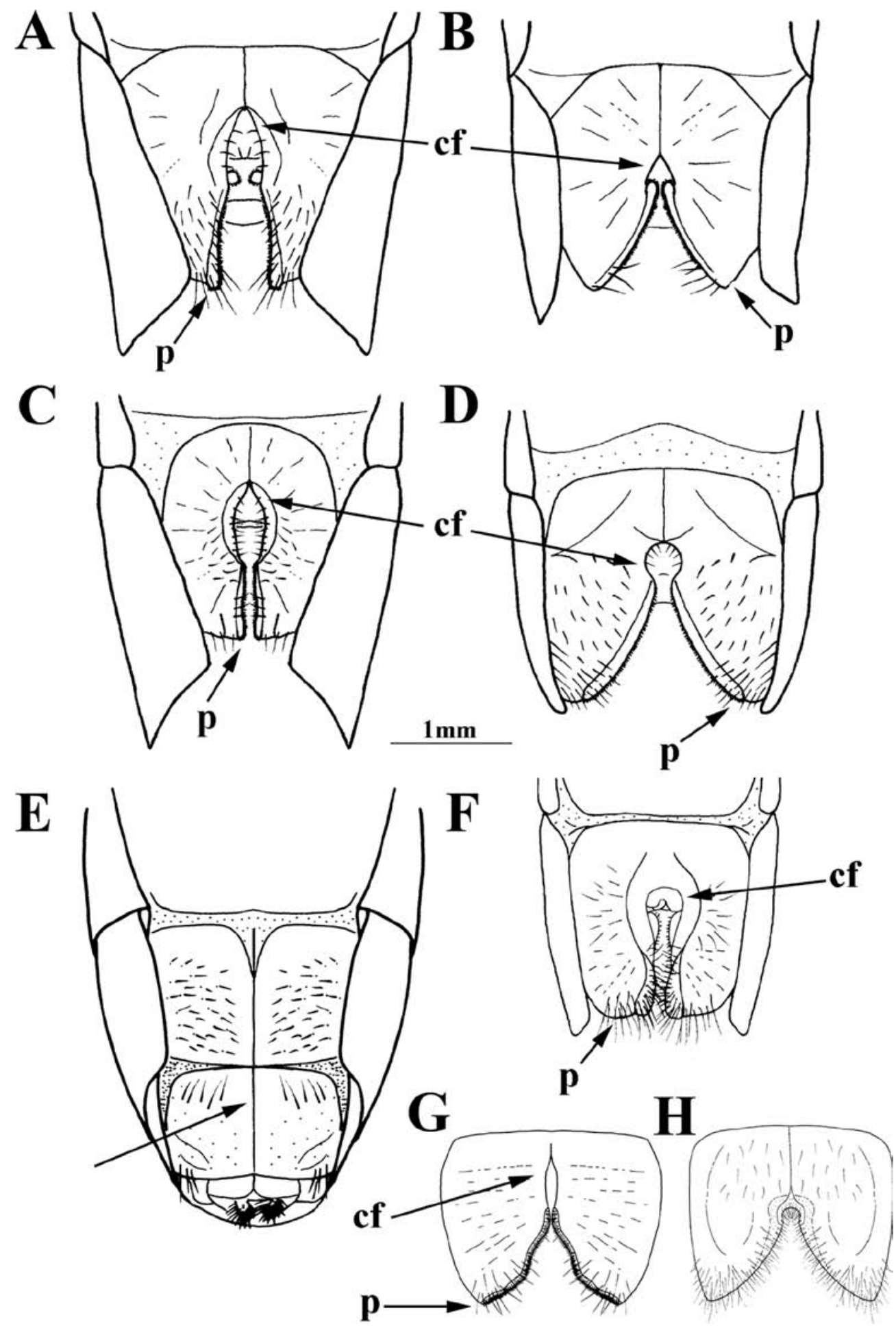

FIGURE 22 Sternum 4. Ventral view, A) Merodon longisetus sp. n., male, B) Merodon nigritarsis, male, C) Merodon obstipus sp. n., male, D) Merodon femoratoides, male, E) Merodon obstipus sp. n., female (central longitudinal suture marked with arrow), F) Merodon cohurnus sp. n., male, G) Merodon rutitarsis sp. n., male, H) Merodon avidus, male. Scale: 1 mm. cf-central notch D p-pgsterolateral corner 

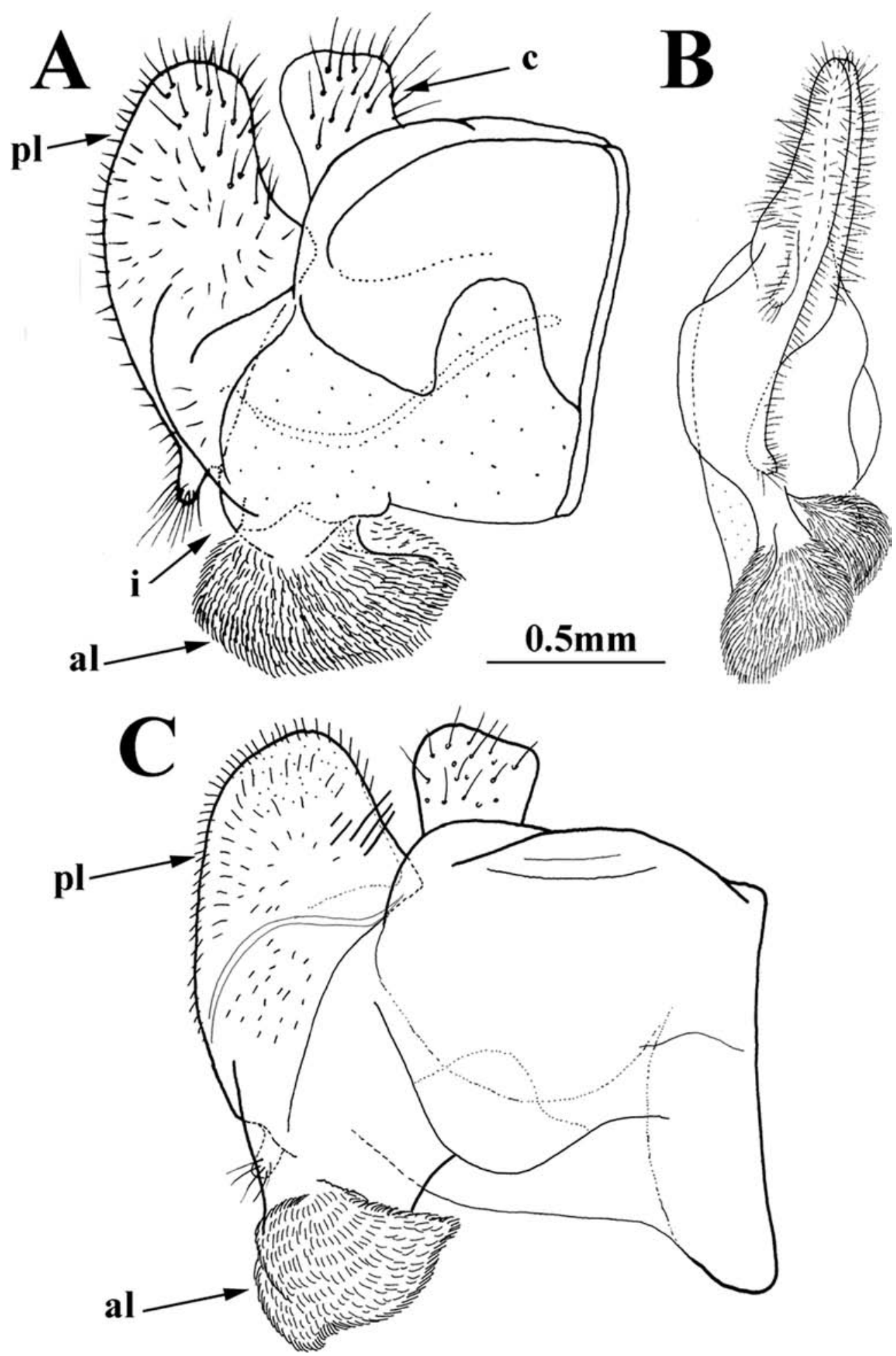

FIGURE 23 Male genitalia. Epandrium. A) Merodon longisetus sp. n, lateral view, B) Merodon longisetus sp. n., ventral view of surstyle lobe, C) Merodon toscanus, lateral view. Scale: $0.5 \mathrm{~mm}$. al-anterior surstyle lobe, c-circus, i-incision, pl-posterior surstyle lobe. 

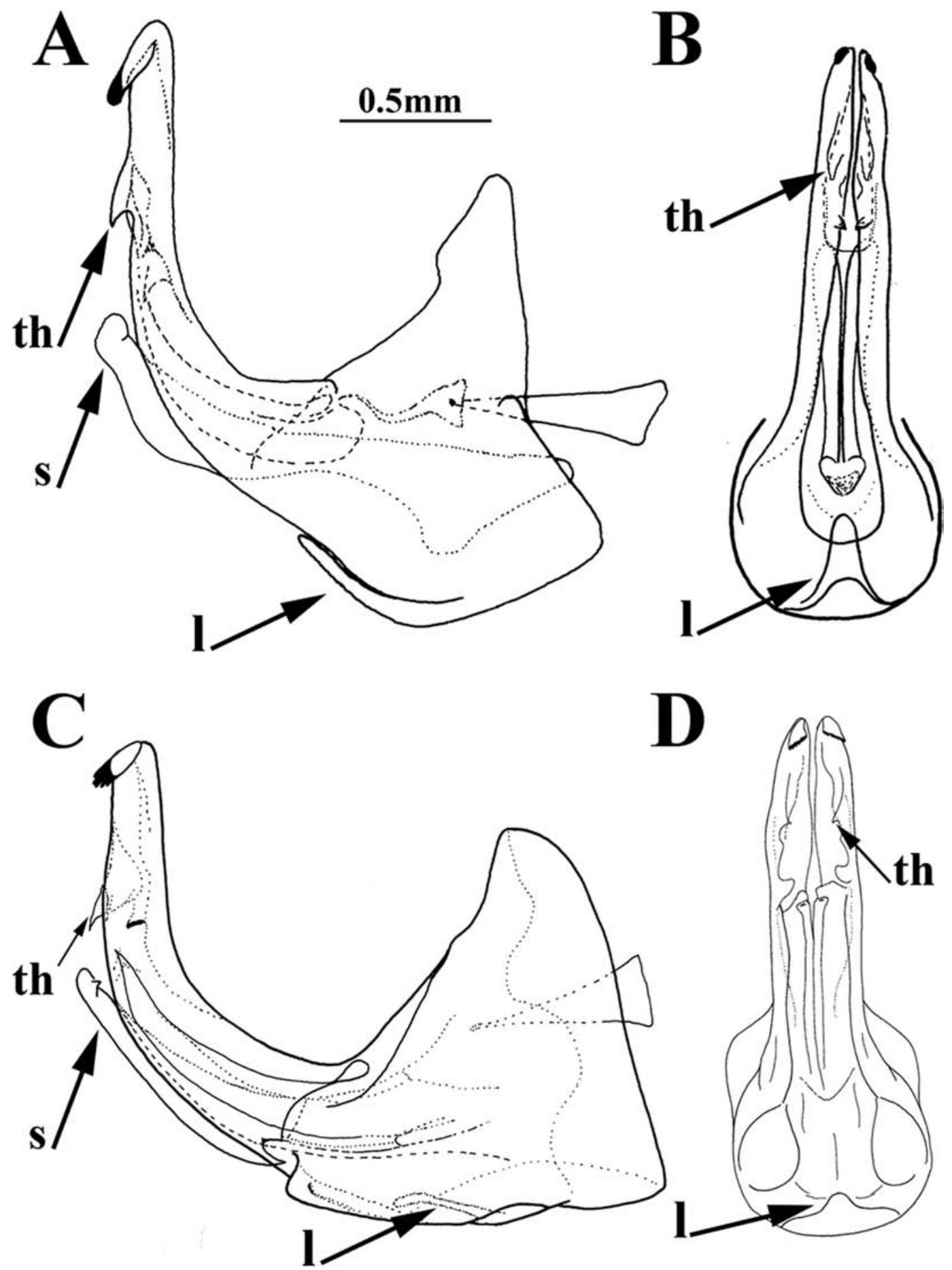

FIGURE 24 Male genitalia. Hypandrium. A) Merodon longisetus sp. n., lateral view, B) Merodon longisetus sp. n., ventral view, C) Merodon toscanus, lateral view, D) Merodon toscanus, ventral view. Scale: $0.5 \mathrm{~mm}$. l-lingual, s-lateral sclerite of aedeagus, th-subapical thorn on ventral margin. 
Merodon obstipus Vujić, Radenković et Likov sp. n. Type material. Holotype. Male. Turkey: Burdur, Rahat mountain, near Osman kalfalar, $2100 \mathrm{~m}$ a.s.l., 37.1303N, 29.8372E, 3.vii.2015, leg. Vujić (FSUNS). Paratypes. Turkey, one male, Balıkesir, Gönen, $230 \mathrm{~m}$ a.s.l., 40.1336N, 27.5891E, 08.vi.2006, leg. Demirözer (EMIT); one male, Isparta, Sütçüler, 1250 m, 37.664747N, 30.983819E, 10.vi.2014, leg. Hayat, Demirözer, Gök, Uzal (EMIT); one male, Isparta, eastern campus of Süleyman Demirel University, $1017 \mathrm{~m}$ a.s.l., 37.8431N, 30.5419E, 14.v.2015, leg. Uzal, Gök (EMIT); 7 male, three female, Isparta, eastern campus of Süleyman Demirel University, $1017 \mathrm{~m}$ a.s.l., 37.843oN, 30.5419E, 22.v.2015, leg. Uzal, Gök (EMIT); one female, Isparta, eastern campus of Süleyman Demirel University, $1017 \mathrm{~m}$ a.s.l., $37.8377 \mathrm{~N}$, 30.538oE, 02.vi.2016, leg. Uzal (EMIT); one male, Isparta, eastern campus of Süleyman Demirel University, $1017 \mathrm{~m}$ a.s.l., $37.8377 \mathrm{~N}, 30.5380 \mathrm{E}$, 03.vi.2016, leg. Hayat (EMIT); one male, Isparta, Davraz mountain, $1700 \mathrm{~m}$ a.s.l., $37.7825 \mathrm{~N}, 30.7591 \mathrm{E}, 20 . v i .2016$, leg. Hayat, Vujić, Demirözer, Uzal, Ačanski (EMIT); one male, Osmaniye, $670 \mathrm{~m}$ a.s.l., $37.25 \mathrm{~N}, 36.25 \mathrm{E}$, 19.vi.196o, leg. Guichard, Harvey (BMNH) (det. Hurmanks as Merodon femoratoides).

Diagnosis. Large sized species (14-15 $\mathrm{mm}$ ) with bronze lustre; black scutum with four microtrichose vittae; abdomen black and elongated, terga 3 and 4 with a pairs of whitish microtrichose fasciae; at least tergum 2 with a pair of reddish/orange lateral maculae (fig. 26A); at least metatarsi dark brown dorsally; metafemur moderately swollen and curved, with very long pile antero- and posteroventrally, pile slightly longer than half of width of metafemur (fig. $20 \mathrm{~B}$ ); male genitalia: anterior surstyle lobe long and curved downwards, tapering, with pointed apex (fig. 27A: al). Merodon obstipus sp. $\mathrm{n}$. belongs to the M. nigritarsis group, resembling to alagoezicus species subgroup by male genitalia (fig. $12 \mathrm{~B}-\mathrm{F}$ ) (anterior surstyle lobe narrow and elongated) but without ventrolateral lamella in apical part of metatibia, apomorphic character in alagoezicus subgroup (as on fig. 36B: la); male genitalia of $M$. obstipus sp. n. easily can be separated from alagoezicus subgroup based on direction of elongated anterior surstyle lobe: in M. obstipus sp. n. curved downwards with pointed apex directed towards base of epandrium (fig. 27A: al), while in alagoezicus subgroup curved upwards (as on fig. 12: al). Other morphological characters of M. obstipus sp. n. are very similar to M.femoratoides, but they can be distinguished by shapes of male genitalia (figs. $35 \mathrm{C}, 27 \mathrm{~A}$ ) and sternum 4 (in M. obstipus sp. n. with larger circular central notch (fig. $22 \mathrm{C}$ : cf) than in M. femoratoides (Fig. 22D: cf), and the posterolateral corners are rectangular in M. obstipus sp. n. (fig. $22 \mathrm{C}: \mathrm{p}$ ), while they are rounded in M. femoratoides (fig. 22C-D: cf, p)).

Distribution. Merodon obstipus sp. n. is distributed in coastal areas of the Anatolian Peninsula, mainly recorded at altitudes up to $1000 \mathrm{~m}$, at Balıkesir, Burdur, Isparta and Osmaniye provinces (fig. 1). This taxon is an additional Anatolian endemic.

Description. Male. Head (figs. 18C, 25A, C). Antennae dark brown/reddish, with acute apex; basoflagellomere 1.2 times longer than wide, and 1.8 times longer than pedicel; arista 1.5 times longer than basoflagellomere, covered with dense microtrichia, light brown at base, but dark and thickened at tip (fig. 18C); face and frons black, densely covered with microtrichia and with pale yellow-whitish, long pile; ventral part of face shiny; vertical triangle isosceles, shining black except in front of anterior ocellus covered with whitish microtrichia, pilosity long whitish (except for some black pile on the ocellar triangle); ocellar triangle equilateral; eye pile long and dense; eye contiguity about 11 facets long; occiput with whitish-yellow pile, along the eye margins with dense white microtrichia; vertical triangle: eye contiguity: ocellar triangle = $2: 1: 1$ (fig. $25 \mathrm{~A}, \mathrm{C}$ ).

Thorax (fig. 20B). Scutum and scutellum black with bronze lustre, covered with relatively long, dense, pale yellow pile; side of scutum at wing basis with patch of black pile; scutum with four microtrichose vittae, anteriorly connected and posteriorly reaching the scutellum and postalar callus; posterodorsal part of anterior anepisternum, posterior anepisternum (except anteroventral angle), anterior anepimeron, dorsomedial anepimeron, Downloaded from Brill.com04/26/2023 01:30:09PM 

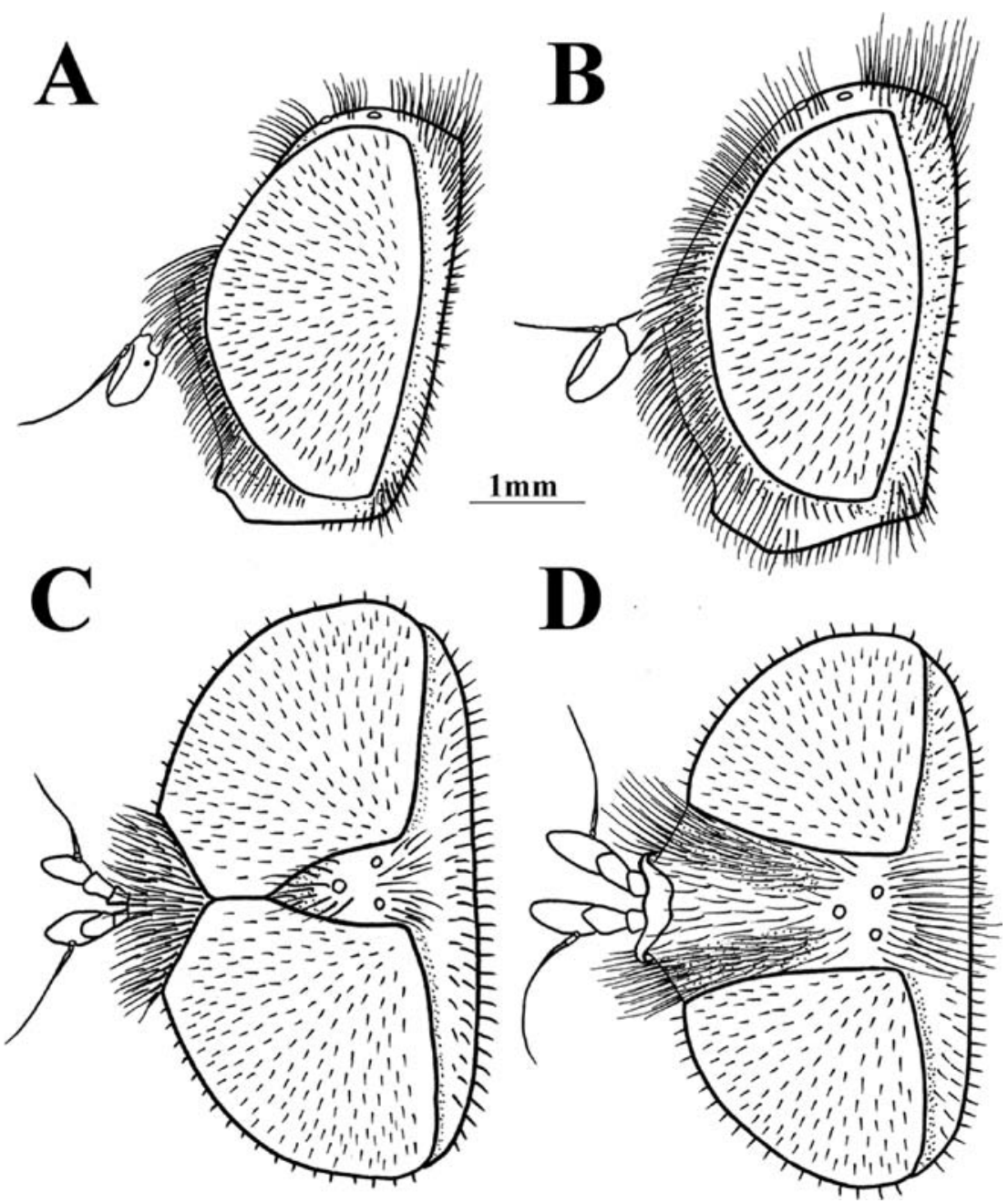

FIGURE 25 Head of Merodon obstipus sp. n. A) male, lateral view, B) female, lateral view; C) male, dorsal view, D) female, dorsal view. Scale: $1 \mathrm{~mm}$.

and posterodorsal and anteroventral parts of katepisternum with long, dense yellow pile and greyish microtrichia; wings covered with microtrichia (except basal parts of cells CuP, R and BM sparsely microtrichose); wing veins brown; calypteres pale yellow; halteres often with brown pedicel and yellow capitulum; legs predominantly black, except pale yellow apex of pro- and mesofemora, basal half of pro- and mesotibiae, basal 1/3 of metatibia, and at least metatarsi ventrally; pile on legs yellow; posterior part of mesocoxa without long pile; metafemur moderately swollen and curved, about
3 times longer than wide; long pile on postero- and anteroventral surface yellow and sparse, slightly longer than half of width of metafemur and much longer than those on dorsal surface (fig. 2oB).

Abdomen (figs. 22C, 26A). Black with bronze lustre, 1.2 times longer than mesonotum; terga black except for a pair of yellow/orange lateral maculae on tergum 2; terga 3 and 4 usually with a pairs of whitish microtrichose fasciae (on tergum 2 exceptionally present); additionally posterior margin of tergum 4 narrowly microtrichose (fig. 26A); pile on terga yellow; sterna translucent, covered 


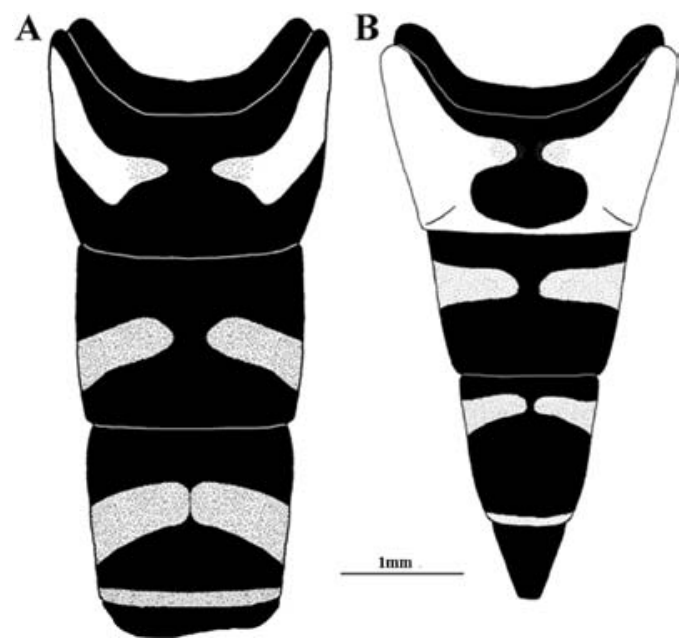

FIGURE 26 Abdomen of Merodon obstipus sp. n. Dorsal view, A) male, B) female. Scale: $1 \mathrm{~mm}$.

circular central notch and rectangular posterolateral corner (fig. $22 \mathrm{C}$ : $\mathrm{cf}, \mathrm{p}$ ).

Male genitalia (fig. 27A-D). Posterior surstyle lobe with parallel margins (fig. 27A: pl); anterior surstyle lobe elongated, sickle-shaped, tapering with pointed apex directed towards base of epandrium (fig. 27A: al); cercus rectangular, without prominences (fig. 27A: c); hypandrium elongated, sickle-shaped, with a small lateral projections near the base (fig. ${ }_{27} \mathrm{C}$ : lp); lingula short (fig. ${ }_{27} \mathrm{C}-\mathrm{D}: \mathrm{l}$ ).

Female (figs. 18D, 22E, 25B, D, 26B). Similar to the male except for normal sexual dimorphism and for the following characteristic: frons with wide, white microtrichose vittae along eye margins (fig. 25D); basoflagellomere about 2 times longer than wide, with rounded apex (fig. 18D); tergum 2 with yellow pile, terga $3-5$ with mixed yellow and black pile (fig. 26B); microtrichose fasciae on terga 3 and 4 narrower; sterna dark, except lighter brown sternum 2; sterna 4 and 5 with central longitudinal dent/suture (fig. 22E: marked with arrow).

Etymology. The name obstipus is derived from a Latin adjective for crooked, bent sideways or at an angle, referring to the shape of the anterior surstyle lobe.

Remarks. One specimen determined by Hurkmans (1987) as Merodon femoratoides from locality Osmaniye area is included in paratypes.
Merodon cohurnus Vujić, Likov et Radenković sp. n.

Type material. Holotype. Male. Turkmenistan: Kopet mountain range, canyon Aj-Dere river, 38.4088N, 56.7202E, 21.vi.1977 (SZMN). Paratypes. Turkmenistan, two male, Kopet mountain range, canyon Aj-Dere river, 38.4088N, 56.7202E, 21.vi.1977 (SZMN).

Diagnosis. Medium sized species (12-14 mm) with bronze lustre; black scutum usually with barely visible four microtrichose vittae; abdomen black with a pairs of yellow-orange maculae on terga 2-4 (fig. 10A); metafemur moderately broad and slightly curved, with some long, pale yellow pile only antero- and posteroventrally (fig. 20C). M. cohurnus sp. $\mathrm{n}$. belongs to the $M$. nigritarsis group, and is closely related to species M. longisetus sp. n. and M. nigritarsis, from which can be distinguished by the different shape of anterior surstyle lobe (in M. cohurnus sp. n. high boot shaped (fig. 29A: al), while in $M$. longisetus sp. $\mathrm{n}$. oval (fig. 23A: al) and in M. nigritarsis tapering and pointed (fig. 35A: al)), and by different shape of sternum 4 (fig. 22A-B, F).

Distribution. Merodon cohurnus sp. $\mathrm{n}$. is known only from Turkmenistan, found on the Kopet Dag mountain range (fig. 1 ).

Description. Male. Head (figs. 18E, 28A-B). Antennae brown-red with acute apex; basoflagellomere about 1.3 times longer than wide, and about 1.5 times longer than pedicel; arista light brown in basal $1 / 3$, and thickened and dark brown at apical $2 / 3$, covered with microtrichia; arista is about 1.5 times longer than basoflagellomere (fig. 18E); face and frons black, with pale yellow-whitish pile, and dense silver microtrichia; ventral part of face shiny; vertical triangle isosceles, shining black, except in front of anterior ocellus covered with microtrichia, pilosity long, pale yellow-whitish (except some black pile on ocellar triangle); ocellar triangle isosceles; eyes covered with dense pile; eye contiguity about 12 facets long; occiput with pale yellow pile, covered with a dense silver microtrichia; vertical triangle: eye contiguity: ocellar triangle $=3: 1.5: 1$ (fig. 28A-B). 

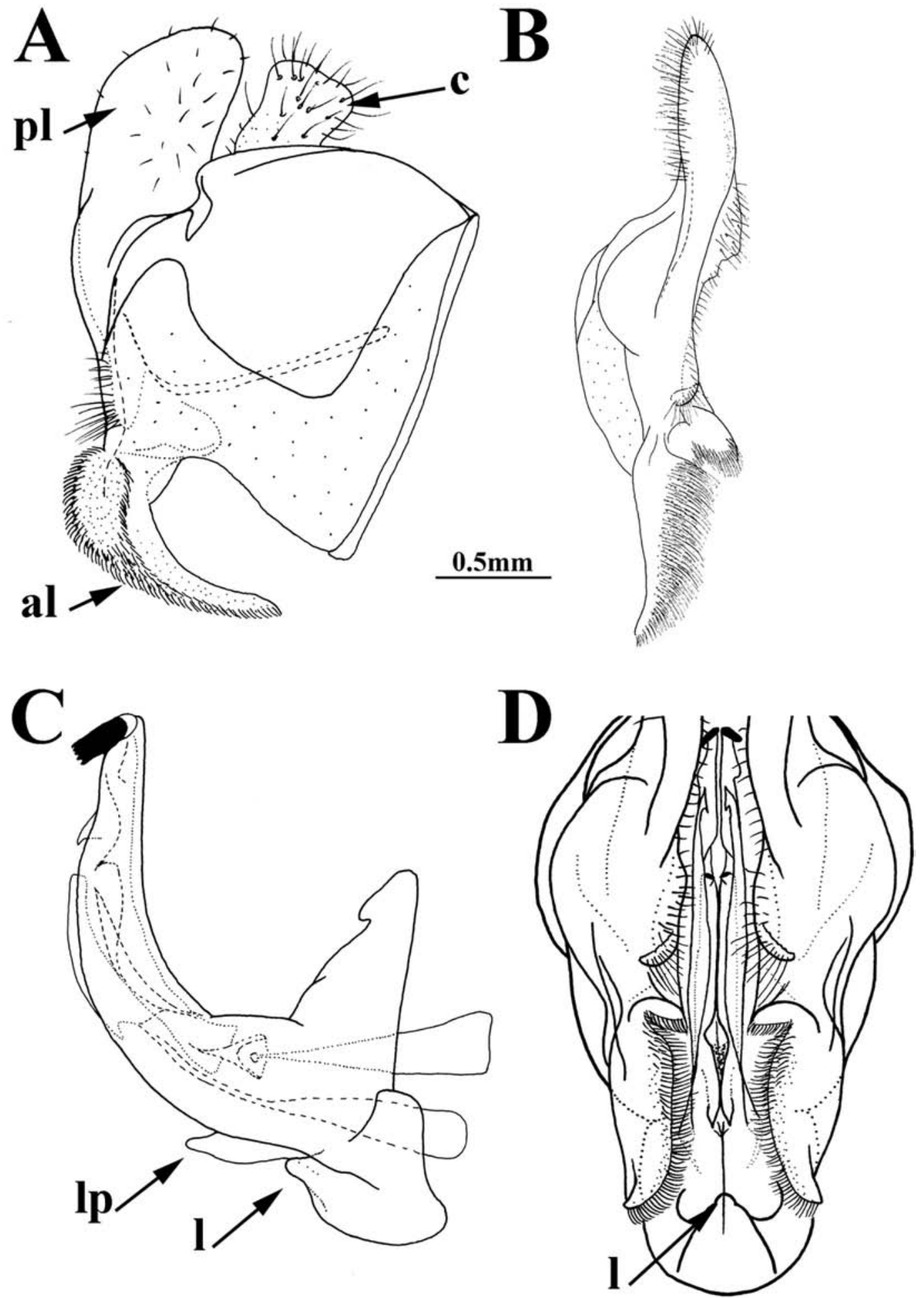

FIGURE 27 Male genitalia of Merodon obstipus sp. n. A) epandrium, lateral view, B) surstyle lobe, ventral view, C) hypandrium, lateral view, D) anterior end of male genitalia, ventral view. Scale: $0.5 \mathrm{~mm}$. al-anterior lobe of surstylus, c-circus, l-lingual, $\mathrm{pl}$ - posterior lobe of surstylus. 


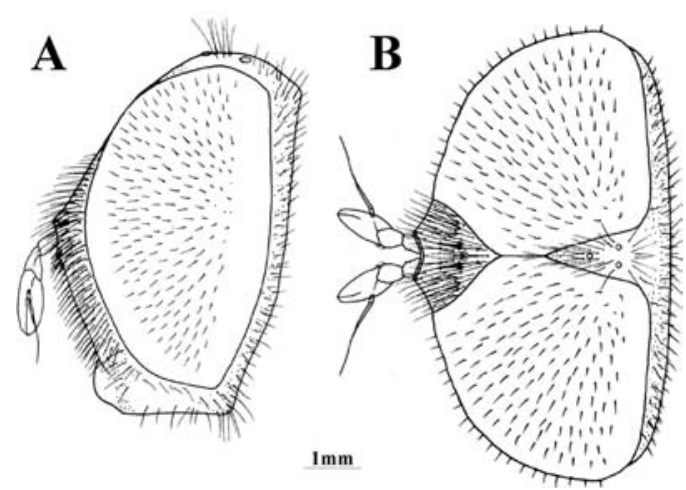

FIGURE 28 Head of male Merodon cohurnus sp. n. A) lateral view, B) dorsal view. Scale: $1 \mathrm{~mm}$.

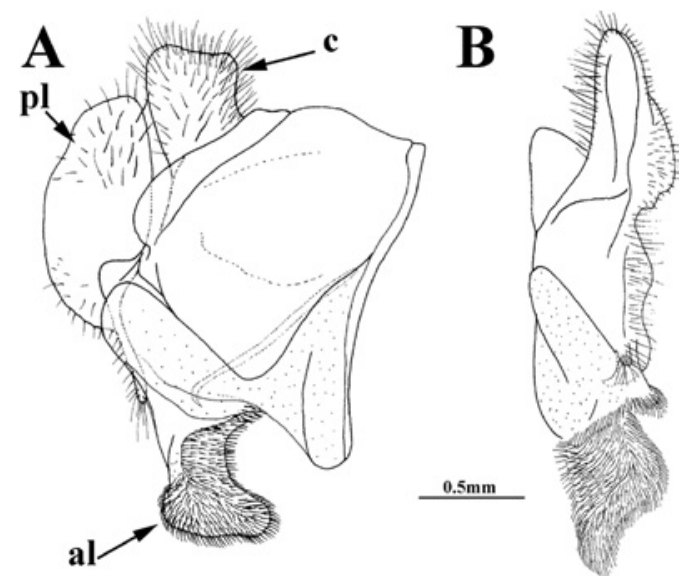

FIGURE 29 Male genitalia of Merodon cohurnus sp. n. A) epandrium, lateral view, B) surstyle lobe, ventral view. Scale: $0.5 \mathrm{~mm}$. al-anterior lobe of surstylus, c-circus, pl-posterior lobe of surstylus.

Thorax (fig. 20C). Scutum and scutellum black with bronze lustre, covered with pale, yellow pile, at wing bases a tuft of black pile; scutum with four microtrichose vittae, anteriorly connected; posterodorsal part of anterior anepisternum, posterior anepisternum (except anteroventral angle), anterior anepimeron, dorsomedial anepimeron, and posterodorsal and anteroventral parts of katepisternum covered with long, pale yellow pile and silverish microtrichia; wings covered with microtrichia (except cells $\mathrm{R}$ and BM sparsely microtrichose); wing veins brown; calypteres pale yellow-whitish; halteres light brown; legs mostly black, except pale yellow apex of pro- and mesofemora, basal half of pro- and mesotibiae, basal 1/4 of metatibia, and at least metatarsi ventrally; pile on legs pale yellow; metafemur moderately curved, about 3.5 times longer than wide; metafemur with some long yellow pile antero- and posteroventrally, much longer than pile on dorsal surface (fig. 20C).

Abdomen (figs. 22F, 10A). Dark, tapering, about 1.3 times longer than mesonotum; terga $2-4$ with a pairs of lateral yellow maculae, on terga 3 and 4 maculae covered with microtrichia; yellow-orange maculae on tergum 2 triangular; microtrichose fasciae on tergum 4 connected medially (fig. 10A); pile on terga pale yellow; sterna translucent and yellow; sternum 4 with U-shaped posteromedial notch, reaching to the $2 / 3$ of the length of sternum, and rounded posterolateral corner (fig. $22 \mathrm{~F}$ : cf, p).

Male genitalia (figs. 29A-B, 30A-B). Anterior surstyle lobe high boot-shaped (fig. 29A: al); posterior surstyle lobe rhomboid-shape, about 2 times longer than wide (fig. 29A: pl); cercus rectangular (fig. 29A: c); hypandrium narrow, elongated, and sickle-shaped; lingula short (fig. 3oA, B: l); lateral projections near the base with rectangular apex in lateral view, and characteristic shape (fig. 3oA: lp).

Female. Unknown.

Etymology. The name cohurnus origin from the Latin noun cohurnus meaning high boot, refers to the shape of anterior surstyle lobe.

\section{Merodon avidus group}

Diagnosis. Similar to M. nigritarsis group, but differs by red-yellow tarsi in $M$. avidus group (fig. 14A-D), while dark brown in M. nigritarsis group (fig. $14 \mathrm{E}-\mathrm{H}$ ) (apical tasomeres can be partly brown dorsally in M. femoratus (fig. 14I-J)), lack of subapical thorns on ventral margin of hypandrium (fig. 33A, B) (projections just behind the ctenidium can be present) (fig. $33 \mathrm{C}$ : marked with arrow) and shape of lateral sclerit of aedeagus (fig. 9B: s). 

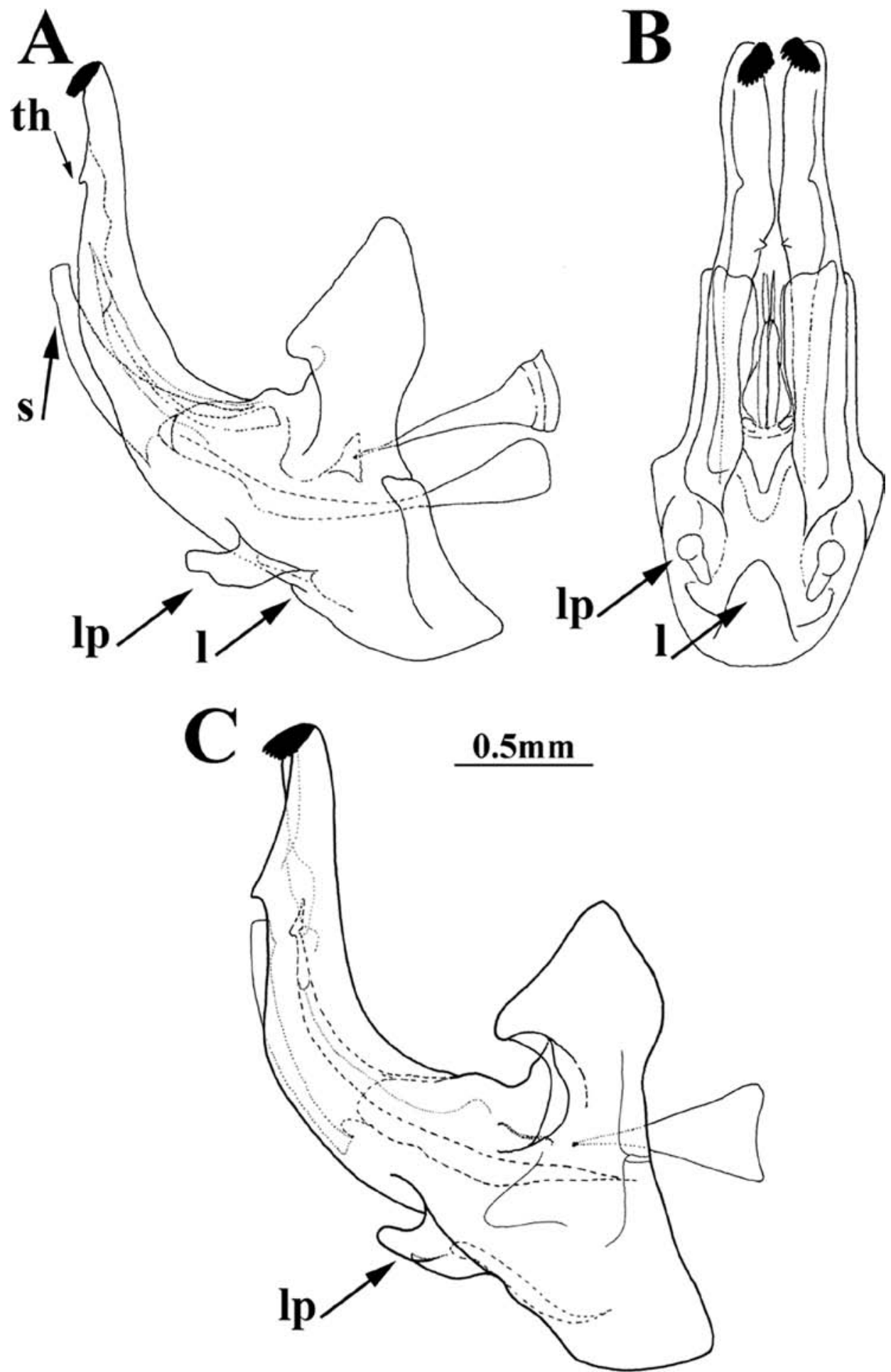

FIgure 30 Hypandrium. A) Merodon cohurnus sp. n., lateral view, B) Merodon cohurnus sp. n., ventral view, C) Merodon quadraticus, lateral view. Scale: $0.5 \mathrm{~mm}$. l-lingual, lp-lateral projection, s-lateral sclerite of aedeagus, th-subapical thorn on ventral margin. 

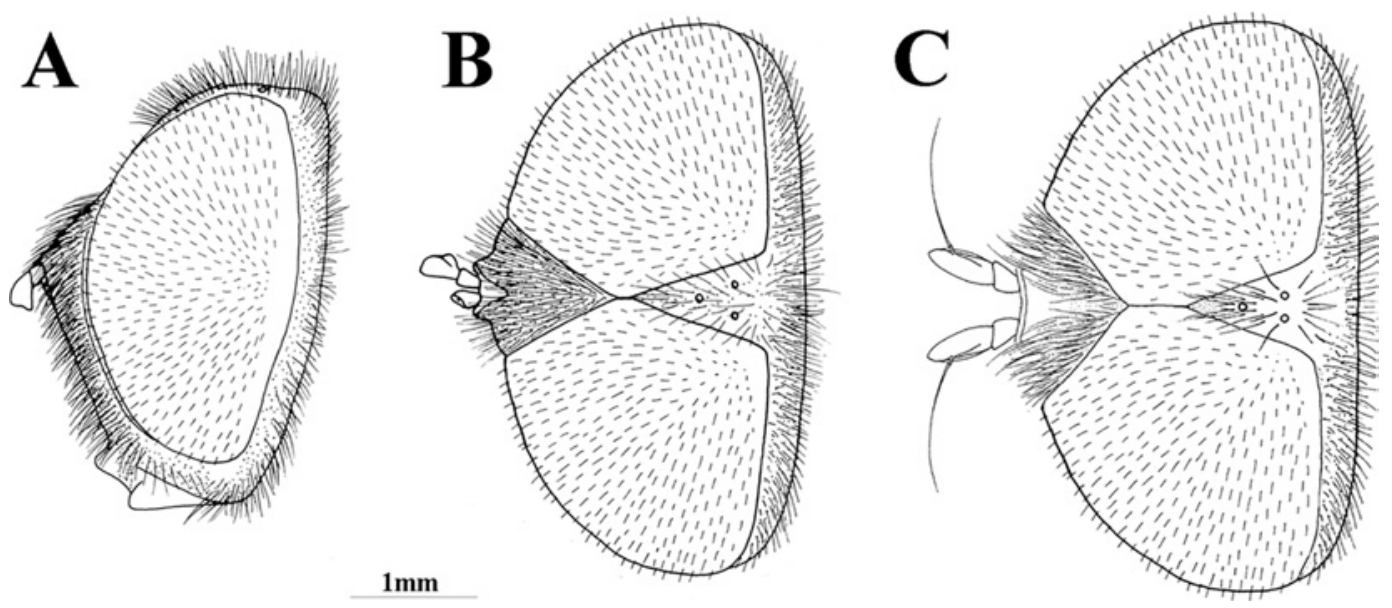

FIGURE 31 Head of male. A) Merodon rutitarsis sp.n., lateral view, B) Merodon rutitarsis sp. n., dorsal view, C) Merodon avidus, dorsal view. Scale: $1 \mathrm{~mm}$.

Merodon rutitarsis Likov, Vujić et Radenković sp. n.

Type material. Holotype. Male. Turkmenistan: Chandyr river valley, tributary of Sumbara river, 38.0175N, 55.2955E, 26.iv.1933, leg. Ušinskii (SZMN).

Diagnosis. Medium sized species (12 mm); body black (except a pair of lateral orange maculae on tergum 2 (fig. 11A)), covered with long, pale yellow, erect, dense pile; metafemur elongated, with few longer pile on anteroventral surface (fig. 2oD); all tarsi yellow; basotarsomere on metaleg narrow, about 4 times longer than wide (fig. $14 \mathrm{~K}$ ); face and frons black; pilosity of the head predominantly pale yellow (except some black pile on ocellar triangle); eye contiguity very short (about 4 facets) (fig. $31 \mathrm{~B}$ ); anterior surstyle lobe simple and short, oval (fig. 32A: al); posterior surstyle lobe with hump in apical half, and short, black setulae at the inner side (fig. 32A-B: pl). Merodon rutitarsis sp. $\mathrm{n}$. is similar to $M$. avidus primarily based on yellow tarsi (fig. 14A-D, K), from which can be distinguished by the following characters: in M. avidus eye contiguity is much longer (about 14 facets long) (fig. ${ }^{1} \mathrm{C}$ ), by different shapes of sternum 4 (fig. $22 \mathrm{G}-\mathrm{H}$ ), and by shape of male genitalia: in $M$. avidus anterior surstyle lobe about 1.5 times longer than wide (fig. $3^{2} \mathrm{C}$ : al), while in M. rutitarsis sp. n. is about as long as wide (fig. $32 \mathrm{~A}$ : al); posterior surstyle lobe in $M$. avidus simple (fig. $32 \mathrm{C}$ : pl), while in M. rutitarsis sp. n. is with a hump (fig. 32A: marked with arrow).

Distribution. Merodon rutitarsis sp. $\mathrm{n}$. was recorded at only one locality in Turkmenistan, in the Chandyr river valley (fig. 1).

Description. Male. Head (fig. 31A-B). Antennae of the holotype are damaged, basoflagellomere with arista missing. Scape and pedicel light brown, scape covered with several long, while pedicel with many short pale yellow pile; face and frons black, covered with pale yellow pile and silver microtrichia (except ventral parts of face); vertical triangle isosceles, shining black, except in front of anterior ocellus covered with whitish microtrichia, pilosity long, pale yellow; ocellar triangle equilateral; eyes covered with dense, pale yellow pile; eyes contiguity short, about 4 facets; occiput covered with silver microtrichia and with long, pale yellow pile; vertical triangle: eye contiguity: ocellar triangle = 2,5:0,5:1 (fig. 31A-B).

Thorax (figs. $20 \mathrm{D}, 14 \mathrm{~K}$ ). Scutum and scutellum black; anterior half of scutum with bluish lust and scarce silver microtrichia; scutum and scutellum covered with pale, yellow, long and dense, erected pile; posterodorsal part of anterior anepisternum, posterior anepisternum (except anteroventral angle), anterior anepimeron, dorsomedial anepimeron, and posterodorsal and anteroventral parts of katepisternum covered with long, dense, pale 

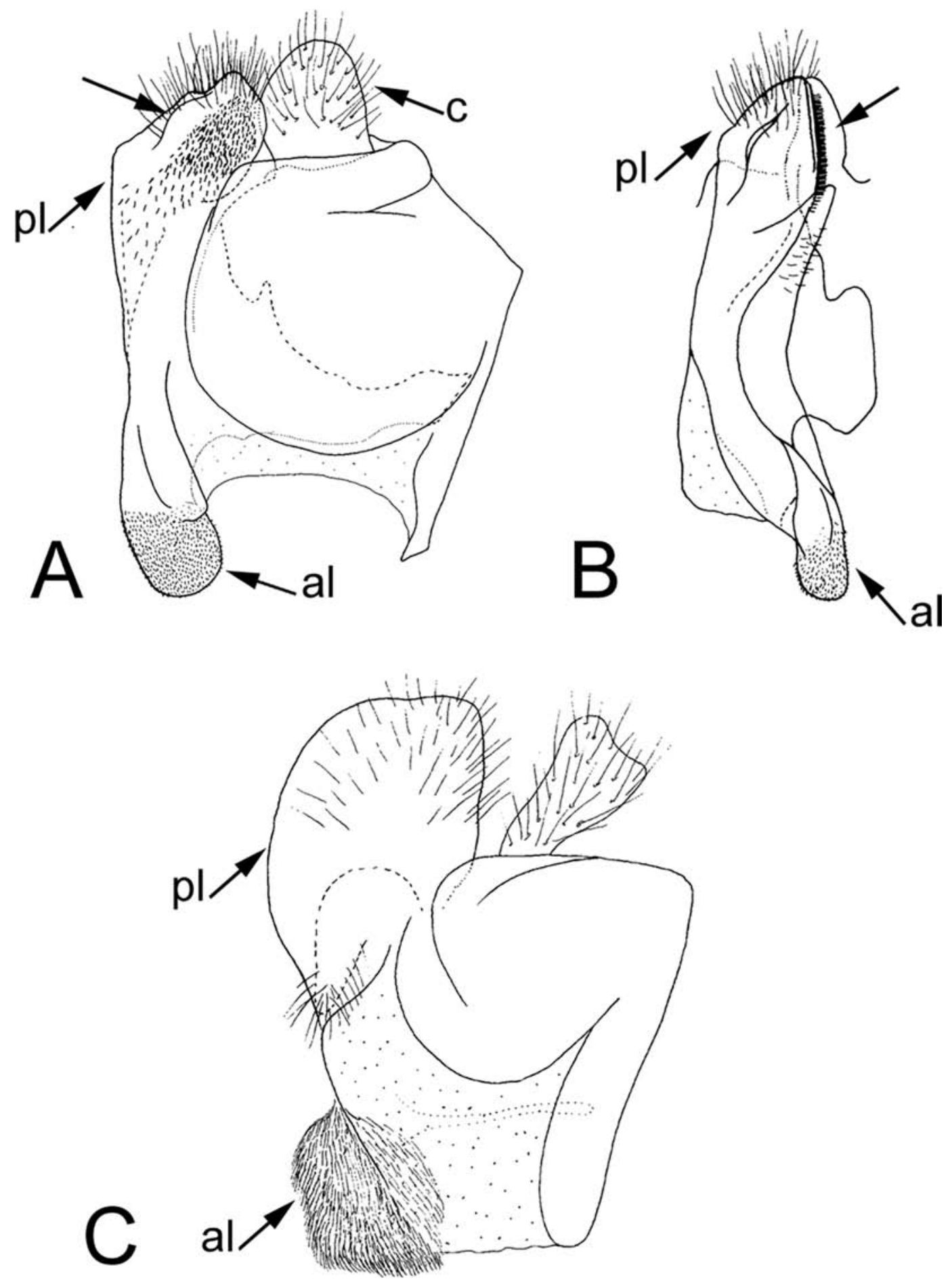

FIGURE 32 Male genitalia. A) Merodon rutitarsis sp. n., epandrium, lateral view (hump marked with arrow), B) Merodon rutitarsis sp. n., surstyle lobe, ventral view (black setulae marked with arrow), C) Merodon avidus, epandrium, lateral view. Scale: $0.5 \mathrm{~mm}$. al-anterior lobe of surstylus, c-circus, pl-posterior lobe of surstylus. 
yellow pile; wings covered with microtrichia (except basal parts of cell $\mathrm{R}$ with reduced microtrichia); wing veins light brown; halteres and calypteres sandy yellow/brown; all femora black (except yellow knees), all tibiae yellow, with broad black ring closer to apical end of tibiae, and all tarsi yellow (fig. $14 \mathrm{~K}$ ); pile on all legs yellow; metafemur elongated, narrow and only slightly curved, about 3.5 times longer than wide; some pile on anteroventral surface of metafemur as long as half of width of metafemur (fig. 20D).

Abdomen (figs. $22 \mathrm{G}, 11 \mathrm{~A}$ ). Slightly longer than mesonotum; all terga black, except a pair of yellow triangular maculae on tergum 2; inner ends of orange maculae slightly covered with microtrichia; terga 3 and 4 with a pairs of microtrichose fasciae, separated medially (fig. 11A); abdomen covered with dense, long, pale yellow pile, except for black pile on the posterior half of terga 3 and 4 near to the posterior margin; sterna translucent, light brown, covered with long, erect, pale yellow pile; sternum 4 with narrow but deep central notch, and angular posterolateral corners (fig. 22G: cf, p).

Male genitalia (figs. 32A-B, 33). Anterior surstyle lobe simple and short, oval, with a rounded margin, about as long as wide (fig. 32A: al); posterior surstyle lobe with hump in apical part (fig. 32A: marked with arrow), at inner side covered with short, black setulae (fig. 32B: marked with arrow); cercus triangular to rectangular (fig. 32A: c); hypandrium sickle-shaped, with enlarged and broad apex (fig. 33).

Female. Unknown.

Etymology. Name rutitarsis refers to the color of the tarsi, derived from the Latin adjective rutilus, meaning reddish-yellow.

\section{Identity of Merodon elegans Hurkmans}

Merodon elegans was described by Hurkmans (1993) based on the large number of specimens collected in the Western Mediterranean. A recent study of all known Merodon types resulted with discovery of two names related to the same taxon. Vujić et al. (2011) cited this species for Turkey under one of these names, M. biarcuatus Curran, 1939 based on the holotype found in AMNH. Syntype of M. femoratus Sack, 1913 found in ZMHB, resolved question about the oldest name that should be used for this species.

\section{Merodon femoratus Sack, 1913}

syn. n. biarcuatus Curran, 1939

syn. n. elegans Hurkmans, 1993

Types. Merodon femoratus Sack, 1913: 446. Typelocality. Corsica, Greece, Asia Minor. Described based on unspecified number of males and females. One syntype was found in ZMHB: France, Corsica "Mann" " 855 ", a male designated here as lectotype.

Merodon biarcuatus Curran, 1939: 6. Typelocality. Morocco. Holotype (studied). 9 forest of Namora, near Rabat, Morocco (AMNH), with clear apomorphic character, broad metafemur, ventrally covered with long whitish pile as in M.femoratus.

Merodon elegans Hurkmans, 1993. Holotype (studied). ơ Italy, Sicilia, "V. S. v. d. Goot! Erna rif. Filiciusa 1400-1500m 22-28.vii.1961 / Lampetia spinipes det. V. S. v.d. Goot 1963 I Type A" (NMNL), conspecific with $M$. femoratus.

Diagnosis. Medium sized species (11-13 mm) similar to M. avidus complex, from which can be distinguished by broad metafemur (narrower in other members from $M$. avidus complex (fig. $37 \mathrm{~A}-\mathrm{B})$ ), ventrally covered with long whitish pile (fig. $37 \mathrm{D}$ ), and by deep incision between anterior and posterior surstyle lobe in male genitalia (fig. ${ }_{13} \mathrm{C}$ : marked with arrow) (absent in M. avidus complex fig. ${ }^{2} \mathrm{C}$ ).

Distribution. Northern Africa (Algeria, Morocco, Tunisia), south and southwest Europe (Croatia, France, Portugal, Spain, Italy).

\section{Identification keys of males of $M$. nigritarsis and M. avidus groups and Merodon crassifemoris}

Following a key to the males of the $M$. nigritarsis group (Vujić et al., 2013) we present an updated identification key for all known members of the M. nigritarsis and M. avidus groups. Identification Downloaded from Brilq.com04/26/2023 01:30:09PM 

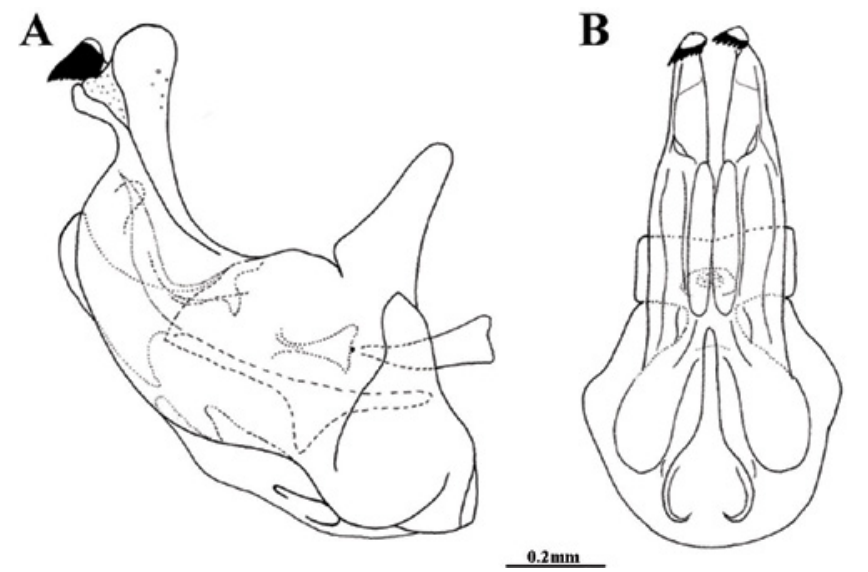

C

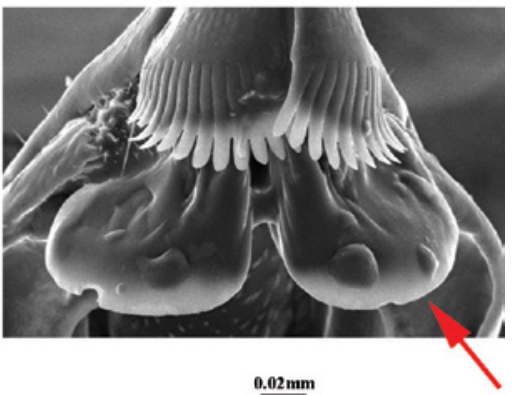

FIGURE 33 Male genitalia. A) Merodon rutitarsis sp. n., hypandrium, lateral view, B) Merodon rutitarsis sp. n., hypandrium, ventral view, C) Merodon avidus, apical part of hypandrium (projections behind the ctenidium marked with arrow) (SEM), ventral view. Scale: A-B) $0.2 \mathrm{~mm}, \mathrm{C}) 0.002 \mathrm{~mm}$.
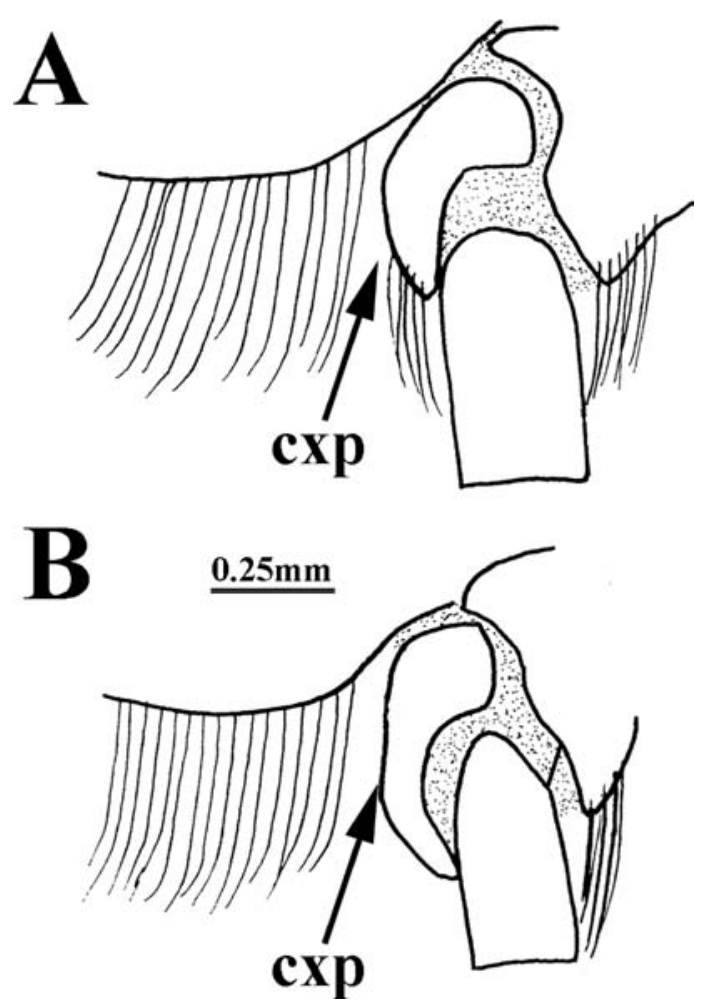

FIGURE 34 Part of mesothorax. Lateral view, A) Merodon albifrons, B) Merodon nigritarsis. Scale: $0.25 \mathrm{~mm}$. cxp-posterior part of mid coxa (Marcos-García et al., 2007). of females is very difficult and will be the subject of future studies, using a combined integrative approach.

1. Posterior part of mesocoxa without long pile (Merodon avidus-nigritarsis lineage) (fig. 34B: cxp) 2

- Posterior part of mesocoxa with long pile (fig. 34A: cxp)

other Merodon lineages (not treated here)

2. Species with white microtrichose vittae on black scutum and white microtrichose fasciae on dark terga; at least tergum 2 with a pair of reddish-orange maculae laterally; abdomen elongated, narrow and tapering, always longer than scutum and scutellum together; legs without spinae or other protuberances; male genitalia: anterior surstyle lobe more or less rhomboid shape, except in the alagoezicus subgroup where it is transformed into a narrow, elongated, strongly curved projection (M. nigritarsis and M. avidus groups $+M$. crassifemoris)

- Species with different combination of characters

other species groups belonging to Merodon avidus-nigritarsis lineage (not treated here) 


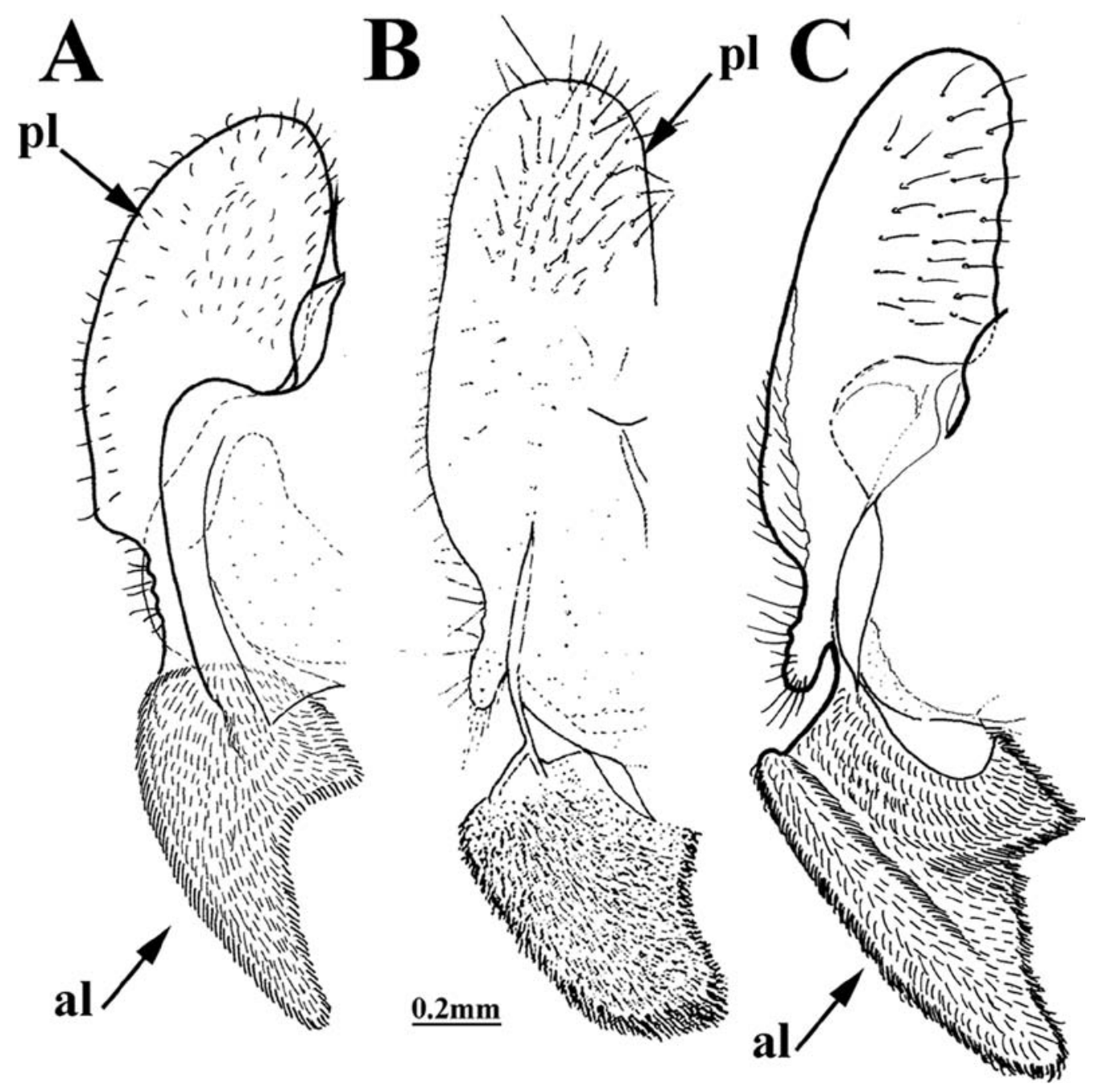

FIGURE 35 Male genitalia. Surstyle lobe, lateral view, A) Merodon nigritarsis, B) Merodon latifemoris, C) Merodon femoratoides. Scale: $0.2 \mathrm{~mm}$. al-anterior lobe of surstylus, pl-posterior lobe of surstylus.

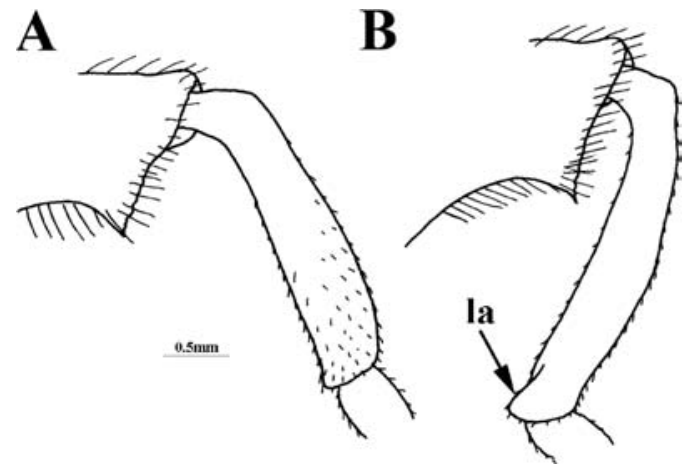

FIGURE 36 Metatibia of male. Lateral view, A)

Merodon lucasi, B) Merodon alagoezicus.

Scale: $0.5 \mathrm{~mm}$. la-lamella.
3. Tarsi dark brown/black dorsally and orange/brown ventrally ( $M$. nigritarsis group) (fig. $14 \mathrm{E}-\mathrm{H}$ ) .9

- Tarsi yellow dorsally and ventrally (M. avidus group) (fig. 14A-D)

4. Posterior surstyle lobe with hump in apical half (fFig. 32A: marked with arrow); anterior surstyle lobe short and rounded, oval (fig. 32A: al). M. rutitarsis sp. $\mathrm{n}$.

- Posterior surstyle lobe simple; anterior surstyle lobe longer, rhomboid shape (fig. $32 \mathrm{C}:$ al) 


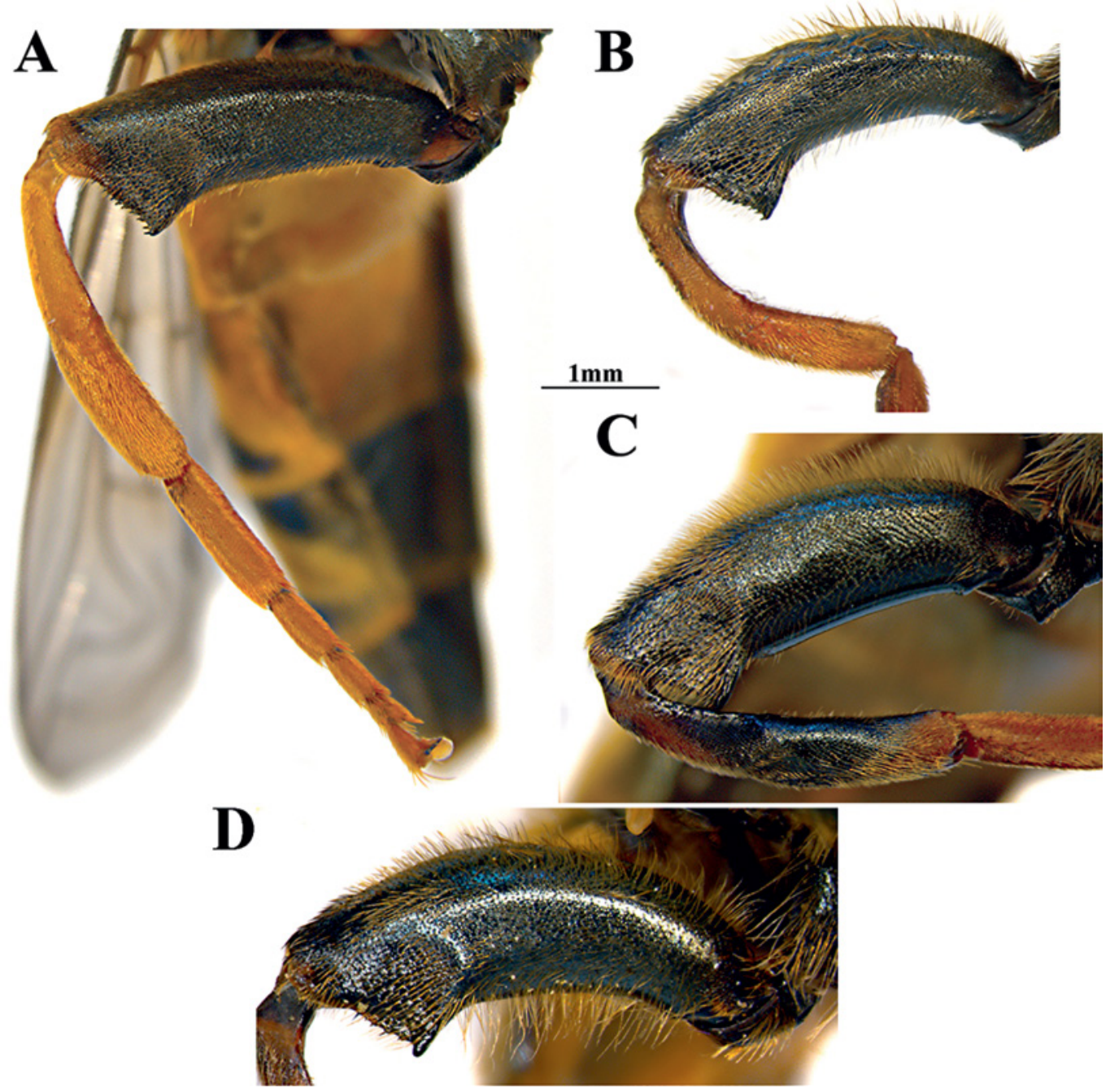

FIGURE 37 Metaleg of male. Lateral view, A) Merodon megavidus, metaleg, B) Merodon avidus, metafemur and metatibia, C) Merodon moenium, metafemur and metatibia, D) Merodon femoratus, metafemur. Scale: $1 \mathrm{~mm}$.

5. Metafemur broad, ventrally covered with long whitish pile (Fig. 37D); surstyle with deep incision between anterior and posterior lobes (fig. 13C: marked with arrow) ..M. femoratus

- Metafemur less broad, without long ventral pilosity (fig. $37 \mathrm{~A}-\mathrm{C}$ ); surstyle without deep incision (fig. $32 \mathrm{C}$ ).

6. Body pile golden; metafemur with very short pile (fig. 37A) M. megavidus

- Body pile yellow to pale/grayish; metafemur with longer pile (fig. $37 \mathrm{~B}-\mathrm{C}$ )
7. Distribution: western Mediterranean; clearly defined with genetic data (see Popović et al., 2015) M. ibericus

- Distribution: Europe, except Iberian Peninsula

8. Tergum 2 with a pair of whitish, microtrichose spots; terga 3 and 4 with broad microtrichose fasciae (fig. 38A); tibiae usually pale (fig. $37 \mathrm{~B}$ ); body pile slightly shorter, especially on the tergum 4 (fig. 39A); tergum 3 with a pair of orange, lateral, triangular maculae, anterior part of tergum 3 is also Downloaded from Brill.com04/26/2023 01:30:09PM 
A
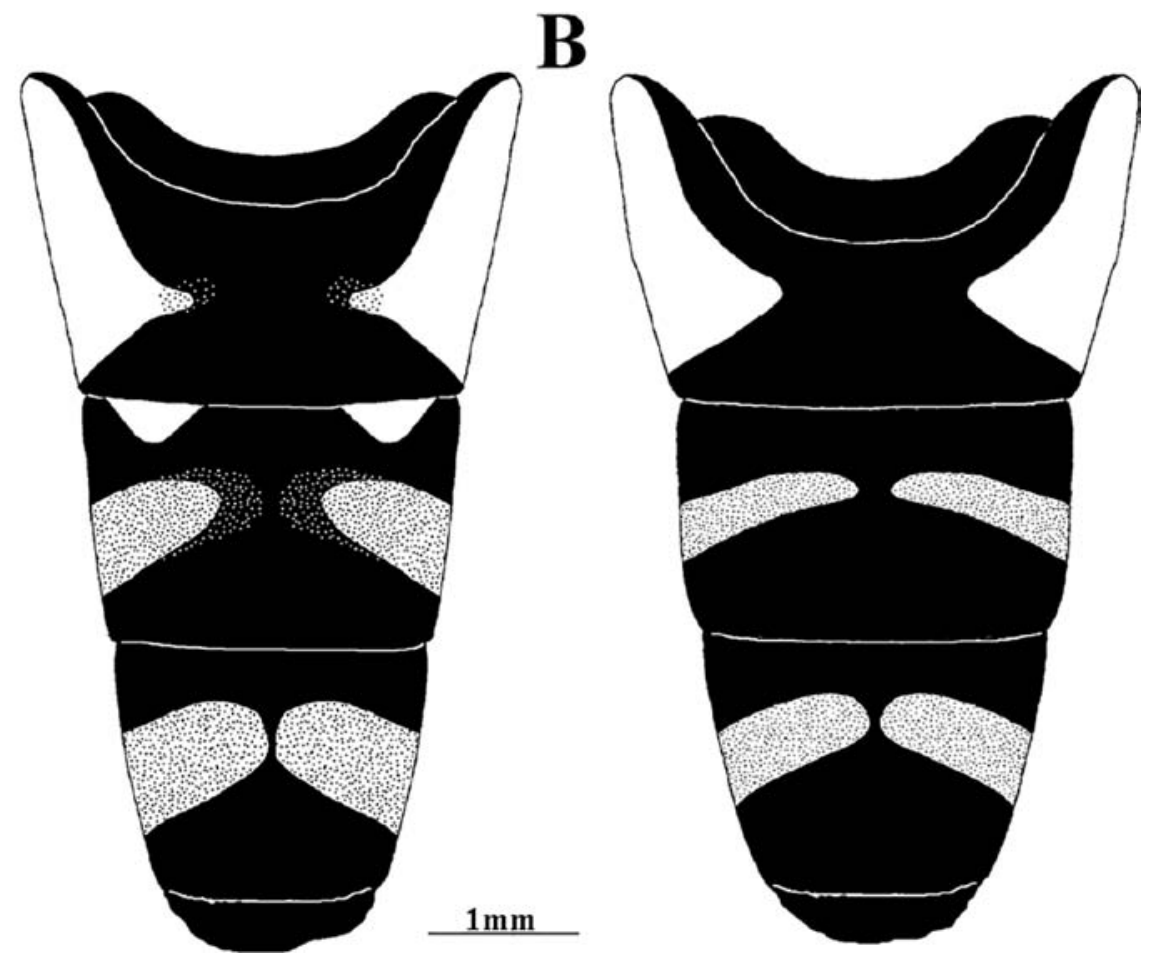

FIG URE 38 Abdomen of male. Dorsal view, A) Merodon avidus, B) Merodon moenium. Scale: $1 \mathrm{~mm}$.

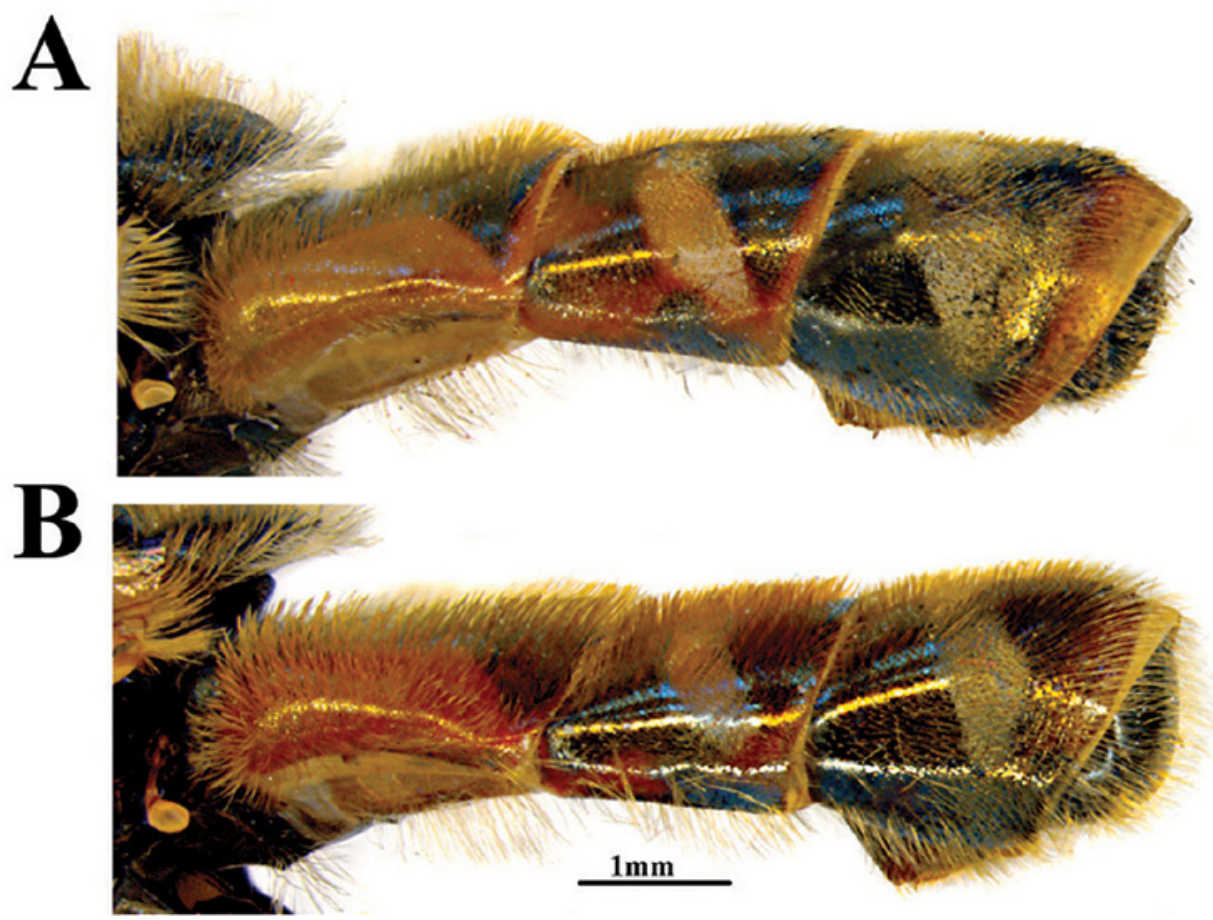

FIGURE 39 Abdomen of male. Lateral view, A) Merodon avidus, B) Merodon moenium. Scale: $1 \mathrm{~mm}$. 
predominantly orange-red, except medially, where it is narrowly black (in darker specimens at least, small orange areas are present antero-sublaterally) M. avidus

- Tergum 2 shiny, without microtrichia; terga 3 and 4 with narrow microtrichose fasciae (fig. 38B); tibiae always partly dark (fig. $37 \mathrm{C}$ ); body pile longer (fig. $39 \mathrm{~B}$ ); tergum 3 black (in some specimens orangered anterolaterally, but with a black posterior margin) M. moenium

9. Metafemur narrow (about 4.5 times longer than wide); anterior surstyle lobe with strong interior accessory lobe (fig. 12A) M. nitidifrons

- Metafemur broad (as on fig. 20A-B); anterior surstyle lobe without or with small interior accessory lobe 10

10. Anterior surstyle lobe transformed to narrow, long, curved, pointed extension (fig. 12B-F). ... 11

- Anterior surstyle lobe rhomboid or triangular shape... ... 16

11. Anterior surstyle lobe, sickle-shaped, curved downwards, with pointed apex directed towards base of epandrium (fig. $27 \mathrm{~A}$ : al) M. obstipus sp. $\mathrm{n}$.

- Anterior surstyle lobe curved upwards (as on fig. 12B: al).

12. Apical part of metatibia with clear ventrolateral lamella (fig. 36B: la) . .13

- Apical part of metatibia without clear ventrolateral lamella (fig. 36A)

13. Posterior surstyle lobe two times as long as wide, straight (fig. $12 \mathrm{~B}$ : pl); anterior surstyle lobe long, narrow, with rounded curve (fig. 12B: al); M. alagoezicus

- Posterior surstyle lobe S- shaped; anterior surstylelobewithangularcurve(fig.12C-D)

14. Anterior surstyle lobe with additional basal extension (fig. 12C: marked with arrow) .........

..M. satdagensis

- Anterior surstyle lobe without additional basal extension (fig. 12D) M. schachti
15. Abdomen covered with pale pile; tergum 2 without white microtrichose maculae; posterior surstyle lobe broader basally and narrower in apical part (fig. 12E: pl)

M. hakkariensis

- Abdomen with short black pile on posteromedial part of tergum 3 and medial parts of tergum 4; tergum 2 usually with a pair of white microtrichose spots; posterior surstyle lobe the same width along the entire length and with lamellar structure (fig. 12F: marked with arrow)

M. lucasi

16. Face with a bulge below antennae (fig. $4 \mathrm{D}$ : marked with arrow); posterior surstyle lobe hook-like (fig. 13A: pl); metafemur very broad M. crassifemoris

- Face without bulge 17

17. Pile on metafemur very short on ventral surface; surstylus on fig. $13 \mathrm{~B}$ M. angustus

- Pile on metafemur longer on ventral surface; surstylus of different shape 18

18. Metafemur and metatibia extremely curved; male genitalia: posterior and anterior surstyle lobe separated by deep incision (fig. 13D: marked with arrow)

M. testaceus

- Metafemur and metatibia less curved; male genitalia: posterior and anterior surstyle lobe not deeply divided 19

19. Metafemur broad and covered with long anteroventral and posteroventral pile, as long as half of width of metafemur (as on fig. 20A) 20

- Metafemur narrower and covered with shorter pile, usually on posteroventral surface much shorter or absent .24

20. Anterior surstyle lobe 2.5 times shorter than posterior surstyle lobe (as on fig. 23A: al) .....

- Anterior surstyle lobe less than 2 times shorter than posterior surstyle lobe (as on fig. $35 \mathrm{C}:$ al) 22 21. Lateral orange maculae on tergum 2 large, cover $2 / 3$ of the posterior margin (fig. $11 \mathrm{C}$ ); Downloaded from Brill. com04/26/2823 01:30:09PM 
anterior surstyle lobe is about as long as wide (fig. ${ }_{23} \mathrm{C}$ : al); lingula shorter (fig. $24 \mathrm{C}, \mathrm{D}: \mathrm{l}$ ); distribution: Apennine Peninsula ... M. toscanus

- Lateral orange maculae on tergum 2 smaller, reaching the posterior margin only at outer corners of tergum (fig. 21A); anterior surstyle lobe is about 2 times wider than long (fig. 23A: al); lingula longer and pointed upward (fig. 24A, B: 1); distribution: Anatolian Peninsula and Greece M. longisetus sp. $\mathrm{n}$.

22. Anterior surstyle lobe elongated, triangular; posterior surstyle lobe elongated and narrow (fig. 35C: al)

M. femoratoides

- Anterior surstyle lobe shorter, not triangular; posterior surstyle lobe shorter
23. Anterior surstyle lobe square-shaped (Fig. 13E: al); lateral projections on hypandrium gradually tapering to the tip (fig. 3oC: lp) M. quadraticus

- Anterior surstyle lobe high boot-shaped (fig. 29A: al); lateral projections on hypandrium narrow only in apical1/4 (fig.30A:lp) M. cohurnus sp.n.

24. Posterior surstyle lobe broad, anterior surstyle lobe very short (fig. $13 \mathrm{~F}$ : al, pl)

M. taniniensis

- Posterior surstyle lobe narrower, anterior surstyle lobe longer 25

25. Posterior surstyle lobe shorter, 1.5 times as long as wide (fig. $35 \mathrm{~A}: \mathrm{pl}$ )

M. nigritarsis

- Posterior surstyle lobe longer, 2.5 times as long as wide (fig. $35 \mathrm{~B}$ : pl)

M. latifemoris 